Aplicação de redundância para atingir altas acelerações com manipuladores robóticos planares

João Vitor de Carvalho Fontes 



\title{
Aplicação de redundância para atingir altas acelerações com manipuladores robóticos planares
}

\author{
João Vitor de Carvalho Fontes
}

Orientadora: Profa. Dra. Maíra Martins da Silva

Dissertação apresentada à Escola de Engenharia de São Carlos - EESC-USP da Universidade de São Paulo, como parte dos requisitos para obtenção do título de Mestre em Engenharia Mecânica. Área de concentração: Dinâmica de Máquinas e Sistemas.

$$
\begin{aligned}
& \text { ESTE EXEMPLAR TRATA-SE DA } \\
& \text { VERSÃO CORRIGIDA. } \\
& \text { A VERSÃO ORIGINAL ENCONTRA- } \\
& \text { SE DISPONIVEL JUNTO AO } \\
& \text { DEPARTAMENTO DE } \\
& \text { ENGENHARIA MECANICA DA } \\
& \text { EESC-USP. }
\end{aligned}
$$

USP - São Carlos

Abril/2015 
AUTORIZO A REPRODUÇÃO TOTAL OU PARCIAL DESTE TRABALHO, POR QUALQUER MEIO CONVENCIONAL OU ELETRÔNICO, PARA FINS DE ESTUDO E PESQUISA, DESDE QUE CITADA A FONTE.

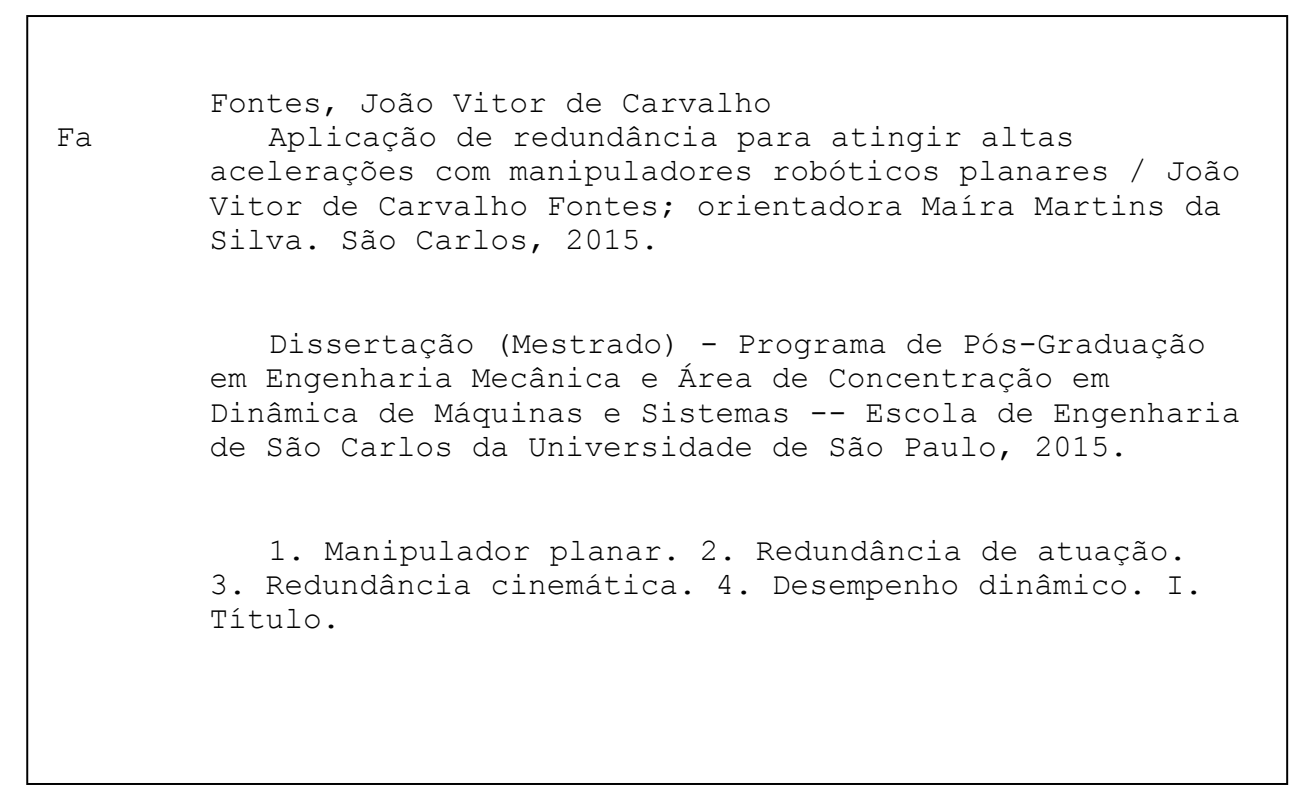




\section{FOLHA DE JULGAMENTO}

Candidato: Engenheiro JOÃO VITOR DE CARVALHO FONTES.

Título da dissertação: "Aplicação de redundância para atingir altas acelerações com manipuladores robóticos planares".

Data da defesa: 05/03/2015

\section{Comissão Julgadora:}

Profa Dra. Maíra Martins da Silva

(Orientadora)

(Escola de Engenharia de São Carlos/EESC)

Prof. Dr. Valder Steffen Junior

(Universidade Federal Uberlândia/UFU)

Prof. Associado Tarcisio Antonio Hess Coelho (Escola Politécnica/EP-USP)
Resultado:

APROVADO
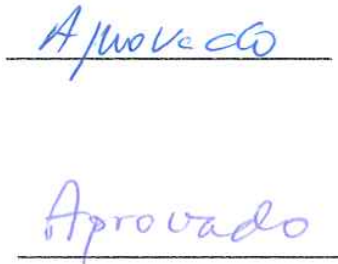

Coordenador do Programa de Pós-Graduação em Engenheira Mecânica: Prof. Associado Marcelo Areias Trindade

Presidente da Comissão de Pós-Graduação:

Prof. Associado Paulo César Lima Segantine 

Aos meus pais, José Augusto e Maria Aparecida que nunca mediram esforços para que hoje eu pudesse estar finalizando mais este projeto. Ficam meus agradecimentos pelo apoio moral e financeiro e por acreditarem na minha capacidade de concluir um mestrado. Às minhas irmãs Ana Clara e Ana Beatriz por terem depositado em mim todo apoio moral nestes dois anos.

À amizade e orientação da Prof ${ }^{a}$ Dra $^{a}$ Maíra Martins da Silva, que me orientou em questões técnicas e até mesmo em momentos de dificuldades pessoais. Agradeço todo o empenho e competência para que este projeto pudesse se tornar realidade e todas as horas dedicadas a me ajudar a construir uma consciência acadêmica ampla, sólida e ética.

Aos amigos de São Carlos, que dividiram diversos momentos de estudo e de descontração: Rodolfo Adamshuk, Felipe Andrade, Luana Próspero, Marcela Borilli, Beatriz Machado e João Paulo Orlando. Aos amigos de Bauru, que apesar do afastamento, serão sempre amigos de longa data: Tatiane Bardeli, Anderson Ortega, Helen Iwamoto e Talissa Gaspareli.

A minha amiga e colega de mestrado Giuliana Venter pelo apoio, companhia e conversas que com certeza contribuíram para a realização do projeto.

E em especial agradeço de coração ao meu eterno companheiro Daniel Pigatto que esteve ao meu lado durante o mestrado me apoiando, ensinando e acalmando nas horas difíceis. Que assim seja, como foi no mestrado, de forma recíproca em outras fases da vida.

Aos docentes do departamento de engenharia mecânica da EESC que sempre contribuíram em conversas e em disciplinas cursadas.

Aos alunos de graduação da Universidade de São Paulo que desenvolveram iniciações científicas e trabalhos de conclusão de curso dos quais eu pude participar ativamente: Daniel Frederice, João Santos, Felipe e Marcos.

Aos amigos, tanto os de Bauru quanto os que fiz em São Carlos. É impossível citar nomes e não esquecer alguém, por isso deixo meu agradecimento a todos que de uma forma ou de outra tiveram alguma participação. 
E por fim, mas não menos importante, ao CNPq pelo apoio financeiro, a Escola de Engenharia de São Carlos e à Universidade de São Paulo pela estrutura disponibilizada para realização deste projeto. 
Fontes, J. V. C. Aplicação de redundância para atingir altas acelerações com manipuladores robóticos planares. 2015. 61 f. Dissertação (Mestrado) - Escola de Engenharia de São Carlos, Universidade de São Paulo, São Carlos, 2015

Propõe-se, com este trabalho, estudar numericamente se a redundância cinemática e a redundância de atuação podem ser boas alternativas para que manipuladores planares de cinemática paralela atinjam altas acelerações. Sabe-se que estes tipos de redundância promovem uma redução de singularidades do sistema robótico entre outros benefícios. No entanto, a avaliação comparativa do desempenho dinâmico de manipuladores redundantes ainda é pouco estudada. Este estudo não é trivial pois a redundância significa não somente o aumento do torque disponível, mas também que a inércia do sistema foi aumentada. A avaliação numérica deste trabalho se dará por meio do desenvolvimento de modelos cinemáticos e dinâmicos das possíveis configurações de manipuladores paralelos planares com redundância cinemática e redundâcia de atuação. Esta avaliação pode ser feita pela comparação entre os manipuladores redundantes e o não-redundante para desenvolver uma mesma trajetória do end-effector. Entretanto, esta avaliação é dependente da trajetória, logo esse trabalho também propõe uma avaliação através de um índice dinâmico em toda a área de trabalho dos manipuladores.

Palavras Chave: Manipulador planar; Redundância de atuação; Redundância cinemática; Desempenho dinâmico. 

Fontes, J. V. C. Application of redundancy to reach high accelerations with planar robotic manipulators. 2015. $61 \mathrm{f}$. Dissertação (Mestrado) - Escola de Engenharia de São Carlos, Universidade de São Paulo, São Carlos, 2015

The aim of this work is to study numerically if the kinematic redundancy and the actuation redundancy can be good alternatives for parallel planar manipulators to achieve high accelerations. It is known that types of redundancy promote, among other benefits, a significant reduction in the singularities. However, the evaluation of the redundancy as a good solution to increase the dynamic performance was not studied. This study is not trivial because the redundancy means not only that there is more torque available, but also that the inertia of the system has been considerably increased. Different configurations of the redundant manipulator will be evaluated numerically through kinematic and dynamic models. This evaluation can be performed by the comparison among the non redundant manipulator and the redundant manipulators to execute the same task. This evaluation is task dependent, so this work proposes a dynamic index to desing dynamic maps over the workspace.

Keywords: Planar manipulator; Actuation redundancy; Kinematic redundancy; Dynamic performance 

$\begin{array}{lll}\text { Abstract } & \text { v }\end{array}$

1 Introdução $\quad 1$

1.1 Contextualização . . . . . . . . . . . . . . . . . . . . . 1

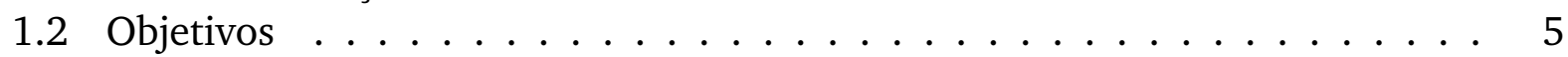

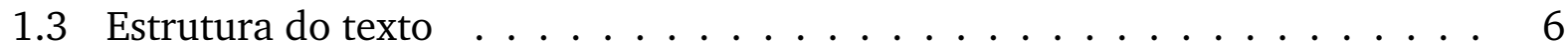

2 Manipuladores robóticos $\quad 7$

2.1 Considerações iniciais . . . . . . . . . . . . . . . . . 7

2.2 Manipuladores paralelos: definição e características . . . . . . . . . . . 8

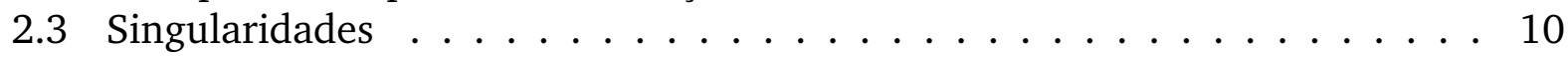

2.4 Redundância . . . . . . . . . . . . . . . . . . . . . . . . . . . . . . .

2.4.1 Redundância cinemática . . . . . . . . . . . . . 13

2.4.2 Redundância de atuação . . . . . . . . . . . . . . . 15

2.5 Considerações finais . . . . . . . . . . . . . . . 16

3 Metodologia e modelagem 17

3.1 Considerações iniciais . . . . . . . . . . . . . . . . . 17

3.2 Metodologia básica . . . . . . . . . . . . . . . . . 17

3.2 .1 Cinemática inversa . . . . . . . . . . . . . 17

3.2 .2 Dinâmica inversa . . . . . . . . . . . . . . . 18

3.3 Modelagem dos manipuladores . . . . . . . . . . . . . . 20

3.3.1 Cinemática inversa . . . . . . . . . . . . . . . . . . 22

3.3 .2 Jacobiana . . . . . . . . . . . . . . . . . . 25

3.3.3 Velocidades e acelerações . . . . . . . . . . . . . . 26

3.3 .4 Dinâmica . . . . . . . . . . . . . . . . 28

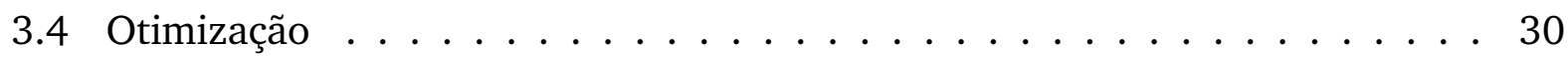

3.5 Mapas dinâmicos . . . . . . . . . . . . . . . . . . 33

3.6 Considerações finais . . . . . . . . . . . . . 35

4 Resultados e discussões $\quad 37$

4.1 Considerações iniciais . . . . . . . . . . . . . . . . . . . . . . . . . . . . . . . .

4.2 Dados da simulação . . . . . . . . . . . . . . . 37 
4.3 Máximo torque calculado . . . . . . . . . . . . . . . 38

4.4 Mapas dinâmicos calculados . . . . . . . . . . . . . . . . 45

4.5 Considerações finais . . . . . . . . . . . . . . . 50

5 Conclusões e considerações para trabalhos futuros 53

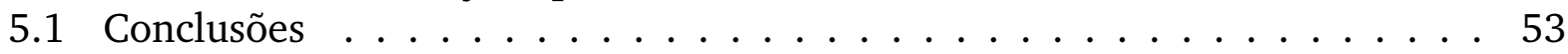

5.2 Contribuições científicas . . . . . . . . . . . . . 55

5.3 Propostas para trabalhos futuros . . . . . . . . . . . . 55 
1.1 Par2: robô de cinemática paralela projetado e desenvolvido pela Fundación Fatronik e pelo CNRS (Adaptado de Company et al. (2011)). . . . . . . . . . 2

1.2 KUKA: robô de cinemática em série fabricado e distribuído pela KUKA Roboter (KUKA Roboter do Brasil Ltda., 2014). . . . . . . . . . . . . . . 2

1.3 Modelo de manipulador: 3RRR não redundante; (4)RRR com redundância de atuação; $(\underline{P}) \underline{R R R}+2 \underline{R} R R$ com redundância cinemática. . . . . . . . . . 3

2.1 Os diferentes manipuladores completamente planares paralelos de 3 graus de liberdade com cadeias idênticas (Merlet, 2006) . . . . . . . . . . . . 10

2.2 Representação dos parâmetros do manipulador 3RRR (Bonev e Gosselin, 2001). . . . . . . . . . . . . . . . . . 12

2.3 Da esquerda para a direita, exemplos de redundância cinemática, redundância de atuação e redundância de medidas (as linhas tracejadas representam os sensores) (Merlet, 2006). . . . . . . . . . . . . . . . . 13

2.4 Reconfiguração do sistema proporcionando que a trajetória seja realizada livre de singularidades (linha em vermelho) (Kotlarski et al., 2009). . . . . . 14

2.5 Reconfiguração do sistema proporcionando o aumento da área de trabalho, diminuindo a área onde a precisão não é adequada (área em amarelo) e permitindo que a trajetória seja realizada com a precisão desejada (Kotlarski et al., 2009). . . . . . . . . . . . . . . . . . . . 14

2.6 Manipulador planar $(\underline{P}) \underline{R} R+2 \underline{R} R R$ construído pelo Instituto de Sistemas Mecatrônicos, Universidade de Leibniz, Hanover, Alemanha (Kotlarski et al., 2011). . . . . . . . . . . . . . . . 15

3.1 Representação de força e momento em um corpo qualquer. . . . . . . . . . 19

3.2 Manipuladores não-redundante e cinematicamente redundantes. . . . . . . . 21

3.3 Manipuladores com redundância de atuação. . . . . . . . . . . . . . . . 21

3.4 Manipulador robótico paralelo com 3 níveis de redundância cinemática. 22

3.5 Modelo cinemático de 3(므)RRR: (a) Pontos e medidas lineares; (b) Ângulos e sistema de coordenadas. . . . . . . . . . . . . . . 23

4.1 Manipulador 3RRR: área de trabalho e trajetórias executadas. . . . . . . . . 39

4.2 Perfil da trajetória I. . . . . . . . . . . . . . . . . . . . . . . . . . . . . . . . . . . . . . . . .

4.3 Perfil da trajetória II. . . . . . . . . . . . . . . . . . . . . . . . . . . . . . . . . . . . . . . . . . .

4.4 Torques executados pelo manipulador $3 \underline{R} R R . \quad \ldots \ldots \ldots$. . . . . . 41 
4.5 Torques executados pelo manipulador (4)RRR. . . . . . . . . . . . . . . 42

4.6 Torques executados pelo manipulador (6)RRR. . . . . . . . . . . . . . . 42

4.7 Torques executados pelo manipulador $(\underline{\mathrm{P}}) \mathrm{R} R \mathrm{R}+2 \mathrm{R} R \mathrm{R} . \ldots \ldots$. . . . . . . . . . . . . . 43

4.8 Torques executados pelo manipulador $2(\mathrm{P}) \mathrm{RRR}+\mathrm{R} R \mathrm{R} . \quad \ldots \ldots$. . . . . . . . . 44

4.9 Torques executados pelo manipulador 3(P)RRR. . . . . . . . . . . . . . . 44

4.10 Mapa dinâmico do manipulador 3RRR. . . . . . . . . . . . . . . . . 45

4.11 Mapa dinâmico do manipulador (4)RRR. . . . . . . . . . . . . . . . 46

4.12 Mapa dinâmico do manipulador (6)RRR. . . . . . . . . . . . . . . . . . . . . . . . . . 47

4.13 Mapa dinâmico do manipulador $(\underline{P}) R R R+2 R R R . \ldots . . . .47$

4.14 Posição ótima $\delta$ da guia linear em relação à área de trabalho do manipulador

(P)RRR+2RRR . . . . . . . . . . . . . . . . . . . 48

4.15 Mapa dinâmico do manipulador $2(\underline{\mathrm{P}}) \mathrm{RRR}+\underline{\mathrm{R} R R}$. . . . . . . . . . . . . . 49

4.16 Posições ótimas a) $\delta_{1}$ b) $\delta_{2}$ das guias lineares em relação à área de trabalho do manipulador $2(\underline{P}) R R R+\underline{R} R$. . . . . . . . . . . . . . . . . 49

4.17 Mapa dinâmico do manipulador 3(P)RRR. . . . . . . . . . . . . . . 50

4.18 Posições ótimas a) $\delta_{1}$, b) $\delta_{2}$ e c) $\delta_{3}$ das guias lineares em relação à área de trabalho do manipulador $3(\underline{\mathrm{P}}) \mathrm{RRR}$. . . . . . . . . . . . . . . 51 


\section{Lista de Tabelas}

3.1 Cadeias e elos dos manipuladores. . . . . . . . . . . . . . . . 22

4.1 Parâmetros utilizados para definir os manipuladores. . . . . . . . . . . . . 38

4.2 Máximo torque realizado por cada manipulador para desempenhar prédeterminada tarefa $[\mathrm{N} . \mathrm{m}] \ldots \ldots \ldots \ldots$. . . . . . . . . . 40

4.3 Configuração dos gráficos. . . . . . . . . . . . . . . . . 40 


\subsection{Contextualização}

Recentemente, manipuladores paralelos têm recebido grande visibilidade tanto na área acadêmica quanto industrial, devido a algumas características que se sobressaem quando comparados aos manipuladores em série, como por exemplo: alta relação entre a capacidade de carga e massa da máquina, altas acelerações, rigidez superior e precisão melhorada (Merlet, 1996, 2006).

O conceito de manipulador paralelo se deve as suas cadeias cinemáticas serem fechadas, isto é, tomando como ponto de partida a base do manipulador, é possível seguir por diferentes caminhos ao longo dos braços para atingir o end-effector ${ }^{1}$ (Donelan, 2007). Na Fig. 1.1 é apresentado o robô Delta Par2, um manipulador paralelo que pode atingir altas acelerações chegando até $400 \mathrm{~m} / \mathrm{s}^{2}$ com grande precisão (Company et al., 2011). Já nos manipuladores em série, a cadeia cinemática é dita aberta, uma vez que existe apenas um caminho possível da base ao end-effector (Donelan, 2007). Um exemplo de manipulador em série é representado na Fig. 1.2 pelo robô KUKA, muito empregado na indústria (KUKA Roboter do Brasil Ltda., 2014).

O foco da proposta deste trabalho é o manipulador paralelo que, apesar de possuir características positivas, apresenta também características indesejadas, tais como baixa relação entre a área de trabalho e o espaço de montagem do manipulador e a presença de frequentes singularidades, as quais dificultam a execução de tarefas e trajetórias.

\footnotetext{
${ }^{1}$ End-effector, neste trabalho, se refere à ferramenta final do mecanismo. A nomenclatura em inglês é adotada por ser usualmente utilizada em trabalhos em português.
} 


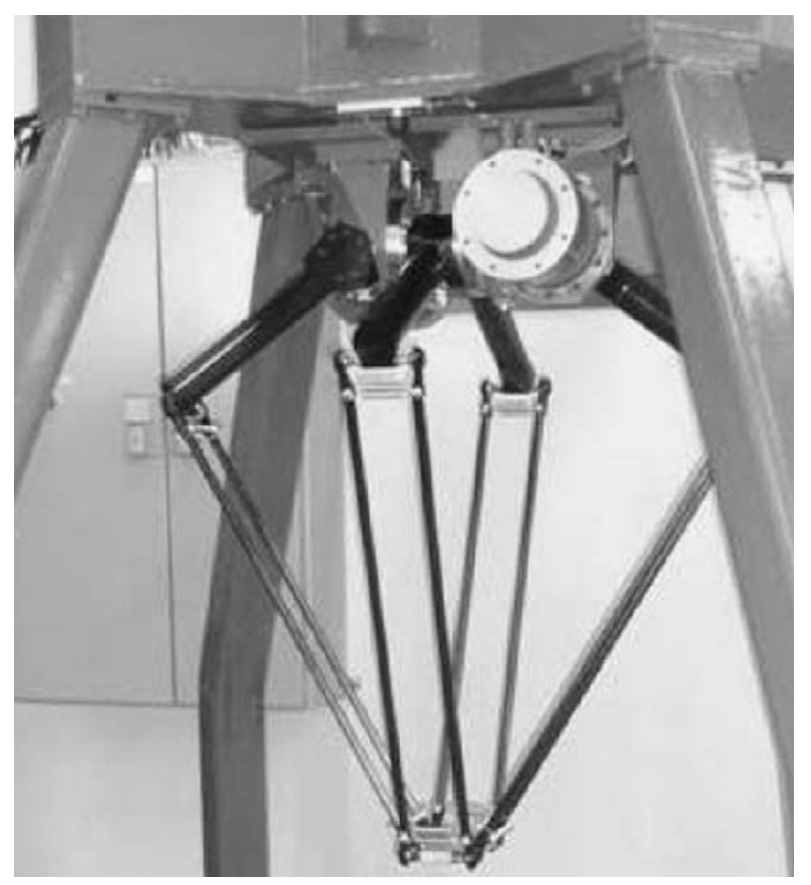

Figura 1.1: Par2: robô de cinemática paralela projetado e desenvolvido pela Fundación Fatronik e pelo CNRS (Adaptado de Company et al. (2011)).

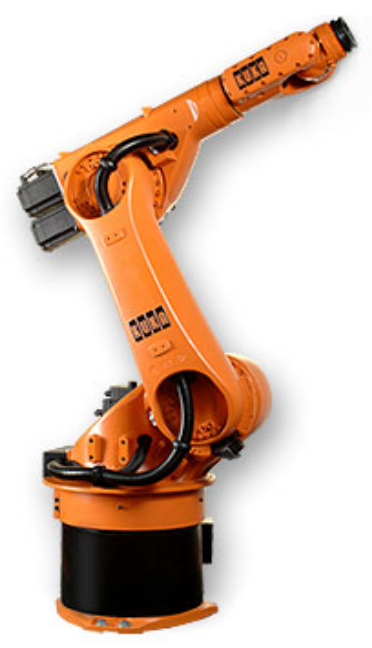

Figura 1.2: KUKA: robô de cinemática em série fabricado e distribuído pela KUKA Roboter (KUKA Roboter do Brasil Ltda., 2014).

Algumas técnicas podem ser aplicadas ao manipulador para que as características indesejadas sejam eliminadas ou minimizadas e, ao mesmo tempo, manter ou aperfeiçoar características desejadas se otimizadas corretamente. Um exemplo destas técnicas é o conceito de redundância que pode ser dividido em três segmentos (Merlet, 2006):

- Redundância de medidas: sensores são adicionados ao manipulador não redundante de forma que a quantidade de sensores seja maior que o número de graus 
de liberdade do end-effector. Esta redundância geralmente é utilizada para calibrar robôs e reduzir o erro de posição (Marquet et al., 2002);

- Redundância de atuação: adição de um atuador na junta passiva do manipulador não redundante ou a adição de uma cadeia cinemática ao manipulador não redundante. De acordo com Liu et al. (2001), este tipo de redundância permite o desvio das singularidades. Porém, manipuladores com redundância de atuação apresentam um controle desafiador (Mohamed e Gosselin, 2005) e podem diminuir a área de trabalho (Rocha e da Silva, 2013);

- Redundância cinemática: adição de uma junta ativa em uma das cadeias cinemáticas do manipulador não redundante. A redundância cinemática permite que a configuração do manipulador seja alterada, assim podendo evitar singularidades (Kotlarski et al., 2009, 2011).

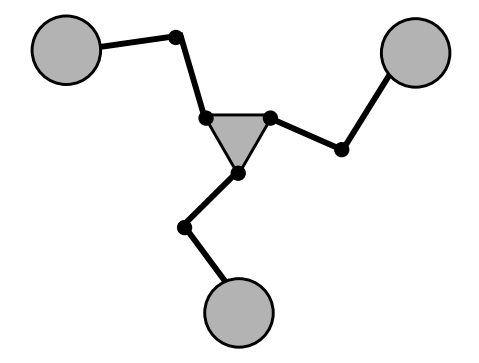

3RRR

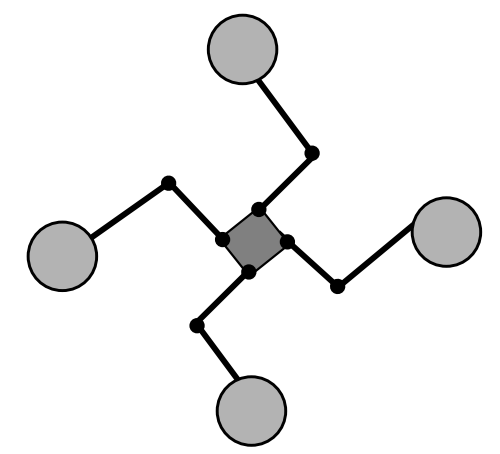

4RRR
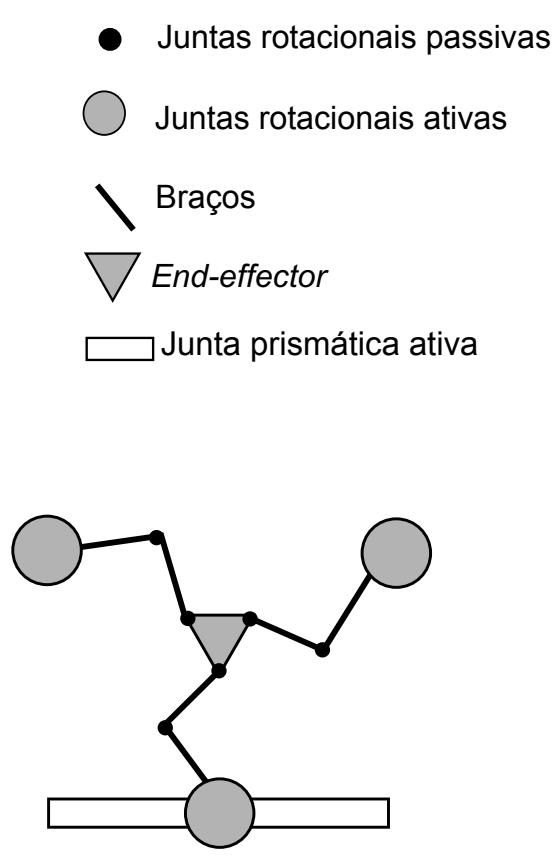

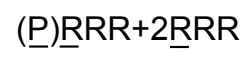

Figura 1.3: Modelo de manipulador: $3 \underline{R} R R$ não redundante; (4) $\underline{R} R R$ com redundância de atuação; ( $\underline{\mathrm{P}} \underline{\mathrm{R} R R}+2 \underline{R} R R$ com redundância cinemática.

Um manipulador paralelo planar não redundante é ilustrado na Fig. 1.3 e é denominado 3RRR, pois se trata de um manipulador com 3 cadeias cinemáticas constituídas por 3 juntas de revolução ( $\underline{R R R}$ ) proporcionando para o end-effector 3 graus de liberdade. As juntas ativas são representadas pelo texto sublinhado ( $\underline{R}$ e $\underline{P}$ ). Também são ilustrados na Fig. 1.3 exemplos de aplicação de redundância de atuação, (4)RRR, e de redundância 
cinemática, $1(\underline{P}) \underline{R} R R+2 \underline{R} R R$, nos quais os símbolos entre parênteses representam a redundância. Em (4)RRR, o manipulador não redundante recebeu uma cadeia cinemática a mais, porém o número de graus de liberdade do end-effector se manteve o mesmo. Para $1(\underline{P}) \underline{R} R R+2 \underline{R} R R$, uma junta prismática foi colocada em uma das cadeias cinemáticas permitindo que o sistema se reconfigure e também mantendo o mesmo número de graus de liberdade do end-effector. Nota-se que o end-effector em ambos os casos continua possuindo 3 graus de liberdade, porém o sistema ganha um grau de liberdade passando de 3 para 4 graus. O manipulador com redundância cinemática possui infinitas possibilidades de reconfiguração, por isso é necessário um procedimento de otimização. Por outro lado, o manipulador com redundância de atuação possui apenas uma configuração descartando a necessidade de realizar uma otimização.

A redundância pode aumentar o desempenho das PKM's e além disso, utilizando o grau de liberdade a mais do sistema, as máquinas paralelas podem se reconfigurar de acordo com diferentes critérios de otimização e estratégias (Mohamed e Gosselin, 2005; Thanh et al., 2012).

O trabalho de Cha et al. (2007) apresenta um manipulador redundante projetado de forma que a junta prismática seja um dos braços de cada cadeia cinemática, formando um manipulador três vezes cinematicamente redundante denominado $3 \underline{R}(\underline{P}) R R$. A cinemática inversa é modelada e a partir desta um processo de otimização é feito para se evitar as singularidades. A comparação do manipulador redundante com o não redundante demonstra que é possível o desvio de singularidades presentes no manipulador 3 RRR e que ocorre o aumento da área de trabalho.

Kotlarski et al. (2009) fizeram um estudo comparativo entre manipuladores não redundante e uma vez cinematicamente redundante. O foco foi obter uma área de trabalho útil em que se possua um mínimo de erro de posição aceitável e livre de singularidades. Os resultados demonstraram que o manipulador redundante é capaz de se reconfigurar evitando as singularidades e, a partir de uma otimização adequada, possuir uma área de trabalho maior e com precisão aceitável.

Métodos de otimização para o manipulador cinematicamente redundante são apresentados por Kotlarski et al. $(2008,2010,2011)$ os quais possuem duas características principais, podendo ser offline ou online. A otimização offline se dá quando a configuração do manipulador é alterada pelas cadeias redundantes antes da realização da trajetória do end-effector. Já na otimização online, a movimentação das juntas redundantes e do end-effector ocorrem ao mesmo tempo. Os resultados destes trabalhos comprovam, por meio de validação experimental e numérica, que a redundância cinemática contribui para a melhoria do desempenho do manipulador em termos de precisão.

A cinemática inversa e a dinâmica inversa dos manipuladores $\underline{R} R R+\underline{R R} R, 3 \underline{R} R R$ e (4)RRR são apresentadas por Wu et al. (2011). Um índice de desempenho dinâmico baseado em uma trajetória é especificado e calculado para cada manipulador de modo 
que, quando comparados, comprova que a redundância de atuação causa uma melhora no desempenho de manipuladores planares.

Nahon e Angeles (1989) comparam o máximo torque necessário para uma mesma tarefa realizada por dois manipuladores, sendo um não redundante e outro com redundância de atuação. Nota-se uma melhor distribuição de forças internas e externas nos manipuladores redundantes por otimização, o que permite, por sua vez, que um manipulador redundante realize a mesma trajetória com motores menos potentes.

Um resultado similar é encontrado por Corbel et al. (2010). Neste trabalho é aplicada a redundância de atuação a um manipulador delta não redundante obtendo dois manipuladores redundantes, um com apenas uma redundância e outro com três redundâncias. As cinemáticas inversas de cada manipulador são determinadas e comparadas com o intuito de determinar se a redundância de atuação é uma boa alternativa para atingir altas acelerações. A pesquisa comprova que a capacidade dinâmica ao longo de uma determinada trajetória é mais homogênea em manipuladores com redundância de atuação o que torna possível atingir altas acelerações. Porém, comparando os dois manipuladores redundantes observa-se que o custo de se adicionar duas cadeias cinemáticas ao manipulador é muito alto pelo fato de não ocorrer um ganho expressivo no desempenho dinâmico do manipulador já uma vez redundante.

Wu et al. (2013) investigam o condicionamento, a rigidez, a velocidade e a máxima carga útil de dois manipuladores paralelos planares, um com uma cadeia cinemática adicional, e outro com duas cadeias adicionais. As simulações mostram que o manipulador redundante com uma cadeia adicional tem maior condicionamento e velocidade contra menor rigidez e capacidade de carga útil do que aquele com duas cadeias adicionais.

Esta revisão foi realizada com foco em estudos da aplicação de redundância cinemática e de atuação em manipuladores paralelos com os objetivos de definir uma base de conhecimento das modelagens e características dos manipuladores, assim como, métricas e métodos de otimização. É possível perceber que os trabalhos apresentados não possuem resultados que avaliem a dinâmica do manipulador em toda a área de trabalho, isto é, as avaliações dinâmicas existentes são dependentes da trajetória a ser executada.

\subsection{Objetivos}

O estudo sobre a redundância de atuação mostrou que com a adição de cadeias cinemáticas ao sistema é possível diminuir o torque máximo atingido para uma desejada trajetória, logo sendo possível melhorar o desempenho dinâmico. Também foi demonstrado que dependendo da tarefa a ser realizada, o sistema possui uma capacidade máxima de melhoria de desempenho pela adição de redundância de atuação. Entretanto, uma avaliação em toda a área de trabalho ainda é pouco discutida. 
De acordo com a revisão bibliográfica realizada, não foram encontrados estudos sobre o desempenho dinâmico de manipuladores planares com a adição de redundância cinemática. Pode-se tentar supor que a adição de uma junta ativa na configuração do manipulador aumente a força/torque disponível, assim também aumentando o desempenho dinâmico, porém essa questão não é trivial. A adição de uma junta ativa também significa adicionar massa ao sistema e para se determinar se o desempenho dinâmico melhorou, é necessário realizar um estudo para investigar o impacto da adição de corpos ao manipulador no torque necessário para realizar uma tarefa.

Portanto, tendo em vista o estudo de mensurar o impacto no desempenho dinâmico dos manipuladores planares pelo uso da redundância cinemática e de atuação, este projeto de mestrado se propôs a:

- Modelar e simular cinemática e dinamicamente manipuladores com redundância de atuação;

- Modelar e simular cinemática e dinamicamente manipuladores com redundância cinemática;

- Realizar otimizações offline e online das configurações cinematicamente redundantes do manipulador com o objetivo de obter melhor desempenho dinâmico;

- Definir um índice dinâmico independente da trajetória;

- Desenhar mapas dinâmicos de todos os manipuladores;

- Definir se as redundâncias são boas soluções para atingir melhor desempenho dinâmico.

\subsection{Estrutura do texto}

Este trabalho está organizado da seguinte maneira:

- O capítulo 2 apresenta uma revisão dos conceitos de manipuladores robóticos, singularidades e redundância para o entendimento básico do estudo do mestrado;

- O capítulo 3 apresenta de forma detalhada a metodologia e a modelagem utilizadas nas simulações, como também a definição do índice dinâmico proposto;

- O capítulo 4 apresenta os resultados obtidos de simulações de algumas tarefas pré determinadas e os mapas dinâmicos;

- O capítulo 5 apresenta as conclusões deste trabalho, as contribuições e as sugestões para trabalhos futuros. 


\subsection{Considerações iniciais}

Os manipuladores robóticos podem ser agrupados quanto à cadeia cinemática, assim, manipuladores em série são aqueles que possuem a cadeia cinemática aberta e, por terem esta característica, a modelagem cinemática deste manipuladores é mais simples do que os manipuladores paralelos, já que estes são caracterizados pelas suas cadeias cinemáticas fechadas tornando seu movimento mais restrito, porém com maior robustez.

Algumas características de um manipulador devem ser consideradas quando determinada tarefa é necessária. A precisão é muito importante em tarefas de montagem enquanto a amplitude do movimento pode ser reduzida. A dinâmica deve ser muito bem especificada para manipuladores que envolvem contato, ou mesmo, para tarefas que exigem velocidades altas, o manipulador deve ter partes leves (Merlet, 2006).

Devido às características do manipuladores paralelos, eles são utilizados em diversas áreas, como por exemplo, em processos cirúrgicos que exigem grande precisão (Kobler et al., 2012) ou na indústria em processos de pega-e-põe que necessitam grande velocidade (Corbel et al., 2010).

O foco deste trabalho são os manipuladores planares paralelos os quais são representados por várias configurações e possuem características específicas que serão apresentadas neste capítulo para que se possa especificar corretamente o manipulador estudado. 


\subsection{Manipuladores paralelos: definição e características}

Merlet (2006) define manipulador paralelo como um mecanismo de cadeia fechada cujo end-effector é ligado à base por mais de uma cadeia cinemática independente.

Esta definição de manipulador paralelo é muito abrangente, pois pode ser representada por várias configurações de manipuladores, podendo ser não redundante ou redundante, espacial ou planar, entre outras. Portanto, deve-se enumerar algumas características desejadas para a definição do manipulador a ser estudado:

- No mínimo duas cadeias sustentam o end-effector. Cada uma dessas cadeias contém no mínimo um atuador e um sensor apropriado para medir as variáveis associadas à atuação;

- O número de atuadores deve ser igual ao número de graus de liberdade do endeffector;

- A mobilidade do end-effector é nula quando os atuadores estão fixos.

Estas características definem um manipulador paralelo não redundante. Este tipo de mecanismo é notável pelas seguintes consequências:

- O mínimo de duas cadeias cinemáticas já permite a distribuição de carga;

- O número de atuadores e de sensores é mínimo;

- Quando os atuadores estão parados, o end-effector também permanece parado.

Pode-se restringir ainda mais a classificação de um manipulador paralelo se houver a consideração de que o número de cadeias é igual ao número de graus de liberdade do endeffector. Isto implica que cada cadeia tenha apenas um atuador. Este tipo de manipulador é denominado manipulador completamente paralelo e pode ser identificado pelo índice de paralelismo $d$ dado por (Earl e Rooney, 1983):

$$
d=\frac{k}{l-1}
$$

onde $k$ é o número de laços independentes, ou seja, a diferença entre o número de juntas de um grau de liberdade e o número de corpos em movimento do sistema, e $l$ é o número de graus de liberdade do sistema. O índice varia entre 0 e 1 sendo o valor 0 para manipuladores em série e 1 para manipuladores completamente paralelos.

A definição de manipuladores completamente paralelos permite que os manipuladores sejam caracterizados pelo movimento, podendo ser separados em dois principais casos: 
manipuladores planares, com no máximo 3 graus de liberdade em um plano (2 de translação e 1 de rotação), ou manipuladores espaciais com no máximo 6 graus de liberdade. Para este estudo será utilizado o manipulador planar com 3 graus de liberdade.

Para completar a definição do manipulador a ser estudado, é preciso determinar quantos corpos rígidos formam cada cadeia cinemática do manipulador. A fórmula de Grübler pode ser usada para determinar o número de corpos de um manipulador a partir do número de graus de liberdade do end-effector $m$ (Merlet, 2006):

$$
m=3(l-n-1)+\sum_{i=1}^{n} d_{i}
$$

onde $l$ é o número de corpos do manipulador, incluindo a base, $n$ é o número total de juntas e $d_{i}$ é o número de graus de liberdade da junta $i$.

Sabe-se que o manipulador planar possui 3 graus de liberdade $(m=3)$, portanto, possui 3 cadeias cinemáticas e, assumindo que elas sejam idênticas, pode-se denominar como $n_{1}$ o número de corpos rígidos em cada cadeia. Assim, o mínimo de juntas de um grau de liberdade em cada cadeia é $n_{1}+1$ e, com isso, pode-se obter algumas relações (Eq. (2.3)) e reescrever a Eq. (2.2):

$$
\begin{gathered}
l=2+3 n_{1} \quad n=3\left(n_{1}+1\right) \quad \sum_{i=1}^{n} d_{i}=3\left(n_{1}+1\right) \\
3=-6+3\left(n_{1}+1\right)
\end{gathered}
$$

Conclui-se que cada cadeia cinemática possui dois corpos rígidos $\left(n_{1}=2\right)$ e três juntas independentes $\left(n_{1}+1\right)$. Utilizando dessas informações, pode-se calcular o índice de paralelismo. Sabendo que a quantidade de corpos em movimento é 7 ( 6 elos e o endeffector) e o número de juntas é 9 , o valor encontrado de $d$ é 1 comprovando a definição de manipulador completamente paralelo.

Uma cadeia cinemática pode ser representada pela sequência de suas juntas que, no caso do manipulador paralelo planar, podem ser prismáticas (P) ou rotacionais (R). Logo, as cadeias podem ter as seguintes representações: RRR, PRR, RPR, RRP, PPR, PRP, RPP (Fig. 2.1).

Seguindo a notação de que $\underline{R}$ é a junta atuadora, o manipulador $3 \underline{R} R R$ é o mais comum devido ao fato de os atuadores estarem fixos à base o que permite o uso de motores de baixo custo e diminui o peso de equipamentos que se movimentam (Bonev e Gosselin, 2001), logo este manipulador é tomado como base para este trabalho.

Considerando todas estas características, a definição do manipulador estudado é um manipulador completamente paralelo planar de 3 graus de liberdade com 3 cadeias idênticas formadas por 2 corpos rígidos ligados entre si, à base e ao end-effector por juntas 


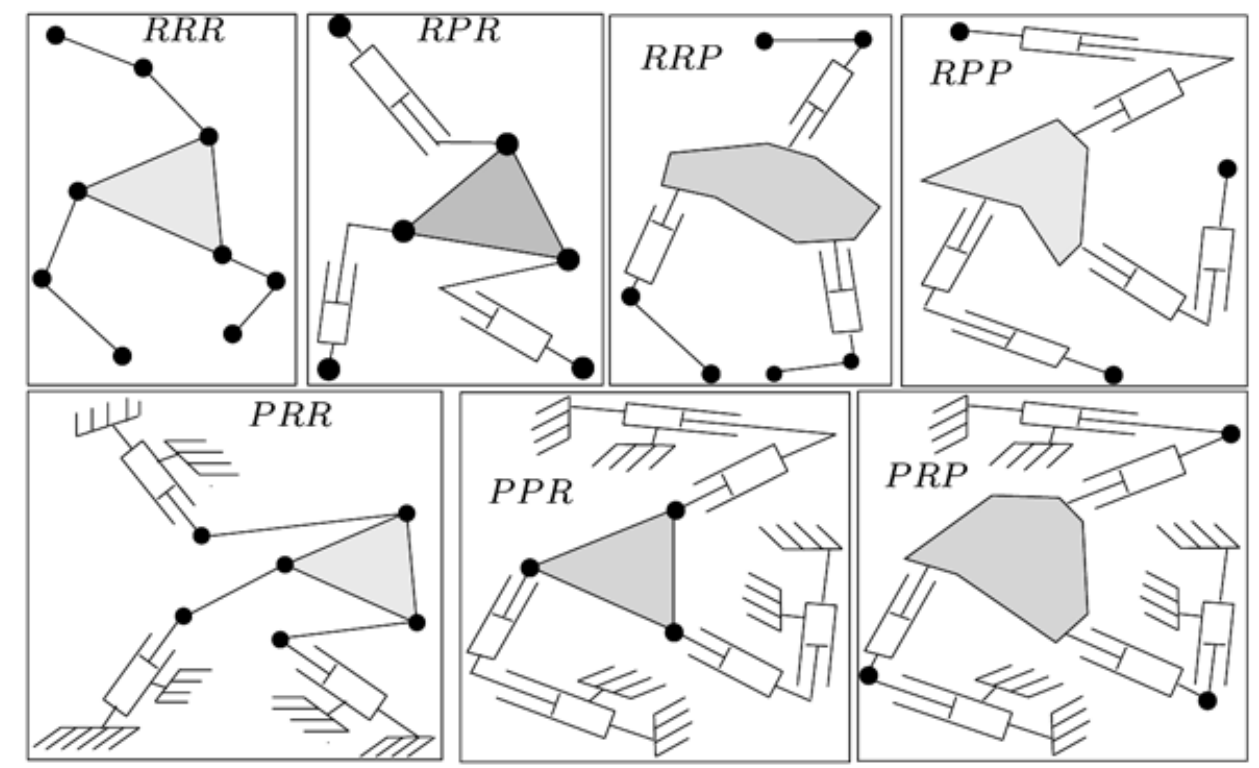

Figura 2.1: Os diferentes manipuladores completamente planares paralelos de 3 graus de liberdade com cadeias idênticas (Merlet, 2006).

rotacionais, denominado $3 \underline{R} R R$. Sendo o manipulador $3 \underline{R} R R$ um sistema mecânico, inevitavelmente ele possui singularidades. Elas são posições do sistema onde ocorre instantânea mudança de graus de liberdade do sistema, isto é, as matrizes jacobianas que relacionam as velocidades dos atuadores com as velocidades do end-effector têm seu rank diminuído (Gosselin e Angeles, 1990). Este conceito será melhor discutido na seção 2.3.

\subsection{Singularidades}

Considere um manipulador com $m$ atuadores e $n$ graus de liberdade sendo que $\Theta$ e $\mathrm{X}$ são os vetores que representam as variáveis de entrada e saída, respectivamente. Com as considerações já tomadas, é correto dizer que o número de atuadores e de graus de liberdade são o mesmo e, portanto, a dimensão dos vetores $\Theta$ e $\mathbf{X}$ é a mesma, $n$.

A relação entre as coordenadas de entrada e saída pode ser escrita por um função $F$ implícita de $\Theta$ e $\mathbf{X}$ com dimensão $n$ :

$$
F(\boldsymbol{\Theta}, \mathbf{X})=\mathbf{0}
$$

onde 0 é o vetor de zeros com dimensão $n$.

A diferenciação em relação ao tempo da função $F$ apresenta como resultado a relação entre as velocidades de saída e entrada do sistema:

$$
A \dot{\mathbf{X}}+B \dot{\Theta}=\mathbf{0}
$$


onde $A$ e $B$ são matrizes $n \times n$ chamadas de jacobianas e são dependentes de $\Theta$ e $\mathbf{X}$, $A(\boldsymbol{\Theta}, \mathbf{X})$ e $B(\boldsymbol{\Theta}, \mathbf{X})$.

A classificação apresentada por Gosselin e Angeles (1990) demonstra que a posição de singularidade ocorre quando a matriz $A$ ou a matriz $B$ é singular. Assim, conclui-se que as singularidades podem ser de três tipos diferentes que apresentam significados físicos distintos.

1. O primeiro tipo de singularidade ocorre quando:

$$
\operatorname{det} B=0
$$

O primeiro tipo de singularidade corresponde a uma configuração em que o endeffector está em um deadpoint. A configuração correspondente é aquela em que o endeffector alcança tanto uma fronteira da sua área de trabalho ou uma fronteira interna limitante de diferentes sub-regiões da área de trabalho. Em outras palavras, este tipo de singularidade consiste no conjunto de pontos em que o cálculo da cinemática inversa não pode ser determinado. Uma vez que a nulidade de $B$, isto é, a dimensão do seu espaço nulo, é diferente de zero, é possível encontrar vetores não nulos de $\dot{\Theta}$ para o qual $\dot{\mathbf{X}}$ vai ser sempre igual a zero, e assim, a velocidade $\dot{\mathbf{X}}$ desejada não pode ser produzida como saída. Tipicamente, estas seriam velocidades ortogonais ao limite da área de trabalho ou dirigidas para o exterior da área de trabalho. Em tal configuração, é considerado que o end-effector perde um ou mais graus de liberdade.

2. O segundo tipo de singularidade ocorre quando:

$$
\operatorname{det} A=0
$$

O segundo tipo de singularidade corresponde a uma configuração em que o atuador se encontra em um deadpoint. Esta configuração corresponde a qual o end-effector é localmente móvel mesmo quando os atuadores estão fixos. Ao contrário do primeiro, este tipo de singularidade encontra-se dentro da área de trabalho e corresponde a um ponto ou um conjunto de pontos onde o problema se encontra no cálculo da cinemática direta. Considerando que o espaço nulo de A não está vazio, existem vetores não nulos de velocidade de saída $\dot{X}$ que irão corresponder a uma velocidade $\dot{\Theta}$ igual a zero das juntas atuadoras. Em tal configuração, considera-se que o endeffector ganha um ou mais graus de liberdade

3. O terceiro tipo de singularidade possui uma natureza diferente dos demais, uma vez que exige condições sobre os parâmetros dos braços. Isto ocorre quando, em certas configurações, ambos A e B tornam-se simultaneamente singulares. Se forem satisfeitas determinadas condições específicas sobre os parâmetros de ligação, a cadeia 
pode chegar a configurações em que a relação de posição, dada por $F$ (equação 2.5), degenera. Este caso corresponde a configurações em que o sistema pode sofrer pequenos movimentos quando os atuadores são bloqueados ou em que um movimento das entradas produz nenhum movimento das saídas.

Bonev e Gosselin (2001) realizaram um estudo sobre singularidades em manipuladores 3 RRR e determinaram em quais configurações cada tipo de singularidade ocorre neste manipulador. Considerando a representação ilustrada na Fig. 2.2, a singularidade do tipo 1 ocorre quando o end-effector atinge os limites da área de trabalho, a singularidade do tipo 2 ocorre quando as retas formadas pelos braços mais próximos do end-effector se interceptam em um mesmo ponto ou quando estas são paralelas. Satisfazendo a condição que o tamanho do braço $1, l_{1}$, é igual ao tamanho do braço $2, l_{2}$, sabe-se que a singularidade do tipo 3 ocorre quando $B_{i} \equiv O_{i}$.

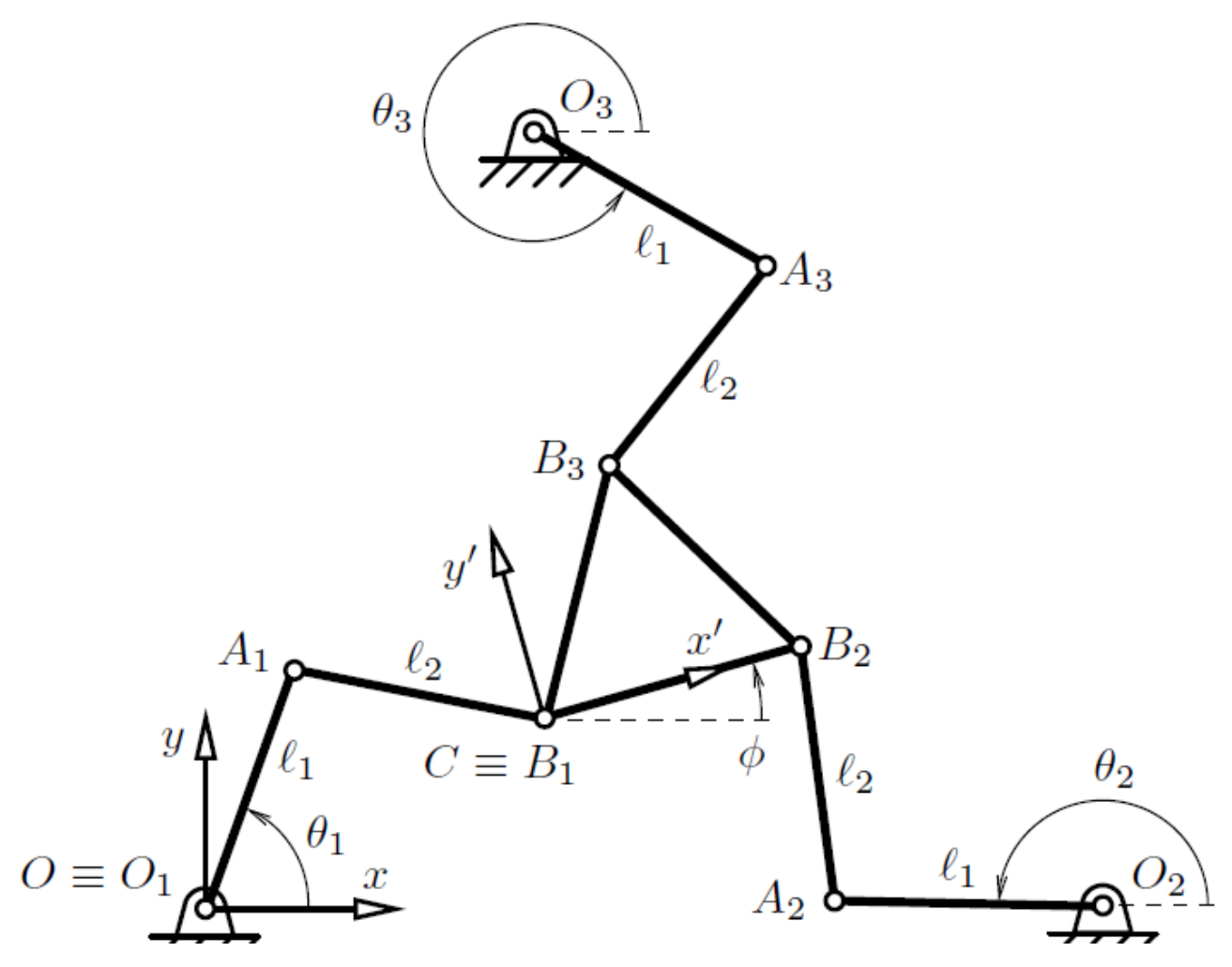

Figura 2.2: Representação dos parâmetros do manipulador 3RRR (Bonev e Gosselin, 2001).

Conhecendo o espaço das singularidades no manipulador é possível determinar estratégias para que este problema seja solucionado. A redundância é um exemplo dessas estratégias que proporciona um problema de otimização o qual, além de desviar de singularidades, pode conseguir melhoria de outras características dependo dos objetivos secundários propostos pela otimização. 


\subsection{Redundância}

Considere um manipulador com $m$ graus de liberdade e $n$ atuadores, logo, é correto notar que o espaço das juntas possui $n$ graus de liberdade. Segundo Conkur e Buckingham (1997), pode-se dizer que o sistema é redundante quando $n$ é projetado para ser maior que $m$. Porém, Merlet (2006) também faz a consideração que ocorre redundância quando o número de sensores é maior que o número de graus de liberdade do sistema. Assim, a redundância pode ser separada em três principais segmentos, como já apresentado: redundância de medidas; redundância cinemática; e redundância de atuação (Fig. 2.3).
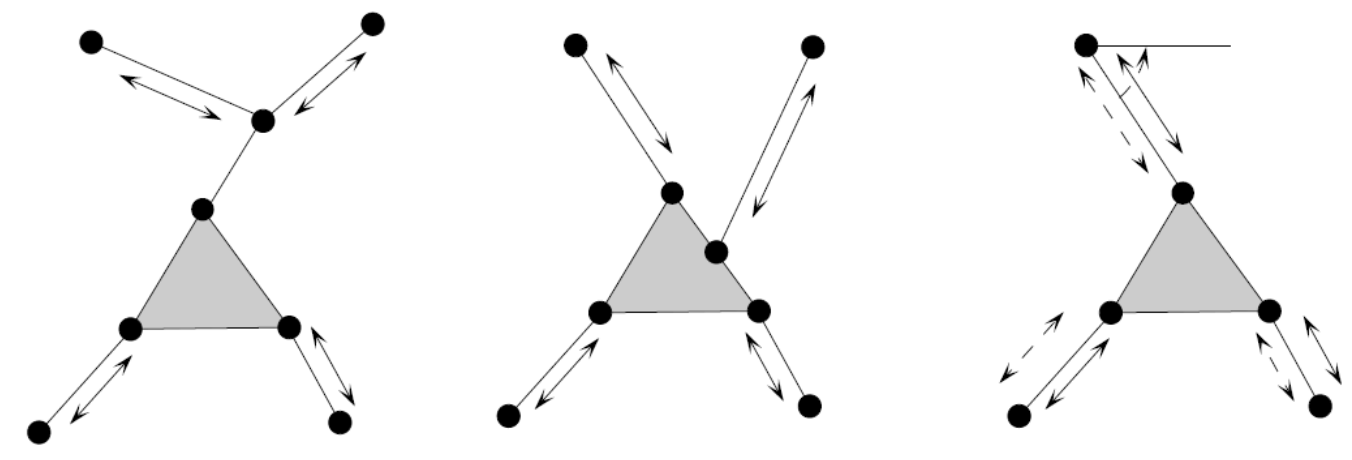

Figura 2.3: Da esquerda para a direita, exemplos de redundância cinemática, redundância de atuação e redundância de medidas (as linhas tracejadas representam os sensores) (Merlet, 2006).

A redundância de atuação e a redundância cinemática se mostraram eficazes para solucionar o problema de singularidades, porém estas aplicações podem ser tratadas para atingir diferentes objetivos secundários. Os trabalhos de Rocha e da Silva (2013); Corbel et al. (2010); Company et al. (2011) indicam que a redundância de atuação pode melhorar o desempenho dinâmico de um manipulador, porém não foram encontrados trabalhos que estudem o desempenho dinâmico avaliando toda a área de trabalho dos manipuladores. Como também, não foram encontrados trabalhos que avaliem a dinâmica dos manipuladores cinematicamente redundantes. Uma revisão bibliográfica mais aprofundada sobre redundância cinemática e de atuação em manipuladores planares foi realizada para se adquirir os conhecimentos básicos para este estudo e é apresentada a seguir.

\subsubsection{Redundância cinemática}

Kotlarski et al. (2009) fizeram um estudo comparativo entre 2 manipuladores, 1 não redundante e outro uma vez cinematicamente redundante. O foco foi obter uma área de trabalho útil em que se possuía um mínimo de erro de posição aceitável e livre de singularidades. Uma trajetória do end-effector com singularidades foi determinada para demonstrar que com a reconfiguração do sistema é possível realizar a mesma trajetória 
livre de singularidades. A reconfiguração do sistema é ilustrada na Fig. 2.4. Realizou-se a otimização adequada para o problema proposto e os resultados demonstraram que o manipulador redundante possui uma área de trabalho maior com precisão aceitável (Fig. 2.5). É interessante notar que as áreas que não possuem a precisão desejada (áreas em amarelo) se encontram próximas às posições de singularidades.
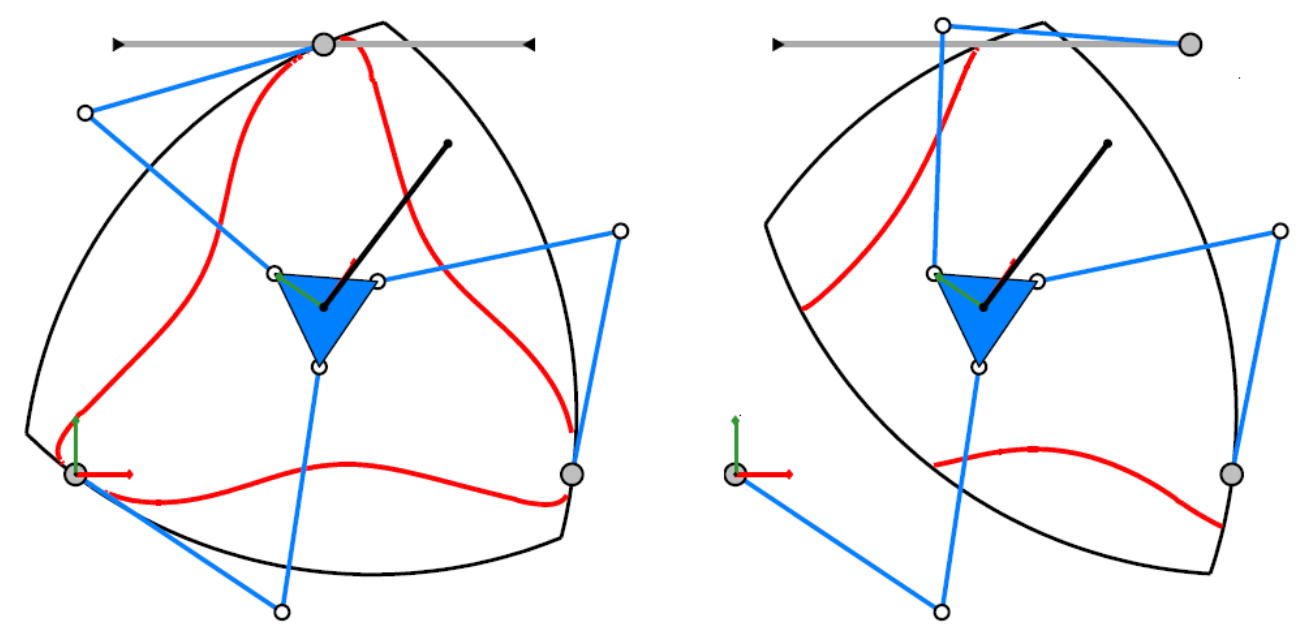

Figura 2.4: Reconfiguração do sistema proporcionando que a trajetória seja realizada livre de singularidades (linha em vermelho) (Kotlarski et al., 2009).
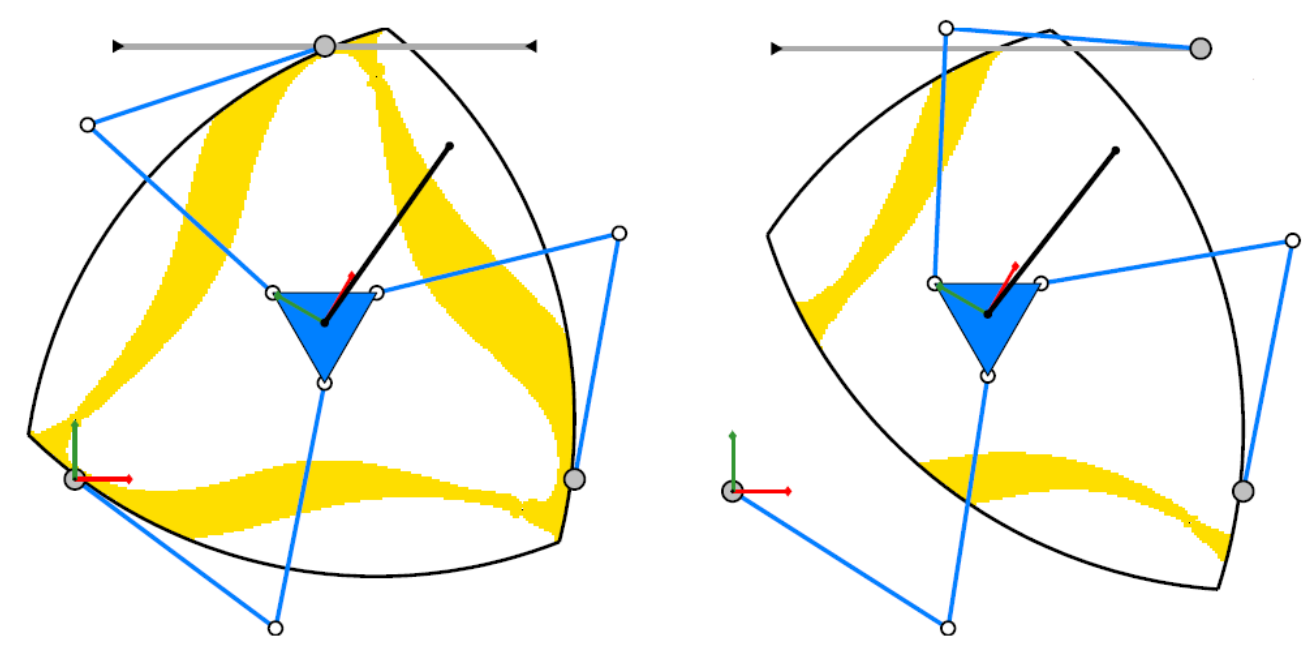

Figura 2.5: Reconfiguração do sistema proporcionando o aumento da área de trabalho, diminuindo a área onde a precisão não é adequada (área em amarelo) e permitindo que a trajetória seja realizada com a precisão desejada (Kotlarski et al., 2009).

Kotlarski et al. (2011) apresentam um protótipo de um manipulador cinematicamente redundante apresentado na Fig. 2.6 com o qual realizaram a validação experimental de algoritmos de otimização que melhoraram o controle de posição do manipulador.

O processo de otimização possui duas características distintas, podendo ser offline ou online. A otimização offline posiciona a cadeia redundante em uma posição ótima antes 
da movimentação do end-effector, já a online faz com que as juntas redundantes realizem movimentos ao mesmo tempo que o end-effector realiza sua trajetória. A otimização offline requisita menor esforço computacional, porém a online utiliza maior potencial de melhoria do desempenho pela aplicação da redundância.

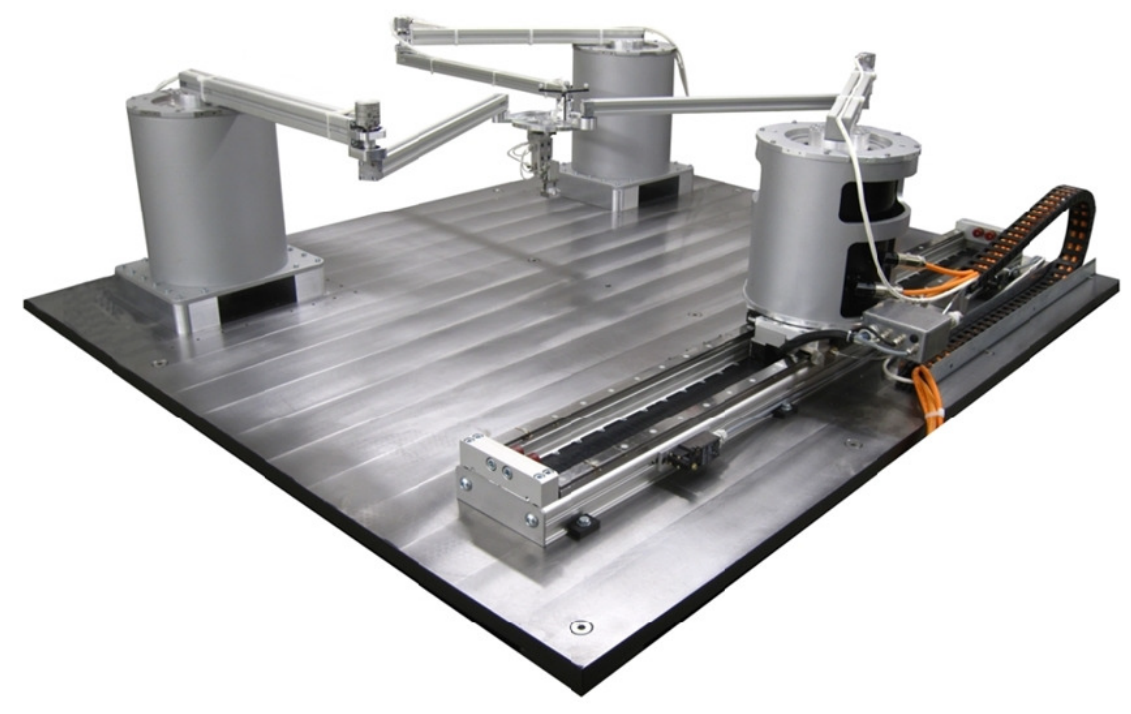

Figura 2.6: Manipulador planar $(\underline{P}) \underline{R} R+2 \underline{R} R R$ construído pelo Instituto de Sistemas

Mecatrônicos, Universidade de Leibniz, Hanover, Alemanha (Kotlarski et al., 2011).

O trabalho de Cha et al. (2007) apresenta um manipulador 3 vezes redundante e também demonstra que a redundância cinemática é uma boa alternativa para o aumento da área de trabalho. Este estudo também propõe um método de otimização que pode ser utilizado para controlar o manipulador em tempo real, porém apenas ocorre o desvio de singularidades, isto é, a otimização não possui objetivos secundários.

Um trabalho similar é realizado por Niemann et al. (2013) que apresenta algoritmos para tratar do controle de um manipulador $3(\underline{P}) \underline{R} R R$ em tempo real. O método consiste em diminuir sistematicamente os pontos de otimização, o que leva a uma diminuição do esforço computacional necessário.

Todos os trabalhos apresentados demonstram que a redundância cinemática promove algumas características dos manipuladores planares, entretanto trabalhos sobre a dinâmica dos manipuladores com este tipo de redundância é pouco estudado.

\subsubsection{Redundância de atuação}

A redundância de atuação possui um modelo cinemático exato, diferentemente da redundância cinemática que possui infinitas soluções, assim não necessitando de otimizações para estudar as características do manipulador com redundância de atuação. Por este motivo, o estudo da redundância de atuação se torna mais simples e assim pode-se encontrar 
mais trabalhos sobre este assunto. A seguir, são apresentados alguns destes trabalhos voltados à modelagem e ao estudo dinâmico de manipuladores com este tipo de redundância.

Wu et al. $(2009,2011)$ apresentam modelagens detalhadas de manipuladores com redundância de atuação. Estas modelagens são baseadas na formulação newtoniana e utilizam o princípio de trabalho virtual para a determinação dos torques necessários para realizar uma determinada trajetória. A partir desta modelagem Wu et al. (2009) desenvolvem um controle que é aplicado ao manipulador não redundante e ao uma vez redundante. Por validação experimental, foi demonstrado que o erro utilizando o controle proposto é aceitável e são bem próximos quando comparados os dois manipuladores, como também foi demonstrado que a aplicação da redundância de atuação diminui os picos dos torques do atuadores para realizar uma mesma tarefa, isto é, o manipulador redundante necessita de torques menores para realizar a mesma tarefa que o manipulador não redundante. Seguindo a mesma análise, Wu et al. (2011) demonstra, por validação numérica, a melhoria do desempenho dinâmico em algumas áreas de manipuladores planares pela aplicação da redundância de atuação. Ambos trabalhos analisam o desempenho dos manipuladores realizando uma trajetória pré-definida.

Muller (2010) estuda como as incertezas geométricas interferem no controle de manipuladores com redundância de atuação. Este estudo aponta a necessidade de controles robustos para manipuladores redundantes já que estes manipuladores possuem melhores características quando comparados aos manipuladores não redundantes, entretanto possuem uma modelagem mais complexa dificultando a aplicação de controles tradicionais.

Mehta e Dasgupta (2011) analisa como deve ser introduzida a redundância em mecanismos. Esta análise é feita observando o condicionamento de manipuladores e, assim, se conclui que a redundância deve ser aplicada a manipuladores em sua concepção, e não introduzindo corpos no manipulador não redundante. Isto porque os manipuladores redundantes possuem melhor condicionamento quando sua configuração é isotrópica, isto é, os atuadores devem estar igualmente espaçados.

Estes são alguns exemplos de trabalhos que estudam a redundância de atuação. É interessante notar como estes estudos estão avançados no sentido de já discutir o controle destes manipuladores ou como introduzir a redundância, diferentemente dos estudos sobre manipuladores com redundância cinemática que ainda é pouco conhecido.

\subsection{Considerações finais}

Neste capítulo foi apresentada uma revisão da literatura sobre manipuladores robóticos. O objetivo principal foi apresentar as características do manipulador estudado e a identificação de trabalhos relacionados. Como nenhum trabalho encontrado é exatamente igual, os principais trabalhos foram sintetizados para servir como base para este estudo. 


\section{3}

\section{Metodologia e modelagem}

\subsection{Considerações iniciais}

Neste capítulo é apresentada a teoria básica da metodologia para se obter a modelagem dos manipuladores. Em seguida, é apresentada a modelagem dos manipuladores estudados. Esta modelagem apresenta poucas variações de um manipulador para o outro, assim a modelagem é feita com foco no manipulador com redundância cinemática por este possuir mais corpos por cadeia e, ao longo do texto, serão apresentadas as ressalvas para se determinar a modelagem dos manipuladores similares.

\subsection{Metodologia básica}

Nesta seção são apresentados os métodos para modelar cinemática e dinamicamente os manipuladores. A teoria básica é apresentada assim podendo ser aplicada para modelar os manipuladores.

\subsubsection{Cinemática inversa}

Nesta seção serão detalhados os métodos responsáveis pelo cálculo das posições das juntas $\Theta$ a partir de uma dada posição da plataforma X. Para atingir este objetivo é utilizado o método analítico apresentado por Merlet (2006) discutido abaixo. 
Considere como $A$ o ponto de ligação da base com o braço de uma cadeia cinemática e como $B$ o ponto de ligação do braço dessa cadeia cinemática com o end-effector, pode-se determinar um vetor $\mathbf{A B}$ a partir da posição do end-effector:

$$
\mathbf{A B}=H_{1}(\mathbf{X})
$$

Mas também é possível obter um vetor para cada braço desta cadeia cinemática em função da posição do end-effector $\mathrm{X}$ e das juntas $\Theta$ (aqui considera-se tanto os ângulos das juntas ativas como das passivas).

$$
\mathbf{A B}=H_{21}(\mathbf{X}, \boldsymbol{\Theta})+H_{22}(\mathbf{X}, \boldsymbol{\Theta})+\ldots+H_{21 n}(\mathbf{X}, \boldsymbol{\Theta})=H_{2}(\mathbf{X}, \boldsymbol{\Theta})
$$

Como as duas equações se referem ao vetor $\mathrm{AB}$, podem ser igualadas:

$$
H_{1}(\mathbf{X})=H_{2}(\mathbf{X}, \boldsymbol{\Theta})
$$

Assim, é possível determinar $\Theta$ dada uma posição do end-effector X.

\subsubsection{Dinâmica inversa}

A dinâmica inversa de um manipulador consiste de encontrar os torques necessários de atuação $(\tau)$ para realizar dada trajetória do end-effector, conhecendo posição, velocidade e aceleração (X, $\dot{\mathbf{X}} e \ddot{\mathbf{X}})$ do mesmo.

Existem várias abordagens para se determinar a modelagem dinâmica de um sistema. Pode ser utilizado o formalismo lagrangiano ou equações de Newton-Euler, entre outros (Merlet, 2006). Neste trabalho são utilizadas as equações de Newton-Euler em conjunto com o princípio de trabalho virtual também utilizado em vários trabalhos da área (Wang et al., 2009; Wu et al., 2009, 2011; Küçük, 2012).

Considere um corpo de massa $m$ que apenas realize movimento planar, logo a representação de uma força $\mathbf{F}$ e o momento $\mathbf{M}$ aplicados em um ponto $P$ qualquer do corpo para realizar o movimento em torno deste ponto é apresentada na Fig. 3.1

A formulação de Newton-Euler descreve as forças necessárias para o movimento de translação do corpo como sendo:

$$
\mathbf{F}=m \mathbf{a}_{\mathbf{g}}
$$

onde $G$ é o ponto em que se encontra o centro de massa do corpo e $\mathbf{a}_{\mathrm{g}}$ é a aceleração deste ponto.

Como o ponto de aplicação das forças é o ponto $P$, é interessante escrever a aceleração do ponto $G$ a partir da aceleração do ponto $P, \mathrm{a}_{\mathbf{p}}$ : 


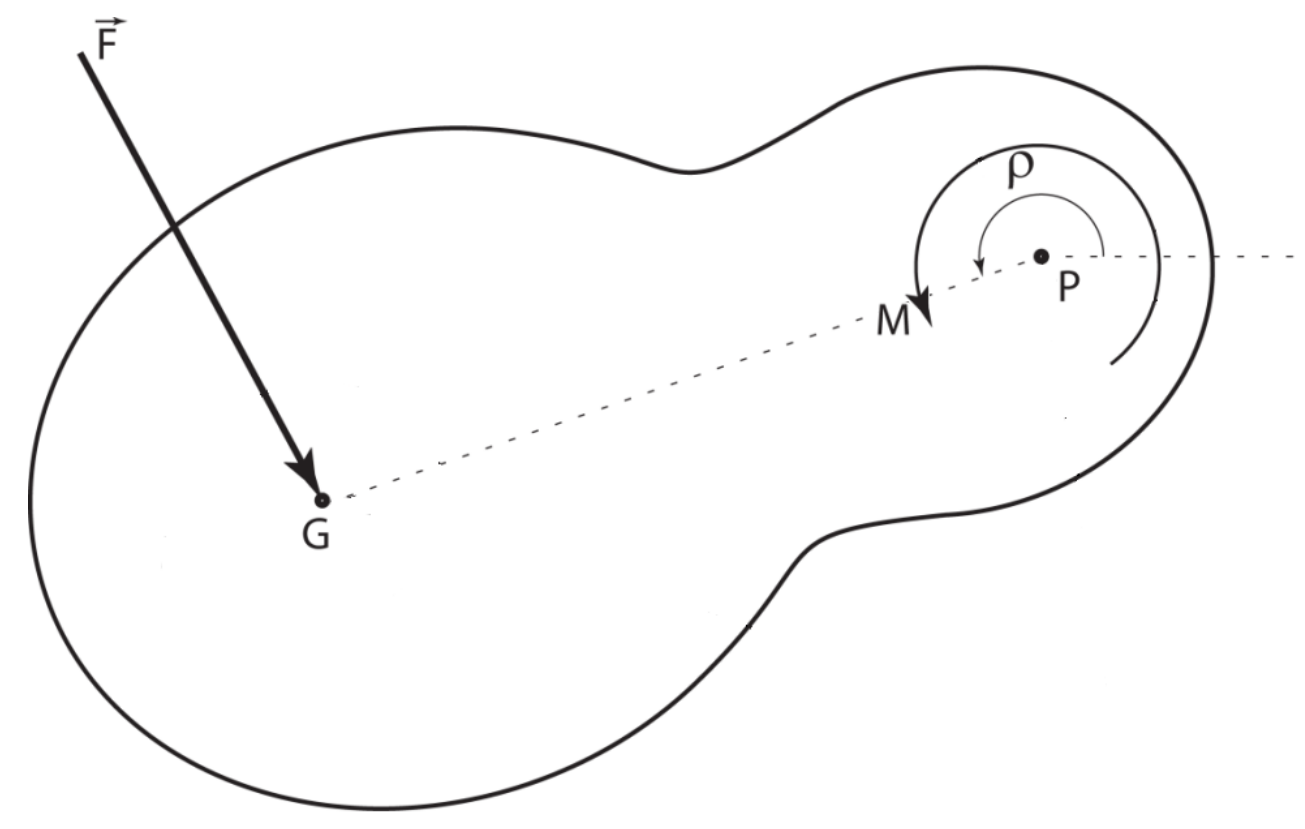

Figura 3.1: Representação de força e momento em um corpo qualquer.

$$
\mathrm{a}_{\mathrm{g}}=\mathrm{a}_{\mathrm{p}}+\ddot{\rho} \times \mathbf{r}-\dot{\rho}^{2} \mathbf{r}
$$

onde $\rho$ é o ângulo absoluto formado entre o ponto $P$ e o centro de gravidade $G$.

Independente do ponto de aplicação, a força $\mathbf{F}$ proporciona a mesma aceleração linear, portanto, pode ser descrita como:

$$
\mathbf{F}=m\left(\mathbf{a}_{\mathbf{p}}+\ddot{\rho} r\left[\begin{array}{c}
-\sin (\rho) \\
\cos (\rho)
\end{array}\right]-\dot{\rho}^{2} r\left[\begin{array}{c}
\cos (\rho) \\
\sin (\rho)
\end{array}\right]\right)
$$

A definição do momento em torno de um ponto qualquer $P$ para um movimento plano pode ser encontrada em Hibbeler (1998), que é dada por:

$$
\mathbf{M}=-\left(\int_{0}^{m} y d m\right)\left(a_{p}\right)_{x}+\left(\int_{0}^{m} x d m\right)\left(a_{p}\right)_{y}+\left(\int_{0}^{m} r^{2} d m\right) \ddot{\rho}
$$

$M$ representa o torque aplicado no corpo gerado pelas forças externas em relação ao ponto $P$. As integrais do primeiro e segundo termos no segundo membro da Eq. (3.7) são utilizadas para determinar o ponto do centro de massa do corpo, $G$, relativamente a $P$. Além disso, a última integral é o cálculo do momento de inércia do corpo em torno do eixo $z$ que passa por $P$. Assim:

$$
\mathbf{M}=-\bar{y} m\left(a_{p}\right)_{x}+\bar{x} m\left(a_{p}\right)_{y}+I_{p} \ddot{\rho}
$$

onde $\left[\begin{array}{ll}\bar{x} & \bar{y}\end{array}\right]$ são as coordenadas do centro de massa e podem ser reescritas em função do ângulo $\rho$ : 


$$
\mathbf{M}=I_{p} \boldsymbol{\rho}+m r[-\sin (\rho) \quad \cos (\rho)] \mathbf{a}_{\mathbf{p}}
$$

Para esta modelagem, o princípio de trabalho virtual será empregado, o qual diz que à soma dos trabalhos realizados pelas juntas ativas é igual a soma dos trabalhos recebidos por todos os corpos móveis do sistema, logo:

$$
\delta W=\boldsymbol{\tau}^{t} \delta \boldsymbol{\Theta}=\mathbf{F}^{t} \delta \mathbf{r}+\mathbf{M} \delta \boldsymbol{\rho}
$$

Fazendo a relação correta de $\boldsymbol{\tau} \delta \boldsymbol{\Theta} \operatorname{com} \delta \mathbf{r}$ e $\delta \rho$ dada pelas matrizes $H$ e $G$, respectivamente, tem-se:

$$
\begin{gathered}
\boldsymbol{\tau}^{t} \delta \boldsymbol{\Theta}=\mathbf{F}^{t} H \delta \boldsymbol{\Theta}+\mathbf{M} G \delta \boldsymbol{\Theta} \\
\boldsymbol{\tau}=H^{t} \mathbf{F}+G^{t} \mathbf{M}
\end{gathered}
$$

Assim, de uma maneira genérica, demonstra-se que é possível determinar os torques exercidos pelas juntas ativas pelo princípio dos trabalhos virtuais.

\subsection{Modelagem dos manipuladores}

O manipulador planar não redundante $3 \underline{R R R}$ apresentado é tomado como base para se determinar as outras configurações redundantes de manipuladores. A introdução da redundância cinemática neste manipulador se dá por meio da adição de juntas ativas prismáticas ao sistema permitindo a mudança de posição dos atuadores do end-effector. Já a introdução da redundância de atuação consiste em adicionar cadeias cinemáticas ativas no manipulador não redundante. Os manipuladores com redundância cinemática estudados e o manipulador não redundante estão representados na Fig. 3.2. Os manipuladores com redundância de atuação são apresentados na Fig. 3.3.

O manipulador cinematicamente redundante consiste do manipulador $3 \underline{R} R R$ com seus motores fixados em guias lineares permitindo que estes tenham movimento linear. Este movimento linear se dá pelo acionamento de motores rotacionais que atuam o fuso da guia linear, assim permitindo a reconfiguração do sistema e caracterizando a redundância cinemática.

A redundância de atuação é feita pela adição de cadeias cinemáticas idênticas às cadeias do manipulador não redundante, acionadas por motores rotativos, permitindo a distribuição de carga entre as cadeias de maneira uniforme.

A modelagem de todos os manipuladores vai seguir o mesmo esquema da Fig. 3.4. 

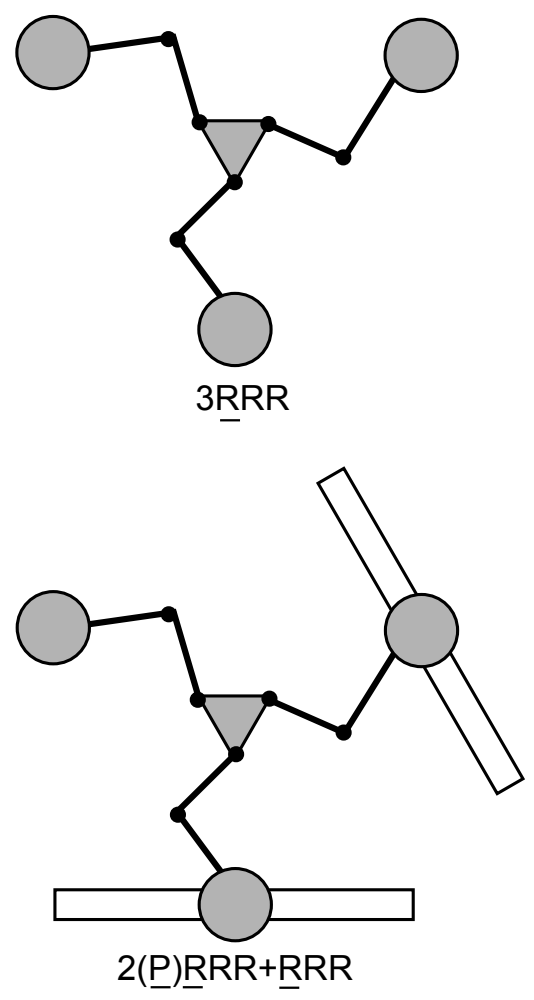

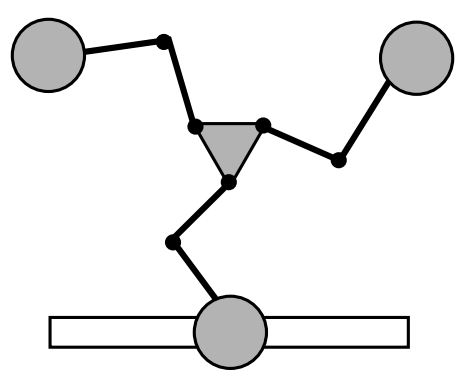

(ㅁ) $\underline{R} R R+2 \underline{R R R}$

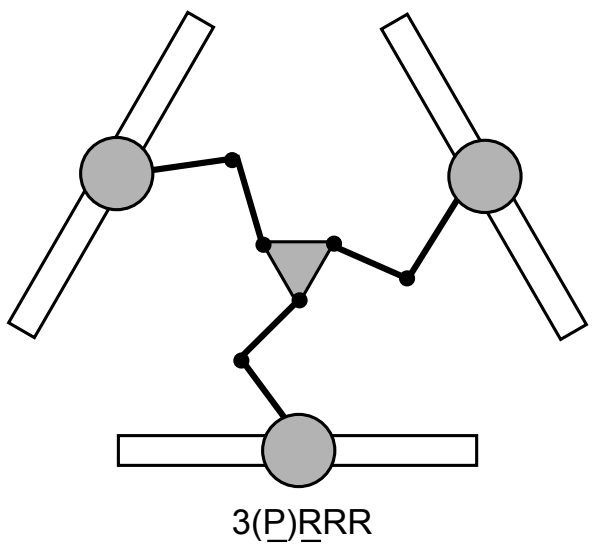

Figura 3.2: Manipuladores não-redundante e cinematicamente redundantes.

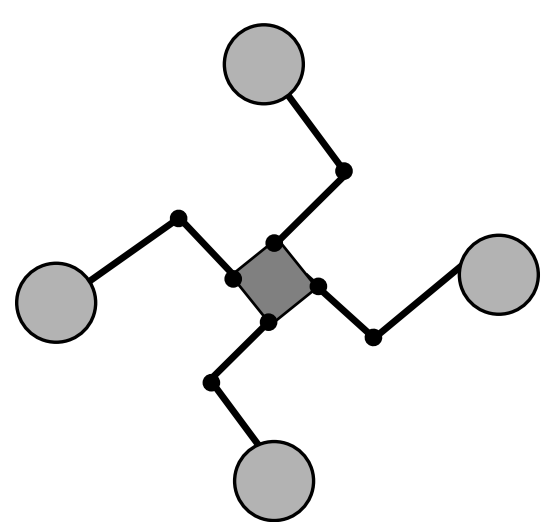

4RRR

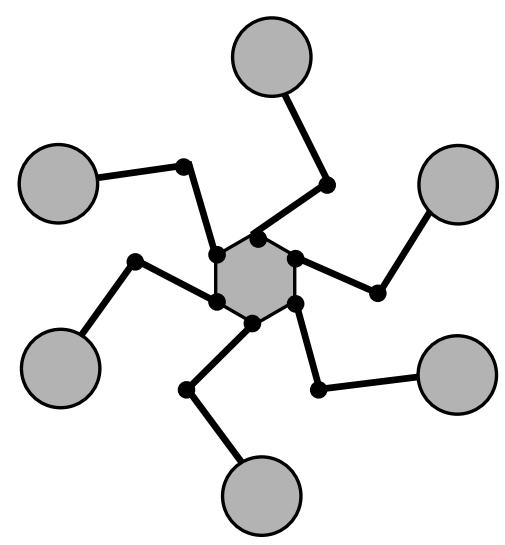

6RRR

Figura 3.3: Manipuladores com redundância de atuação.

Estas configurações possuem diferentes quantidades de elos em suas cadeias ou diferentes quantidades de cadeias, o que altera a modelagem de cada manipulador, entretanto são muito similares. A tabela 3.1 apresenta os valores de quais elos $j$ estão presentes por cadeia $i$ em cada caso de manipulador que são utilizados em suas respectivas modelagens. Os valores de $j$ representam os motores que são movimentados sobre as guias $(j=1)$ e os 

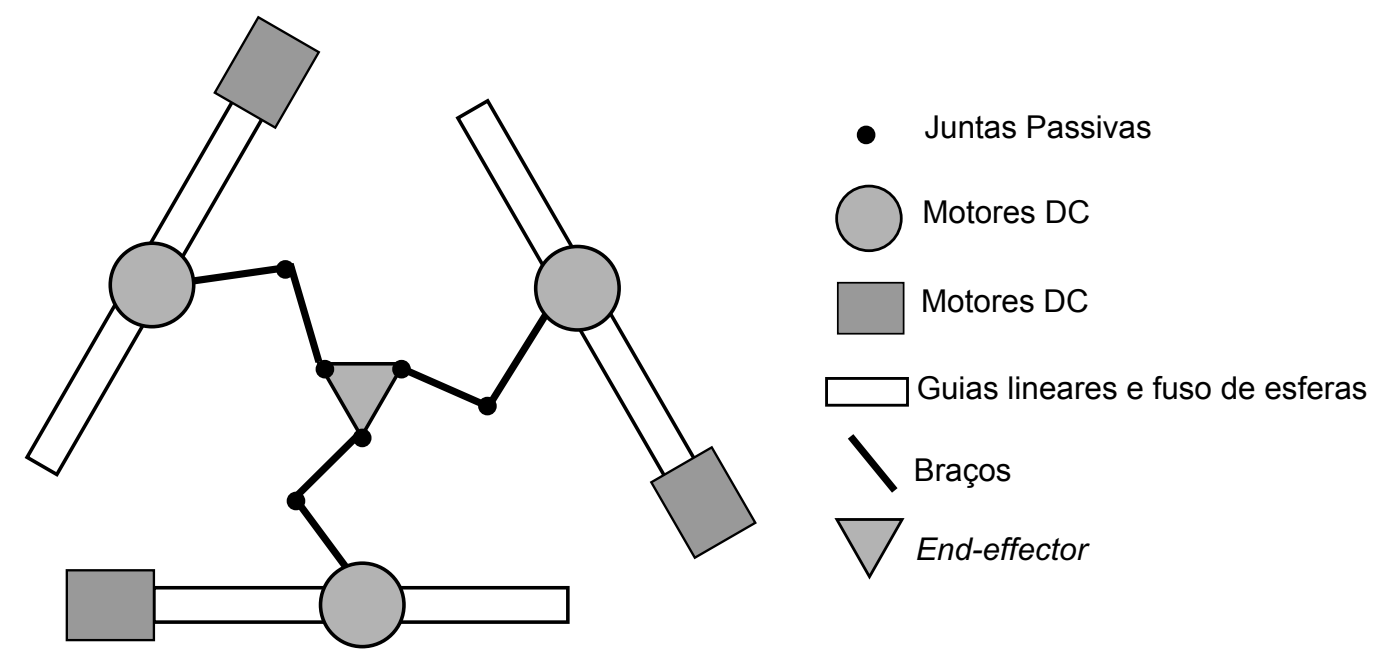

Figura 3.4: Manipulador robótico paralelo com 3 níveis de redundância cinemática.

elos $1(j=2)$ e $2(j=3)$. Por exemplo, no manipulador $2 \underline{(P}) R R R+\underline{R R R}$ existem 3 corpos nas cadeias 1 e 2 e apenas 2 corpos na cadeia 3 .

Tabela 3.1: Cadeias e elos dos manipuladores.

\begin{tabular}{|c|c|c|}
\hline Manipulador & Cadeia $i$ & Elos $j$ \\
\hline 3RRR & 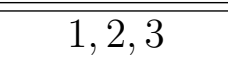 & 2,3 \\
\hline$(4) \underline{R} R R$ & $1,2,3,4$ & 2,3 \\
\hline (6) $\underline{\mathrm{R} R R}$ & $1,2,3,4,5,6$ & 2,3 \\
\hline$(\underline{P}) R R R+2 \underline{R R R}$ & $1,2,3$ & Se $i=1, j=1,2,3$; Se $i=2,3, j=2,3$ \\
\hline $2(\underline{P}) R R R+\bar{R} R R$ & $1,2,3$ & Se $i=1,2, j=1,2,3$; Se $i=3, j=2,3$ \\
\hline $3(\underline{P}) \underline{R R}$ & $1,2,3$ & $1,2,3$ \\
\hline
\end{tabular}

\subsubsection{Cinemática inversa}

A cinemática inversa consiste em determinar as posições das juntas dada uma posição do end-effector. Para isso, relações geométricas devem ser construídas a partir de parâmetros conhecidos como os tamanhos dos braços $\mathrm{AB}$ e $\mathrm{BC}$, definidos como $l_{1}$ e $l_{2}$, respectivamente. O end-effector é construído com a forma de um triângulo equilátero (quadrado para o (4) $\underline{R R R}$ e hexágono para (6)RRR) com vértices $C_{i}$ sendo a distância do baricentro até um dos seus vértices representada por $h$. Assim como o end-effector, o manipulador também é projetado para que os motores rotacionais $A_{i}$ sejam vértices de um triângulo equilátero (quadrado para o (4)RRR e hexágono para (6) $\underline{R} R R$ ) quando $\delta_{i}=0$, onde $\delta_{i}$ é a posição do motor rotacional relativa à respectiva guia linear, com a distância do baricentro até um dos vértices representada por $a$ e o baricentro utilizado como ponto $O$ de origem do sistema de coordenadas (Fig. 3.5). 

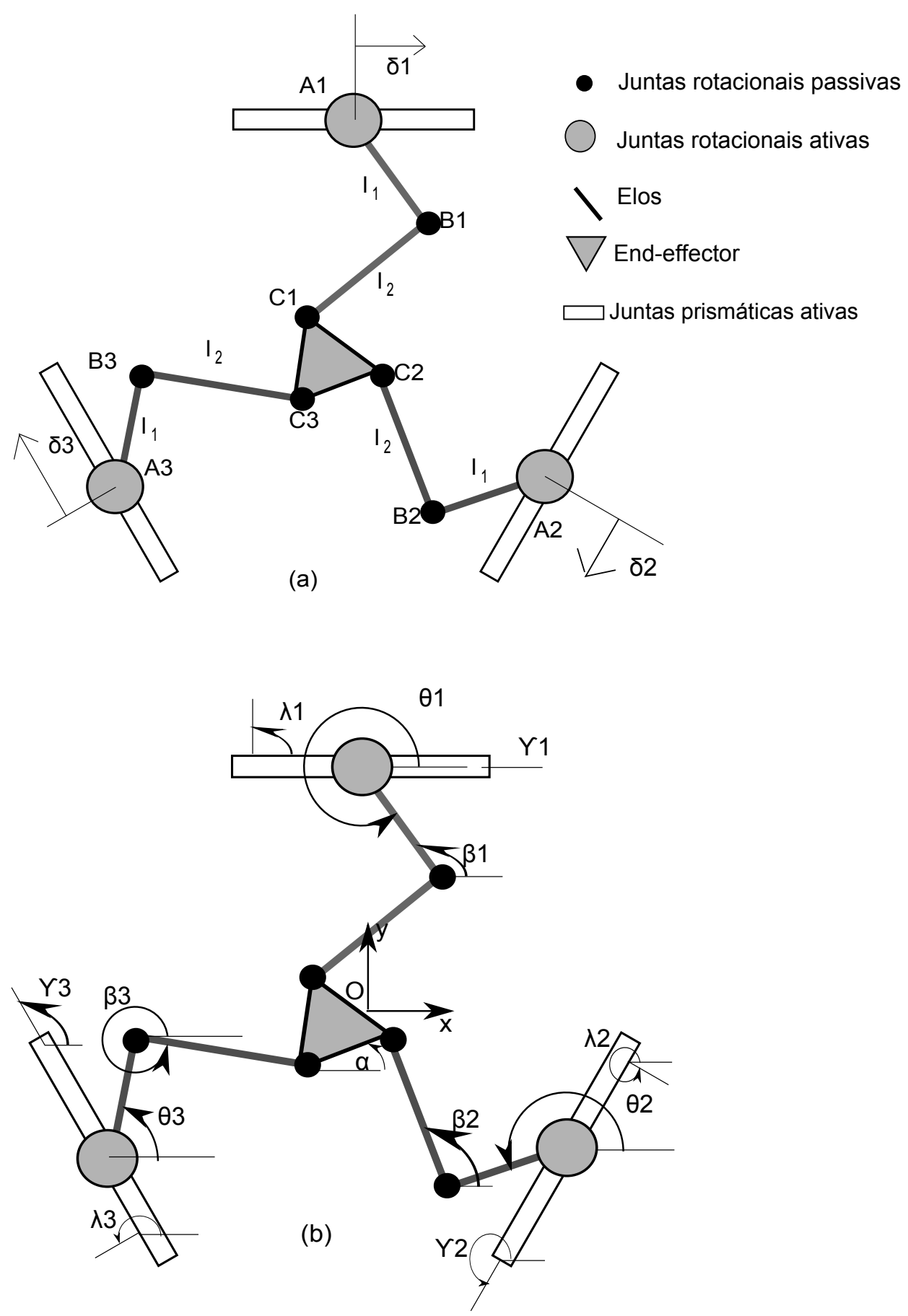

Figura 3.5: Modelo cinemático de 3(믈RR: (a) Pontos e medidas lineares; (b) Ângulos e sistema de coordenadas.

Denominando por $x, y$ e $\alpha$ as posições lineares e angular do end-effector, $\theta_{i}$ o ângulo de rotação da junta $i$ e $\beta_{i}$ o ângulo de rotação do braço $B_{i} C_{i}$, pode-se escrever a seguinte equação que calcula o vetor posição do ponto $C_{i}$ : 


$$
\mathbf{r}_{\mathbf{C}_{\mathbf{i}}}=\mathbf{r}_{\mathbf{B}_{\mathbf{i}}}+l_{2}\left[\begin{array}{l}
\cos \left(\beta_{i}\right) \\
\sin \left(\beta_{i}\right)
\end{array}\right]
$$

onde $\mathbf{r}_{\mathrm{B}_{\mathbf{i}}}$ e $\mathbf{r}_{\mathbf{C}_{\mathbf{i}}}$ são os vetores da posição dos pontos $B_{i}$ e $C_{i}$, respectivamente.

A equação de restrição obtida da Eq. (3.13) é:

$$
\left\|\mathbf{r}_{\mathbf{C}_{\mathbf{i}}}-\mathbf{r}_{\mathbf{B}_{\mathbf{i}}}\right\|=l_{2}
$$

A Eq. (3.14) pode ser reescrita como a Eq. (3.16) usando a definição de $\mu_{i}$ e $\rho_{i}$ (Eq. (3.15)):

$$
\begin{gathered}
{\left[\begin{array}{l}
\mu_{i} \\
\rho_{i}
\end{array}\right]=\left[\begin{array}{l}
x \\
y
\end{array}\right]+h\left[\begin{array}{l}
\cos \left(\alpha+\lambda_{i}\right) \\
\sin \left(\alpha+\lambda_{i}\right)
\end{array}\right]-\delta_{i}\left[\begin{array}{l}
\cos \left(\gamma_{i}\right) \\
\sin \left(\gamma_{i}\right)
\end{array}\right]-a\left[\begin{array}{l}
\cos \left(\lambda_{i}\right) \\
\sin \left(\lambda_{i}\right)
\end{array}\right]} \\
\left\|\left[\begin{array}{l}
\mu_{i}-l_{1} \cos \left(\theta_{i}\right) \\
\rho_{i}-l_{1} \sin \left(\theta_{i}\right)
\end{array}\right]\right\|=l_{2}
\end{gathered}
$$

No caso da cadeia cinemática não possuir guia linear, $\delta_{i}=0$.

Desenvolve-se em:

$$
-2 l_{1} \rho_{i} \sin \left(\theta_{i}\right)-2 l_{1} \mu_{i} \cos \left(\theta_{i}\right)+\mu_{i}^{2}+\rho_{i}^{2}+l_{1}^{2}-l_{2}^{2}=0
$$

Os argumentos da Eq. (3.17) são representados por $e_{i 1}, e_{i 2}$ e $e_{i 3}$ :

$$
\begin{gathered}
e_{i 1}=-2 l_{1} \rho_{i} \\
e_{i 2}=-2 l_{1} \mu_{i} \\
e_{i 3}=\mu_{i}^{2}+\rho_{i}^{2}+l_{1}^{2}-l_{2}^{2}=0
\end{gathered}
$$

Então, o ângulo $\theta_{i}$ pode ser determinado como:

$$
\theta_{i}=2 \tan ^{-1}\left(\frac{-e_{i 1} \pm \sqrt{e_{i 1}^{2}+e_{i 2}^{2}-e_{i 3}^{2}}}{e_{i 3}-e_{i 2}}\right)
$$

Da mesma maneira, $\beta_{i}$ pode ser calculado usando a equação vetorial obtida da Eq. (3.16):

$$
\begin{gathered}
{\left[\begin{array}{l}
\mu_{i}-l_{1} \cos \left(\theta_{i}\right) \\
\rho_{i}-l_{1} \sin \left(\theta_{i}\right)
\end{array}\right]=l_{2}\left[\begin{array}{l}
\cos \left(\beta_{i}\right) \\
\sin \left(\beta_{i}\right)
\end{array}\right]} \\
\beta_{i}=\tan ^{-1}\left(\frac{\rho_{i}-l_{1} \sin \left(\theta_{i}\right)}{\mu_{i}-l_{i} \cos \left(\theta_{i}\right)}\right)
\end{gathered}
$$




\subsubsection{Jacobiana}

A matriz jacobiana é definida como a matriz que relaciona o vetor de velocidades dos $m$ atuadores com o vetor de velocidades do end-effector. No caso do manipulador $3 \underline{P R R R}$, têm-se:

$$
\dot{\mathbf{X}}=J \dot{\boldsymbol{\Theta}} \text { onde } \dot{\mathbf{X}}=\left[\begin{array}{lll}
x & y & \alpha
\end{array}\right]^{T} \text { e } \dot{\boldsymbol{\Theta}}=\left[\begin{array}{llllll}
\dot{\theta_{1}} & \dot{\theta_{2}} & \dot{\theta_{3}} & \dot{\delta_{1}} & \dot{\delta_{2}} & \dot{\delta}_{3}
\end{array}\right]^{T}
$$

Note que o vetor $\dot{\Theta}$ possui diferente dimensões para cada caso de manipulador, isto é, dimensão 3 para o não redundante até dimensão 6 para o manipulador com 3 níveis de redundância.

A matriz jacobiana pode ser determinada pela Eq. (3.14) reescrita de outra maneira:

$$
r_{B C_{x}}^{2}+r_{B C_{y}}^{2}=l^{2}
$$

onde $r_{B C_{x}}$ e $r_{B C_{y}}$ são as medidas entre os pontos $B_{i}$ e $C_{i}$ sobre os eixos $x$ e $y$, respectivamente.

Fazendo a derivada no tempo da Eq. (3.25):

$$
r_{B C_{x}} r_{B C_{x}}+r_{B C_{y}} r_{B C_{y}}=0
$$

Utilizando as relações geométricas já apresentadas na seção 3.3.1 e sabendo que $r_{B C_{x}} \mathrm{e}$ $r_{B C_{y}}$ são numericamente iguais a $l_{2} \cos \left(\beta_{i}\right)$ e $l_{2} \sin \left(\beta_{i}\right)$, respectivamente, a seguinte equação é expressa:

$$
\dot{x}\left[l_{2} \cos \left(\beta_{i}\right)\right]+\dot{y}\left[l_{2} \sin \left(\beta_{i}\right)\right]+\dot{\alpha}\left[l_{2} h \sin \left(\beta_{i}-\lambda_{i}-\alpha\right)\right]=\dot{\theta}_{i}\left[l_{1} l_{2} \sin \left(\beta_{i}-\theta_{i}\right)\right]+\dot{\delta}_{i}\left[l_{2} \cos \left(\beta_{i}-\gamma_{i}\right)\right]
$$

onde $i$ é a cadeia cinemática adotada. Se a cadeia não possuir guia linear, o termo correspondente $\dot{\delta}_{i}\left[l_{2} \cos \left(\beta_{i}-\gamma_{i}\right)\right]$ é descartado.

A partir da Eq. (3.27), a equação matricial que relaciona $\dot{\Theta}$ e $\dot{\mathbf{X}}$ pode ser expressa utilizando da definição de duas matrizes, $A$ e $B$, com termos iguais a:

$$
\begin{gathered}
a_{i 1}=l_{2} \cos \left(\beta_{i}\right) \\
a_{i 2}=l_{2} \sin \left(\beta_{i}\right) \\
a_{i 3}=l_{2} h \sin \left(\beta_{i}-\lambda_{i}-\alpha\right) \\
b_{i i}=l_{1} l_{2} \sin \left(\beta_{i}-\theta_{i}\right) \\
b_{i i+3}=l_{2} \cos \left(\beta_{i}-\gamma_{i}\right)
\end{gathered}
$$


Onde:

$$
\begin{gathered}
A=\left[\begin{array}{lll}
a_{11} & a_{12} & a_{13} \\
a_{21} & a_{22} & a_{23} \\
a_{31} & a_{32} & a_{33}
\end{array}\right] \\
B=\left[\begin{array}{cccccc}
b_{11} & 0 & 0 & b_{14} & 0 & 0 \\
0 & b_{22} & 0 & 0 & b_{25} & 0 \\
0 & 0 & b_{33} & 0 & 0 & b_{36}
\end{array}\right]
\end{gathered}
$$

A matriz A possui dimensão $i \times 3$, logo para os manipuladores com redundância cinemática e para o não-redundante ela tem dimensão $3 \times 3$. Para os manipuladores com redundância de atuação a matriz A possui dimensão $4 \times 3$ para o manipulador (4) $\underline{R} R R$ e $6 \times 3$ para o (6) $\underline{R} R R$. Da mesma maneira, a matriz $B$ possui dimensão $3 \times m$, como o exemplo dado é do manipulador 3 PRRR, a dimensão é $3 \times 6$. Portanto o termo $b_{i i+3}$ vai sendo acrescentado de acordo com que a redundância cinemática é acrescentada nas cadeias. Note que este termo não existe no caso de redundância de atuação. Nos casos de redundância de atuação a matriz $B$ é quadrada diagonal apenas possuindo os termos $b_{i i}$.

Assim sendo:

$$
A \dot{\mathbf{X}}=B \dot{\Theta}
$$

A matriz jacobiana pode ser expressa por:

$$
J=A^{-1} B
$$

Nos casos de redundância de atuação, a matriz A não é quadrada, logo não existindo sua inversa. Para isso é usada a pseudoinversa.

\subsubsection{Velocidades e acelerações}

O modelo dinâmico é feito utilizando trabalho virtual. Para isso, é necessário obter matrizes que relacionem o deslocamento virtual de cada corpo do manipulador com o deslocamento virtual dos atuadores. Relacionar os deslocamentos dos corpos é o mesmo que relacionar as velocidades dos corpos, então, como a matriz jacobiana é para o endeffector, devem ser obtidas matrizes similares à jacobiana para todos os corpos móveis do sistema (Wu et al., 2009).

$H_{i j}$ é definida como a matriz que relaciona o vetor $\dot{\Theta}$ de velocidades das juntas com o vetor $\mathbf{r}_{\mathbf{i j}}$ de velocidades lineares do corpo $j$ da cadeia cinemática $i$. O motor rotacional recebe o valor de $j=1$, o braço $A_{i} B_{i}$ recebe o valor $j=2$ com ponto de giro $A_{i}$ e o braço $B_{i} C_{i} j=3$ com ponto de giro $B_{i}$. Similarmente, a matriz $G_{i j}$ relaciona o vetor $\dot{\Theta}$ 
com a velocidade angular $\dot{\phi_{i j}}$. Consequentemente, $H_{i j}$ and $G_{i j}$ são matrizes esparsas de dimensões $2 \times m$ e $1 \times m$, respectivamente.

Seguindo esta notação, a representação das velocidades para o ponto $A_{i}$ é:

$$
\dot{\mathbf{r}}_{\mathbf{A}_{\mathbf{i}}}=\dot{\mathbf{r}}_{\mathbf{i} 1}=\dot{\delta}_{i}\left[\begin{array}{c}
\cos \left(\gamma_{i}\right) \\
\sin \left(\gamma_{i}\right)
\end{array}\right]=\left[\begin{array}{lllll}
0 & \cdots & \cos \left(\gamma_{i}\right) & \cdots & 0 \\
0 & \cdots & \sin \left(\gamma_{i}\right) & \cdots & 0
\end{array}\right]_{2 \times 6} \dot{\Theta}
$$

onde os valores não nulos se encontram nas colunas $i+3$, o que fornece:

$$
H_{i 1}=\left[\begin{array}{ccccc}
0 & \cdots & \cos \left(\gamma_{i}\right) & \cdots & 0 \\
0 & \cdots & \sin \left(\gamma_{i}\right) & \cdots & 0
\end{array}\right]_{2 \times 6}
$$

Uma vez que $A_{i}$ é tratado como um ponto, ele não possui velocidade angular, logo:

$$
G_{i 1}=\left[\begin{array}{lll}
0 & \cdots & 0
\end{array}\right]_{1 \times 6}
$$

No caso da cadeia cinemática não possuir guia linear, isto é, não possuir redundância cinemática, ambas as matriz são nulas.

Para o braço $A_{i} B_{i}$ a velocidade angular é $\dot{\theta}_{i}$ e a velocidade linear é a mesma do ponto $A_{i}$, então:

$$
\begin{gathered}
H_{i 2}=H_{i 1} \\
\dot{\phi_{i 2}}=\dot{\theta}_{i}=\left[\begin{array}{lllll}
0 & \cdots & 1 & \cdots & 0
\end{array}\right]_{1 \times 6}
\end{gathered}
$$

onde o valor 1 está na coluna $i$, logo:

$$
G_{i 2}=\left[\begin{array}{lllll}
0 & \cdots & 1 & \cdots & 0
\end{array}\right]_{1 \times 6}
$$

A velocidade linear do ponto $B_{i}$ pode ser definida e, conseqüentemente, a matriz $H_{i 3}$ :

$$
\begin{aligned}
& \mathbf{r}_{\mathbf{B}_{\mathbf{i}}}=\mathbf{r}_{\mathbf{i} 3}=\dot{\theta}_{i} l_{1}\left[\begin{array}{c}
-\sin \left(\theta_{i}\right) \\
\cos \left(\theta_{i}\right)
\end{array}\right]+\dot{\delta}_{i}\left[\begin{array}{c}
\cos \left(\gamma_{i}\right) \\
\sin \left(\gamma_{i}\right)
\end{array}\right] \\
& H_{i 3}=\left[\begin{array}{ccccccccc}
0 & \cdots & l_{1}\left(-\sin \left(\theta_{i}\right)\right) & \cdots & 0 & \cdots & \cos \left(\gamma_{i}\right) & \cdots & 0 \\
0 & \cdots & l_{1} \cos \left(\theta_{i}\right) & \cdots & 0 & \cdots & \sin \left(\gamma_{i}\right) & \cdots & 0
\end{array}\right]_{2 \times 6}
\end{aligned}
$$

os valores não nulos estão alocados nas colunas $i$ e $i+3$.

Note que a coluna $i+3$ não existe quando não há guia linear, logo os termos com índice $i+3$ só irão existir se a redundância cinemática estiver presente na cadeia cinemática $i$.

A determinação de $G_{i 3}$ ocorre do cálculo de $\mathbf{r}_{\dot{\mathrm{C}}_{\mathrm{i}}}$ a partir de $\mathbf{r}_{\mathrm{B}_{\mathrm{i}}}$ :

$$
\mathbf{r}_{\mathbf{C}_{\mathbf{i}}}=\mathbf{r}_{\dot{B}_{\mathbf{i}}}+\dot{\beta}_{i} l_{2}\left[\begin{array}{c}
-\sin \left(\beta_{i}\right) \\
\cos \left(\beta_{i}\right)
\end{array}\right]
$$


$\mathbf{r}_{\mathbf{C}_{\mathbf{i}}}$ também pode ser calculada a partir da velocidade do end-effector:

$$
\mathbf{r}_{\mathbf{C}_{\mathbf{i}}}=\left[H_{n}-h\left[\begin{array}{c}
-\sin \left(\lambda_{i}+\alpha\right) \\
\cos \left(\lambda_{i}+\alpha\right)
\end{array}\right] G_{n}\right] \dot{\Theta}
$$

onde $J=\left[\begin{array}{c}H_{n} \\ G_{n}\end{array}\right]$ é a matriz Jacobiana.

Com estas definições, $G_{i 3}$ é expressa como:

$$
G_{i 3}=\frac{1}{l_{2}}\left[-\sin \left(\beta_{i}\right) \cos \left(\beta_{i}\right)\right]\left\{H_{n}+h\left[\begin{array}{c}
\cos \left(\lambda_{i}+\alpha\right) \\
\sin \left(\lambda_{i}+\alpha\right)
\end{array}\right] G_{n}+H_{i 3}\right\}
$$

Todas as matrizes definidas podem ser generalizadas como:

$$
K_{i j}=\left[\begin{array}{l}
H_{i j} \\
G_{i j}
\end{array}\right]
$$

Então, as velocidades podem ser calculadas:

$$
\dot{d}_{\mathbf{i j}}=K_{i j} \dot{\Theta}
$$

onde o vetor $\mathbf{d}_{\mathbf{i j}}$ é a combinação das posições linear e angular do corpo $j$ da cadeia $i$. $\mathbf{d}_{\mathbf{i j}}=\left[\begin{array}{l}\mathbf{r}_{\mathrm{ij}} \\ \phi_{i j}\end{array}\right]$

As acelerações podem ser obtidas a partir da derivação no tempo das velocidades de cada corpo:

$$
\ddot{\mathbf{d}_{\mathbf{i j}}}=K_{i j} \ddot{\Theta}+\dot{K}_{i j} \dot{\Theta}
$$

\subsubsection{Dinâmica}

Uma vez que todas as velocidades e acelerações de cada corpo foram definidas, A formulação de Newton-Euler é aplicada em cada corpo sobre seu respectivo ponto de giro. Nesta análise, se assume que as massas de cada motor em $A_{i}$, de cada braço $A_{i} B_{i}$ e de cada braço $B_{i} C_{i}$ são representadas por $m_{1}, m_{2}$ e $m_{3}$, respectivamente. A massa do end-effector é $m_{n}$.

O vetor $\mathbf{p}_{\mathbf{i j}}$ é formado pela combinação das forças e momentos aplicados no corpo $j$ da cadeia $i$ :

$$
\mathbf{p}_{\mathbf{i j}}=\left[\begin{array}{l}
\mathbf{F}_{\mathbf{i j}} \\
M_{i j}
\end{array}\right]
$$

onde: 


$$
\begin{gathered}
\mathbf{F}_{\mathbf{i j}}=\left[\begin{array}{c}
m_{j}\left(r_{r_{i j}}+\ddot{\phi}_{i j} s_{j}\left(-\sin \left(\phi_{i j}\right)\right)-\dot{\phi}_{i j}{ }^{2} s_{j} \cos \left(\phi_{i j}\right)\right) \\
m_{j}\left(\ddot{r}_{y_{i j}}+\ddot{\phi}_{i j} s_{j}\left(\cos \left(\phi_{i j}\right)\right)-\dot{\phi}_{i j}{ }^{2} s_{j} \sin \left(\phi_{i j}\right)\right)
\end{array}\right] \\
M_{i j}=m_{j} s_{j}\left(r_{x_{i j}}\left(-\sin \left(\phi_{i j}\right)\right)+r_{y_{i j}} \cos \left(\phi_{i j}\right)\right)+I_{j} \ddot{\phi_{i j}}
\end{gathered}
$$

$s_{j}$ é a distância entre o centro de massa e o ponto de giro do corpo $j$.

Similarmente para o end-effector, onde o ponto de giro é o centro de massa $(s=0)$, então:

$$
\begin{gathered}
\mathbf{F}_{\mathbf{n}}=\left[\begin{array}{l}
m_{n} \ddot{x} \\
m_{n} \ddot{y}
\end{array}\right] \\
M_{n}=I_{n} \ddot{\alpha}
\end{gathered}
$$

Portanto, todas as informações necessárias para aplicar o princípio de trabalho virtual foram apresentadas e, assim, é possível determinar o vetor $\tau$ de torques necessários nas juntas ativas.

Note que os somatórios são referentes aos corpos das cadeias, logo para as cadeias que não possuem guia linear, o corpo 1 não existe (Tabela 3.1), assim os valores das matrizes $K_{i 1}$ desta cadeia são nulos. A conseqüência desta nomenclatura é que o somatório em $j$ deve ser feito sempre de 1 até 3 , diferentemente do somatório em $i$ que deve seguir a quantidade de cadeias cinemáticas que o manipulador possui (Tabela 3.1).

$$
\begin{aligned}
& \boldsymbol{\tau}^{t} \boldsymbol{\delta} \Theta=\mathbf{p}_{\mathbf{n}}{ }^{t} \boldsymbol{\delta} X+\sum_{i=1}^{3} \sum_{j=1}^{3} \mathbf{p}_{\mathbf{i j}}{ }^{t} \boldsymbol{\delta} \mathbf{d}_{\mathbf{i j}} \\
& \boldsymbol{\tau}^{t} \boldsymbol{\delta} \Theta=\mathbf{p}_{\mathbf{n}}{ }^{t} J \boldsymbol{\delta} \Theta+\sum_{i=1}^{3} \sum_{j=1}^{3} \mathbf{p}_{\mathbf{i j}}{ }^{t} K_{i j} \boldsymbol{\delta} \Theta \\
& \boldsymbol{\tau}=J^{t} \mathbf{p}_{\mathbf{n}}+\sum_{i=1}^{3} \sum_{j=1}^{3} K_{i j}^{t} \mathbf{p}_{\mathbf{i j}}
\end{aligned}
$$

Os vetores $\mathbf{p}_{\mathrm{ij}}$ e $\mathbf{p}_{\mathrm{n}}$ podem ser reescritos na forma:

$$
\begin{gathered}
\mathbf{p}_{\mathbf{i j}}=Z_{i j}\left[\begin{array}{c}
r_{x_{i j}} \\
r_{y_{i j}} \\
\ddot{\phi_{i j}}
\end{array}\right]+N i j\left[\begin{array}{c}
r_{x_{i j}} \\
r_{y_{i j}} \\
\dot{\phi_{i j}}
\end{array}\right] \\
\mathbf{p}_{\mathbf{n}}=Z_{n}\left[\begin{array}{c}
\ddot{x} \\
\ddot{y} \\
\ddot{\alpha}
\end{array}\right]
\end{gathered}
$$

onde: 


$$
\begin{gathered}
Z_{i j}=\left[\begin{array}{ccc}
m_{j} & 0 & -m_{j} s_{i j} \sin \phi_{i j} \\
0 & m_{j} & m_{j} s_{i j} \cos \phi_{i j} \\
-m_{j} s_{i j} \sin \phi_{i j} & m_{j} s_{i j} \cos \phi_{i j} & I_{j}
\end{array}\right] \\
N_{i j}=\left[\begin{array}{lll}
0 & 0 & -m_{j} \dot{\phi_{i j}} s_{i j} \cos \phi_{i j} \\
0 & 0 & -m_{j} \dot{\phi_{i j}} s_{i j} \sin \phi_{i j} \\
0 & 0 & 0
\end{array}\right]
\end{gathered}
$$

Realizando as corretas transformações das acelerações e velocidades tem-se que:

$$
\boldsymbol{\tau}=M \ddot{\Theta}+V \dot{\Theta}
$$

onde:

$$
\begin{gathered}
M=\left(J^{t} Z_{n} J+\sum_{i=1}^{3} \sum_{j=1}^{3} K_{i j}^{t} Z_{i j} K_{i j}\right) \\
V=\left(J^{t} Z_{n} \dot{J}+\sum_{i=1}^{3} \sum_{j=1}^{3} K_{i j}^{t} Z_{i j} \dot{K}_{i j}+\sum_{i=1}^{3} \sum_{j=1}^{3} K_{i j}^{t} N_{i j} K_{i j}\right)
\end{gathered}
$$

\subsection{Otimização}

Como os manipuladores com redundância cinemática possuem infinitas configurações cinemáticas, para determinar qual o torque necessário para realizar uma determinada tarefa é necessário realizar uma escolha entre as possibilidades existentes. Essa escolha pode ser feita através de uma otimização. Um problema de otimização é definido por uma função custo, a qual deseja-se minimizar, pelas variáveis de otimização e pelas restrições inerentes ao problema.

Para o problema proposto, a função custo é o máximo absoluto torque atingido pelas juntas ativas durante a execução de uma desejada trajetória do end-effector, as variáveis da função são as posições $\delta_{i}$ dos motores rotacionais $A_{i}$ relativas ao centro de suas respectivas guias lineares e as restrições do sistema são os tamanhos das guias lineares. Este problema de otimização pode ser expresso por:

$$
\begin{gathered}
\min \|\boldsymbol{\tau}\|, \delta_{i}(t) \\
\text { sujeito } a:-\delta_{\max } \leq \delta_{i} \leq \delta_{\max }
\end{gathered}
$$

O torque $\boldsymbol{\tau}$ é função dependente das posições das juntas rotacionais ativas $\boldsymbol{\theta}_{\boldsymbol{i}}$ e das posições das guias lineares $\delta_{i}$. A partir de uma trajetória pré-definida $X$ do end-effector 
e da modelagem apresentada pode-se determinar as posições $\theta_{i}$ e, portanto, utiliza-se as posições $\delta_{i}$ como variáveis da otimização. Entretanto, como será realizada uma trajetória, as posições $\delta_{i}$ também são dependentes do tempo $t$ não podendo ser usadas diretamente como variável. Assim, são realizadas diferentes abordagens para se determinar as variáveis de otimização.

Como o processo computacional para realizar as otimizações é considerável, é proposta uma nova nomenclatura que se adequa melhor ao processo de otimização do que as apresentadas por Kotlarski et al. (2009, 2008, 2011). Em todos os casos, a otimização é feita antes da realização da tarefa, portanto o nome offline computation se refere ao processo de cálculo computacional que ocorre em todos os casos antes da execução da tarefa. Já para as tarefas são dadas diferentes nomenclaturas de acordo como ocorre a tarefa.

A tarefa pode ser executada de duas maneiras: o primeiro modo de operação é quando a guia linear é posicionada na melhor posição antes da realização da tarefa, para este processo é dado o nome offline operation; já o segundo modo é quando a guia linear se movimenta ao mesmo tempo que a tarefa do end-effector é executada, este modo é denominado online operation. Por abreviação dos termos, será adotado apenas os termos offline para offline operation e online para online operation, mas é importante ressaltar que o processo offline computation ocorre em ambos os casos.

A abordagem offline consiste de determinar quais as melhores posições $\delta_{i}$ das guias lineares antes da movimentação do end-effector. Em seguida, as guias lineares são fixadas a estas melhores posições para realizar a trajetória atingindo o menor torque possível enquanto o valor de $\delta_{i}$ é o mesmo ao longo de toda execução da trajetória do end-effector.

Já na abordagem online ocorre a movimentação conjunta das guias lineares e do endeffector. Para que isso ocorra, uma trajetória para a posição da guia linear é pré definida de maneira que apenas alguns pontos sejam as variáveis da otimização. O caso online foi realizado com três diferentes trajetórias pré definidas sendo denominados online 1, online 2 e online 3. Estes métodos foram desenvolvidos especificamente para a trajetória do end-effector ser um quadrado de duração igual a 2 segundos:

1. No método online 1 é utilizado um polinômio de grau 5 que descreve o movimento de $\delta_{i}(t)$ partindo de $\delta_{0_{i}}$ a $\delta_{f_{i}}$ em 2 segundos com velocidades/acelerações inicial e final nulas:

$$
\delta_{i}(t)=\left(\delta_{f_{i}}-\delta_{0_{i}}\right)\left(\left(3 t^{5}\right) / 16-\left(15 t^{4}\right) / 16+\left(5 t^{3}\right) / 4\right)+\delta_{0_{i}}
$$

2. No método online 2 é utilizado um polinômio de grau 5 que descreve o movimento de $\delta_{i}(t)$ dividido em quatro partes, $\delta L 1_{i}(t), \delta L 2_{i}(t), \delta L 3_{i}(t)$ e $\delta L 4_{i}(t)$, o qual $\delta L 1_{i}(t)$ parte da posição $\delta_{0_{i}}$ e chega em $\delta_{1_{i}}$ em 0.5 segundo com velocidades/acelerações inicial e final nulas para o primeiro lado do quadrado. Tomando como ponto inicial 
$\delta_{1_{i}}$, utiliza-se o mesmo polinômio para determinar $\delta L 2_{i}(t)$ chegando em $\delta_{2_{i}}$, assim sucessivamente até fechar o quadrado em $\delta_{4_{i}}$ :

$$
\begin{aligned}
\delta L 1_{i}(t) & =\left(\delta_{1_{i}}-\delta_{0_{i}}\right)\left(192 t^{5}-240 t^{4}+80 t^{3}\right)+\delta_{0_{i}} \\
\delta L 2_{i}(t) & =\left(\delta_{2_{i}}-\delta_{1_{i}}\right)\left(192 t^{5}-240 t^{4}+80 t^{3}\right)+\delta_{0_{i}} \\
\delta L 3_{i}(t) & =\left(\delta_{3_{i}}-\delta_{2_{i}}\right)\left(192 t^{5}-240 t^{4}+80 t^{3}\right)+\delta_{0_{i}} \\
\delta L 4_{i}(t) & =\left(\delta_{4_{i}}-\delta_{3_{i}}\right)\left(192 t^{5}-240 t^{4}+80 t^{3}\right)+\delta_{0_{i}} \\
\delta_{i}(t) & =\left[\delta L 1_{i}(t) \delta L 2_{i}(t) \delta L 3_{i}(t) \delta L 4_{i}(t)\right]
\end{aligned}
$$

3. No método online 3 é utilizado um polinômio de grau 8 que descreve o movimento de $\delta_{i}(t)$ partindo de $\delta_{0_{i}}$ e que volta a $\delta_{0_{i}}$ em 2 segundos com velocidades/acelerações inicial e final nulas passando pelos pontos $\delta_{1_{i}}, \delta_{2_{i}}$ e $\delta_{3_{i}}$ quando o end-effector estiver passando pelo vértices do quadrado. Neste método, as velocidades/acelerações só possuem restrições no início e no fim do movimento.

$$
\delta_{i}(t)=a_{8} t^{8}+a_{7} t^{7}+a_{6} t^{6}+a_{5} t^{5}+a_{4} t^{4}+a_{3} t^{3}+\delta_{0_{i}}
$$

onde

$$
\begin{array}{r}
a_{8}=\left(148 \delta_{0_{i}}\right) / 27-\left(128 \delta_{1_{i}}\right) / 27+4 \delta_{2_{i}}-\left(128 \delta_{3_{i}}\right) / 27 ; \\
a_{7}=\left(1088 \delta_{1_{i}}\right) / 27-\left(1184 \delta_{0_{i}}\right) / 27-32 \delta_{2_{i}}+\left(320 \delta_{3_{i}}\right) / 9 ; \\
a_{6}=\left(3727 \delta_{0_{i}}\right) / 27-\left(1216 \delta_{1_{i}}\right) / 9+99 \delta_{2_{i}}-\left(2752 \delta_{3_{i}}\right) / 27 ; \\
a_{5}=\left(6016 \delta_{1_{i}}\right) / 27-\left(5786 \delta_{0_{i}}\right) / 27-146 \delta_{2_{i}}+\left(3712 \delta_{3_{i}}\right) / 27 ; \\
a_{4}=\left(4468 \delta_{0_{i}}\right) / 27-\left(4864 \delta_{1_{i}}\right) / 27+100 \delta_{2_{i}}-\left(256 \delta_{3_{i}}\right) / 3 ; \\
a_{3}=\left(512 \delta_{1_{i}}\right) / 9-\left(1400 \delta_{0_{i}}\right) / 27-24 \delta_{2_{i}}+\left(512 \delta_{3_{i}}\right) / 27
\end{array}
$$

O algoritmo de otimização sequential quadratic programming (SQP) é um dos mais recentemente desenvolvidos e, talvez um dos melhores métodos de otimização. O método tem uma base teórica que está relacionada com a solução de um conjunto de equações lineares usando o método de Newton, e na obtenção de equações lineares simultâneas utilizando condições de Kuhn-Tucker e as funções de restrição escritas pelo método de Lagrange (Rao, 2009). Ele é utilizado quando as funções envolvidas no problema, isto é, a função custo e as funções de restrição, são deriváveis duas vezes e contínuas. Por ser um algoritmo robusto e por ser considerado um dos melhores para este tipo de problema, o algoritmo SQP foi escolhido para otimizar o problema proposto. 
As otimizações são feitas no ambiente MATLAB utilizando a função fmincon que realiza o algoritmo SQP. Assim é possível comparar o desempenho das diferentes configurações do manipuladores propostos, $(\underline{\mathrm{P}}) \underline{R R R}+2 \underline{R} R R, 2(\underline{\mathrm{P}} \underline{\mathrm{R} R R}+\underline{R} R R$ e $3(\underline{\mathrm{P}}) \underline{R} R R$.

\subsection{Mapas dinâmicos}

Com o objetivo de comparar os manipuladores se fez necessário adotar um índice dinâmico que pudesse ser calculado em toda a área de trabalho. Zhao e Gao (2009) propõem um índice dinâmico que consiste de fixar acelerações e velocidades e calcular, para as condições especificadas, qual o torque necessário para realizar estas acelerações e velocidades. Assim, o índice proposto por este trabalho de mestrado é avaliar qual o torque necessário para aplicar uma aceleração de módulo 1 em todas as direções do end-effector quando o mesmo se encontra em repouso, isto é $\dot{\mathbf{X}}=0 e \dot{\boldsymbol{\Theta}}=0$. A formulação do índice é apresentada a seguir.

Considerando a formulação dinâmica e as velocidades iguais a zero, pode-se reescrever a Eq. (3.63) como:

$$
M \ddot{\Theta}+V \dot{\Theta}=\boldsymbol{\tau}
$$

Como $\dot{\Theta}=0$, tem-se que:

$$
M \ddot{\Theta}=\tau
$$

Derivando a equação Jacobiana (Eq.(3.35)), as acelerações das juntas podem ser reescritas em função das acelerações do end-effector utilizando a matriz Jacobiana:

$$
\ddot{\Theta}=J^{-1} \dot{\mathbf{X}}+J^{-1} \ddot{\mathbf{X}}
$$

Como o manipulador está em repouso, $\dot{\mathrm{X}}=0$ e conhecendo a relação das Jacobiana, $J^{-1}=B^{-1} A$, tem-se que:

$$
\begin{gathered}
\ddot{\Theta}=J \ddot{\mathbf{X}} \\
M B^{-1} A \ddot{\mathbf{X}}=\boldsymbol{\tau}
\end{gathered}
$$

Considerando todas as acelerações de $\ddot{\mathrm{X}}$ igual a 1 :

$$
M B^{-1} A \mathbf{1}=\boldsymbol{\tau}
$$


onde 1 é o vetor de colunas com elementos iguais a 1 . O índice dinâmico $I D$ é definido como o máximo torque calculado nas condições indicadas, o que corresponde à norma infinita da matriz $M B^{-1} A$

$$
I D=\left\|M B^{-1} A\right\|_{\infty}=\max \{\boldsymbol{\tau}\}
$$

A matriz B não é quadrada nos casos dos manipuladores com redundância cinemática, logo foi utilizada a pseudoinversa da matriz B. O índice $I D$ pode ser calculado em toda área de trabalho pois ele só é dependente das posições do end-effector e dos atuadores.

Para os manipuladores com redundância de atuação o índice é calculado diretamente pela definição proposta por possuírem o modelo cinemático único, entretanto os manipuladores com redundância cinemática possuem infinitas possibilidades necessitando de um método de busca do melhor índice dinâmico.

$O$ índice dinâmico é dependente do ponto escolhido $X$ do end-effector e das posições das guias lineares $\delta_{i}$. Assim, é possível dividir as guias lineares em $k$ pontos igualmente espaçados e definir qual é o melhor ponto da guia linear para cada ponto $X$ do endeffector que minimiza o índice. Entretanto, deve-se evitar as singularidades, assim o ponto da guia linear que minimiza o índice dinâmico deve satisfazer a condição para evitar a singularidade do tipo 2 ( $\operatorname{det} A>0$ ). $\mathrm{O}$ algoritmo a seguir explica de forma lógica como foi calculado o índice dinâmico para cada ponto do end-effector quando existe uma guia linear no manipulador:

para $\mathrm{z}=1$ ate $\mathrm{k}$

calcule $I D$ para $\delta=\delta_{k}$

auxiliar $=I D$

se $\operatorname{det} A>0 \quad \%$ Evasão da singularidade

se $z>1 \quad \%$ Comparação para determinar o menor índice dinâmico

$I D=$ mínimo entre $I D$ e auxiliar

se $I D=$ auxiliar $\quad \%$ Determinação da posição ótima

$$
\delta_{\text {otimo }}=\delta_{k}
$$

fim

fim

fim

fim 


\subsection{Considerações finais}

Esta seção apresentou as modelagens dos manipuladores, como também o índice dinâmico que será calculado em toda a área de trabalho dos manipuladores com o objetivo de desenhar mapas dinâmicos e, assim, permitir a comparação dinâmica dos manipuladores. 



\subsection{Considerações iniciais}

Neste capítulo é apresentada a avaliação numérica dos manipuladores. Esta avaliação será feita comparando o desempenho de cada manipulador ao executar diferentes trajetórias considerando os diferentes métodos para otimizar os manipuladores com redundância cinemática. Além disso, a avaliação apresenta os mapas dinâmicos calculados para todos os manipuladores possibilitando a comparação do desempenho dinâmico em toda a área de trabalho.

\subsection{Dados da simulação}

Para comparar os manipuladores, foram definidos parâmetros iguais a todos arbitrariamente. Os parâmetros dos manipuladores são mostrados na Tab. 4.1.

Para realizar a avaliação dos manipuladores são pré-determinadas 4 tarefas a serem realizadas pelo end-effector, dois quadrados sem rotação do end-effector e dois quadrados com rotação do end-effector.

Estas trajetórias foram escolhidas com o objetivo de avaliar os manipuladores quando é realizada uma trajetória complexa que passa por várias áreas do manipulador, representada pelo quadrado. Também foram separadas por possuírem rotação ou não para que haja a possibilidade de avaliar o impacto da rotação do end-effector na dinâmica do manipulador. 
Tabela 4.1: Parâmetros utilizados para definir os manipuladores.

\begin{tabular}{|c|c|}
\hline Parâmetro & Valor \\
\hline \hline$m_{1}$ & $0.4 \mathrm{~kg}$ \\
$m_{2}$ & $0.2 \mathrm{~kg}$ \\
$m_{3}$ & $0.2 \mathrm{~kg}$ \\
$m_{n}$ & $0.4 \mathrm{~kg}$ \\
$l_{1}$ & $0.2 \mathrm{~m}$ \\
$l_{2}$ & $0.2 \mathrm{~m}$ \\
$h$ & $0.05 \mathrm{~m}$ \\
$a$ & $0.2 \mathrm{~m}$ \\
$\delta_{\max }$ & $0.3 \mathrm{~m}$ \\
$I_{1}$ & $0.00667 \mathrm{kgm}^{2}$ \\
$I_{2}$ & $0.00667 \mathrm{kgm}^{2}$ \\
$I_{n}$ & $0.008 \mathrm{kgm}^{2}$ \\
\hline
\end{tabular}

As trajetórias realizadas pelo end-effector são descritas utilizando um polinômio de grau 5 , com velocidades/acelerações iniciais e finais iguais a zero e posições iniciais e finais prédefinidas. A duração de todas as trajetórias é de 2 segundos. Os quadrados são executados cada lado em 0.5 segundo. Um dos quadrados possui lado igual a $0.08 m$ e outro possui $0.12 m$ de lado, as velocidades/acelerações nos vértices são nulas. Quando houver rotação, ela ocorre de vértice a vértice seguindo a ordem $-\pi / 8, \pi / 8,-\pi / 8, \pi / 8$ voltando ao ponto inicial com ângulo $-\pi / 8$. As trajetórias dos quadrados podem ser observadas na Fig. 4.1. Os perfis das trajetórias de um lado dos quadrados podem ser observadas nas Figs. 4.2 e 4.2 .

\subsection{Máximo torque calculado}

Foram pré-determinadas duas trajetórias a serem realizadas, a trajetória I é um quadrado de lado $0.08 m$ e a trajetória II é um quadrado de lado $0.12 m$, cada uma sendo realizada uma vez sem rotação e outra vez com rotação do end-effector, logo são quatro tarefas que foram executadas. Os manipuladores com redundância cinemática possuem diferentes métodos de otimização, assim serão apresentados em uma tabela os valores máximos de todos os métodos e o gráfico do melhor caso entre os métodos. Os métodos propostos na seção 3.4 são offline e três onlines. Os máximos torques para executar cada trajetória são apresentados na Tab 4.2.

Os gráficos dos torques realizados por cada manipulador estão dispostos de acordo com a Tab 4.3.

Os resultados dos manipuladores $3 \underline{R} R R$, (4)RR e (6)RR estão apresentados nas Figs. 4.4, 4.5 e 4.6, respectivamente. Eles demonstram que a rotação do end-effector tem grande 


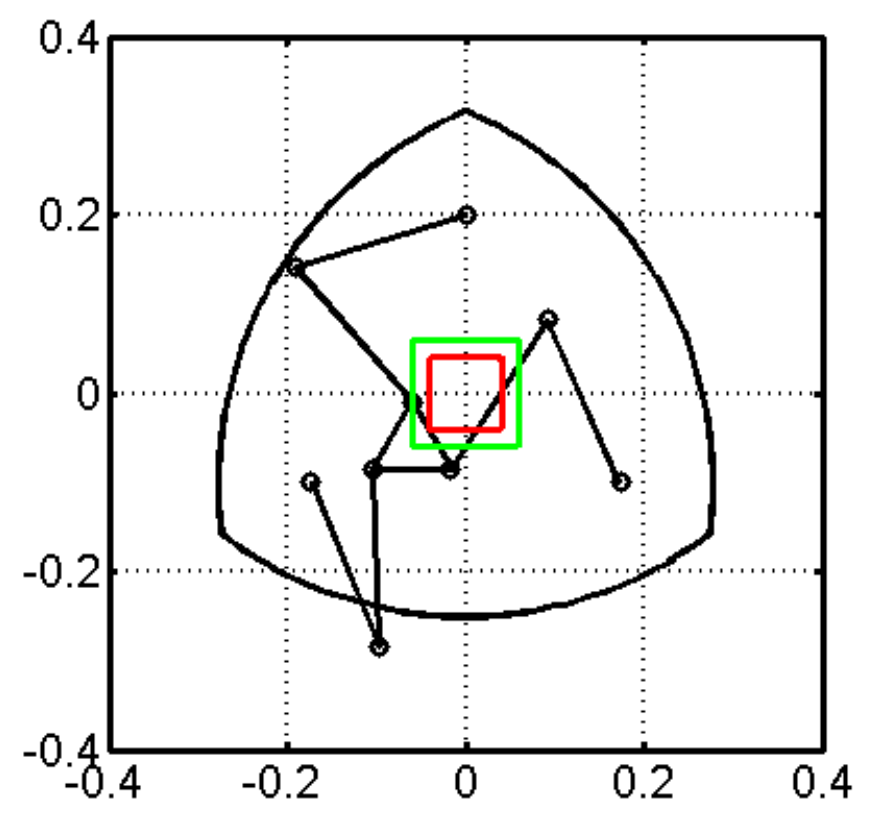

Figura 4.1: Manipulador 3RRR: área de trabalho e trajetórias executadas.
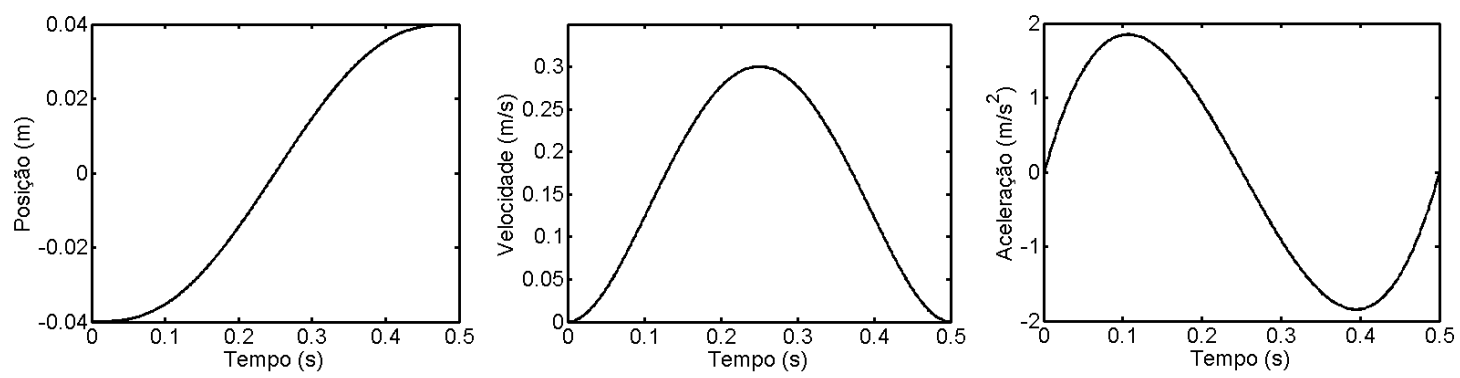

Figura 4.2: Perfil da trajetória I.
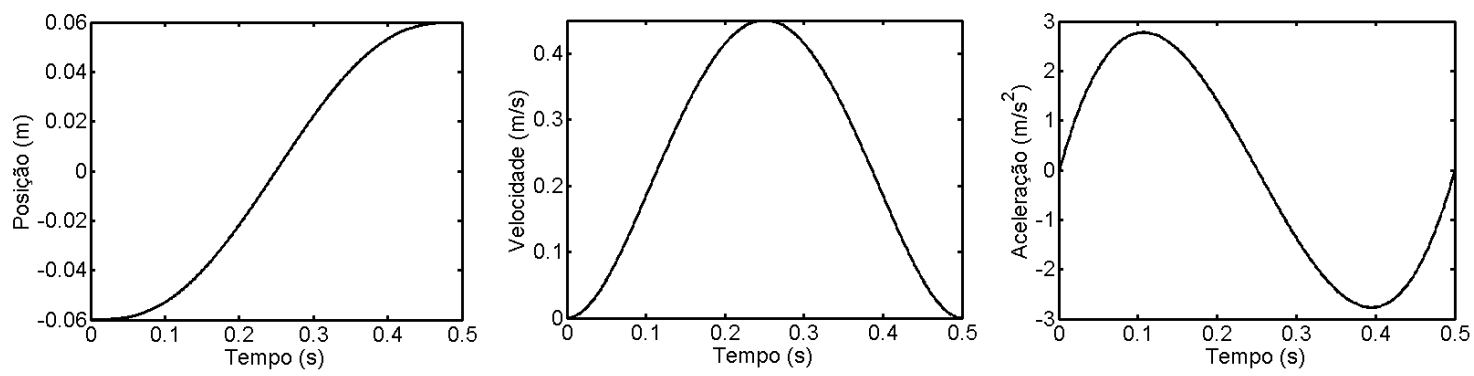

Figura 4.3: Perfil da trajetória II.

impacto na execução da tarefa, podendo duplicar o pico de torque necessário para realizar a tarefa desejada.

Considerando conjuntamente os resultados apresentados na Tab. 4.2 e os gráficos apresentados, é possível notar que a redundância de atuação diminui o máximo torque neces- 
Tabela 4.2: Máximo torque realizado por cada manipulador para desempenhar pré-determinada tarefa [N.m].

\begin{tabular}{|c|c|c|c|c|c|}
\hline Manipulador & Otim. & I sem rotação & II sem rotação & I com rotação & II com rotação \\
\hline$\overline{\text { 3RRR }}$ & - & 0.1874 & 0.3466 & 0.4449 & 0.6539 \\
\hline (4)RRR & - & 0.1287 & 0.2323 & 0.2853 & 0.3857 \\
\hline (6) $\underline{R R R}$ & - & 0.1097 & 0.1703 & 0.2385 & 0.3254 \\
\hline \multirow{4}{*}{$(\underline{\mathrm{P}}) \mathrm{RRR}+2 \underline{\mathrm{R} R R}$} & Offline & 0.1789 & 0.3257 & 0.4191 & 0.6433 \\
\hline & Online 1 & 0.1769 & 0.3255 & 0.3980 & 0.6321 \\
\hline & Online 2 & 0.1853 & 0.3267 & 0.4658 & 0.5672 \\
\hline & Online 3 & 0.1749 & 0.3014 & 0.3782 & 0.5734 \\
\hline \multirow{4}{*}{$2(\underline{P}) R R R+\underline{R R R}$} & Offline & 0.1773 & 0.3212 & 0.3924 & 0.5566 \\
\hline & Online 1 & 0.1729 & 0.3070 & 0.3457 & 0.4660 \\
\hline & Online 2 & 0.2202 & 0.3306 & 0.5369 & 0.8879 \\
\hline & Online 3 & 0.1537 & 0.2517 & 0.3178 & 0.4025 \\
\hline \multirow{4}{*}{$3(\underline{\mathrm{P}}) \underline{\mathrm{RRR}}$} & Offline & 0.1752 & 0.3340 & 0.3588 & 0.5506 \\
\hline & Online 1 & 0.1642 & 0.2924 & 0.3324 & 0.4749 \\
\hline & Online 2 & 0.1562 & inf & 0.5944 & 0.6610 \\
\hline & Online 3 & 0.1557 & 0.2400 & 0.2947 & 0.3682 \\
\hline
\end{tabular}

Tabela 4.3: Configuração dos gráficos.

\begin{tabular}{|l|l|}
\hline I sem rotação & II sem rotação \\
\hline I com rotação & II com rotação \\
\hline
\end{tabular}

sário para realizar diferentes tarefas, como também faz com que os torques necessários sejam mais homogêneos e suaves ao longo da trajetória.

A trajetória II é uma trajetória mais afastada do centro do manipulador, o que pode justificar torques não tão homogêneos quanto o perfil de torques quando se realiza a trajetória I. Ainda assim, esses picos se tornam mais suaves com a adição de redundância de atuação que pode ser notado nos resultados do manipulador (6)RRR. Isto é, a diferença dos picos de torque entre as trajetórias é menor quando há mais redundância.

Comparando o manipulador não redundante ao manipulador com um nível de redundância de atuação, pode-se notar uma diminuição de $31 \%$, $33 \%$ e $36 \%$ do pico de torque na trajetória I sem rotação, trajetória II sem rotação e trajetória I com rotação, respectivamente. Já no caso da trajetória II com rotação, a diminuição foi de $41 \%$. Quando comparado o manipulador não redundante ao manipulador com três níveis de redundância, a diminuição se torna ainda mais expressiva. Para realizar a trajetória I sem rotação foi necessário um pico de torque $41 \%$ menor. Para a trajetória II sem rotação, o pico de 

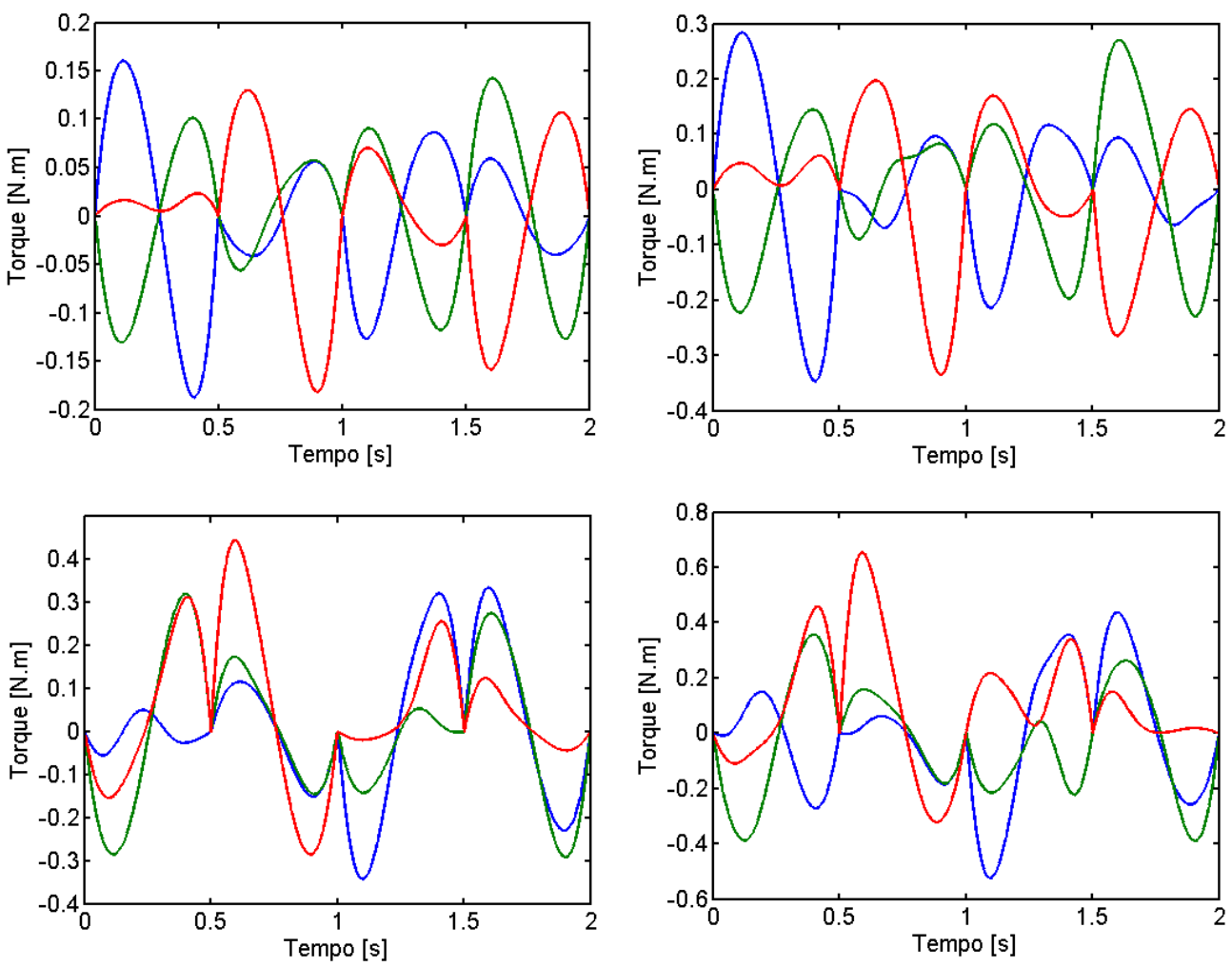

Figura 4.4: Torques executados pelo manipulador 3RRR.

torque foi $51 \%$ menor. Para realizar a trajetória I com rotação houve a diminuição de $46 \%$, já a trajetória II com rotação foi uma diminuição de $50 \%$.

Agora, considerando os manipuladores com redundância cinemática e os métodos apresentados para otimizar a posição da guia linear, é possível notar um potencial de melhoria no desempenho dinâmico, entretanto os métodos são imprevisíveis, em alguns casos não apresentando resultados satisfatórios.

Os melhores casos para o manipulador $(\underline{P}) R R R+2 \underline{R} R R$ estão apresentados na Fig. 4.7. O método online 3 foi o que obteve menor pico de torque nas três primeiras tarefas sendo que na última tarefa o método online 2 obteve o melhor resultado.

A diminuição do pico de torque é entre $6 \%$ a $15 \%$ quando compara-se o manipulador com um nível de redundância cinemática e o não redundante. Esta diminuição demonstra um potencial ganho dinâmico ao se introduzir redundância cinemática.

A Fig. 4.8 apresenta os melhores casos do manipulador com dois níveis de redundância cinemática, 2(ㅁ)RRR $+\underline{R} R R$. Todos eles ocorrem utilizando o método online 3 com uma diminuição do pico de torque de $18 \%$ quando é executada a trajetória I sem rotação. Quando executadas as trajetórias II sem rotação e I com rotação, a redução é de $27 \%$ e $28 \%$, respectivamente. E, por fim, a trajetória II com rotação tem uma diminuição expressiva do pico de torque, sendo $38 \%$ menor. 

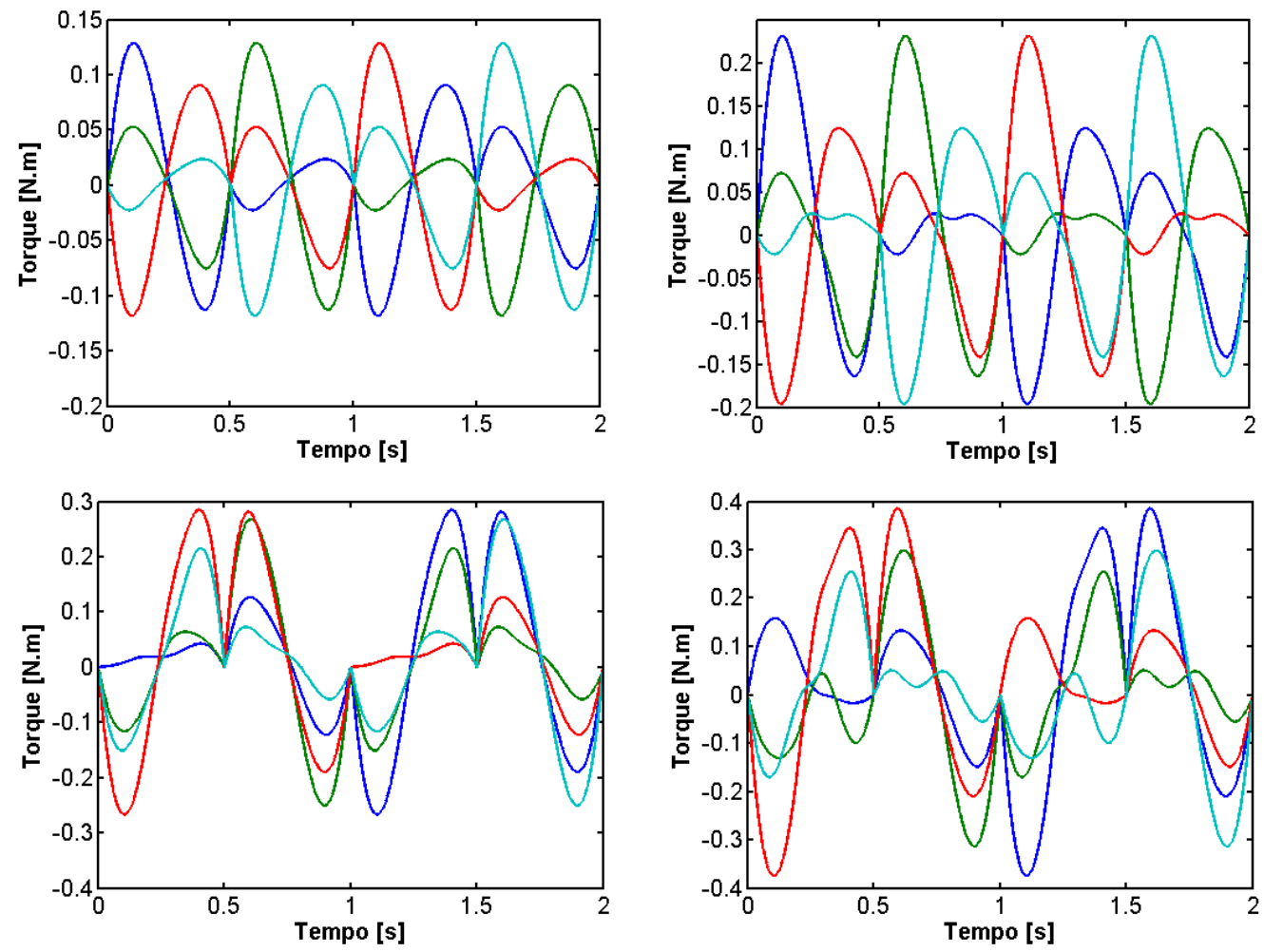

Figura 4.5: Torques executados pelo manipulador (4)RRR.
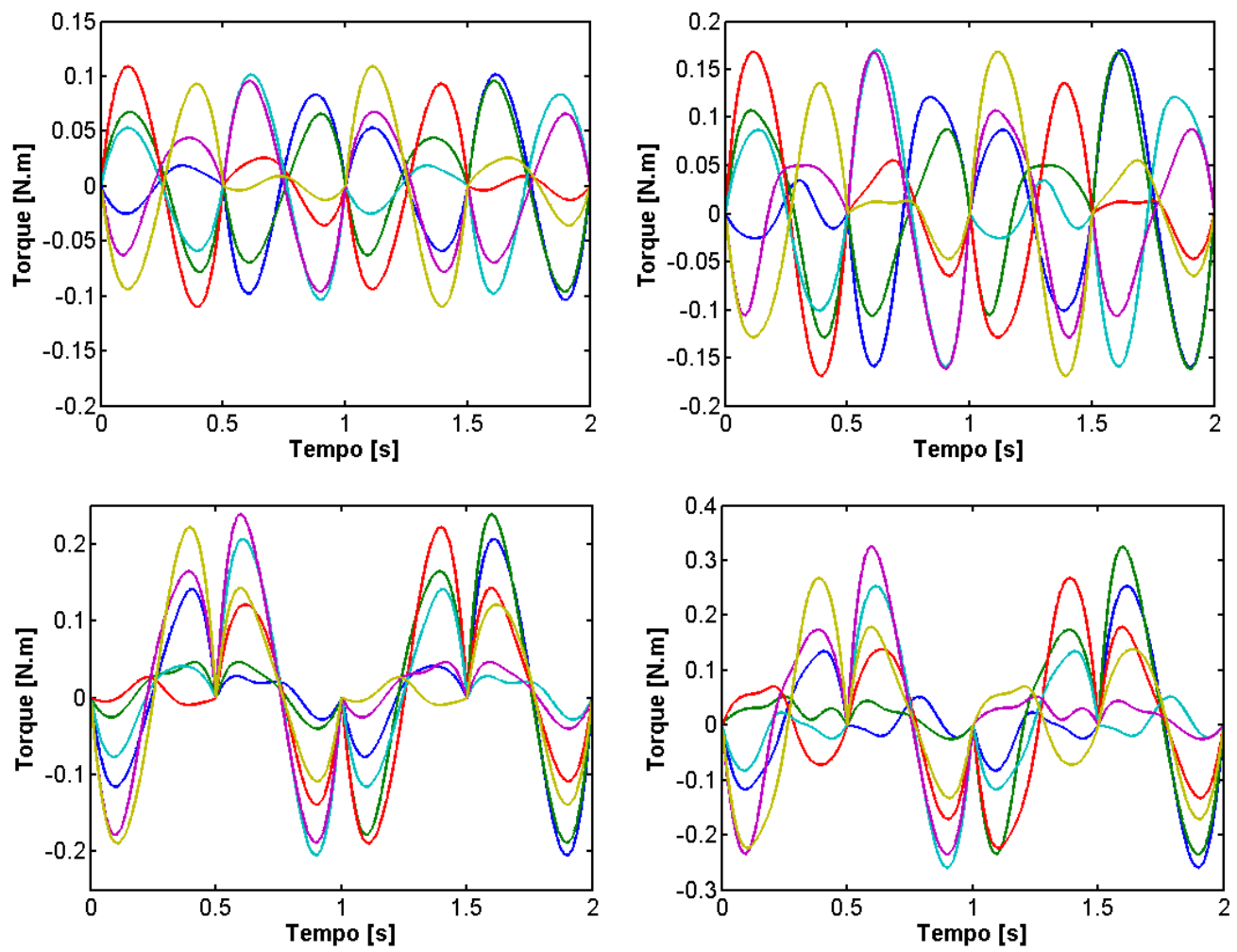

Figura 4.6: Torques executados pelo manipulador (6)RRR. 

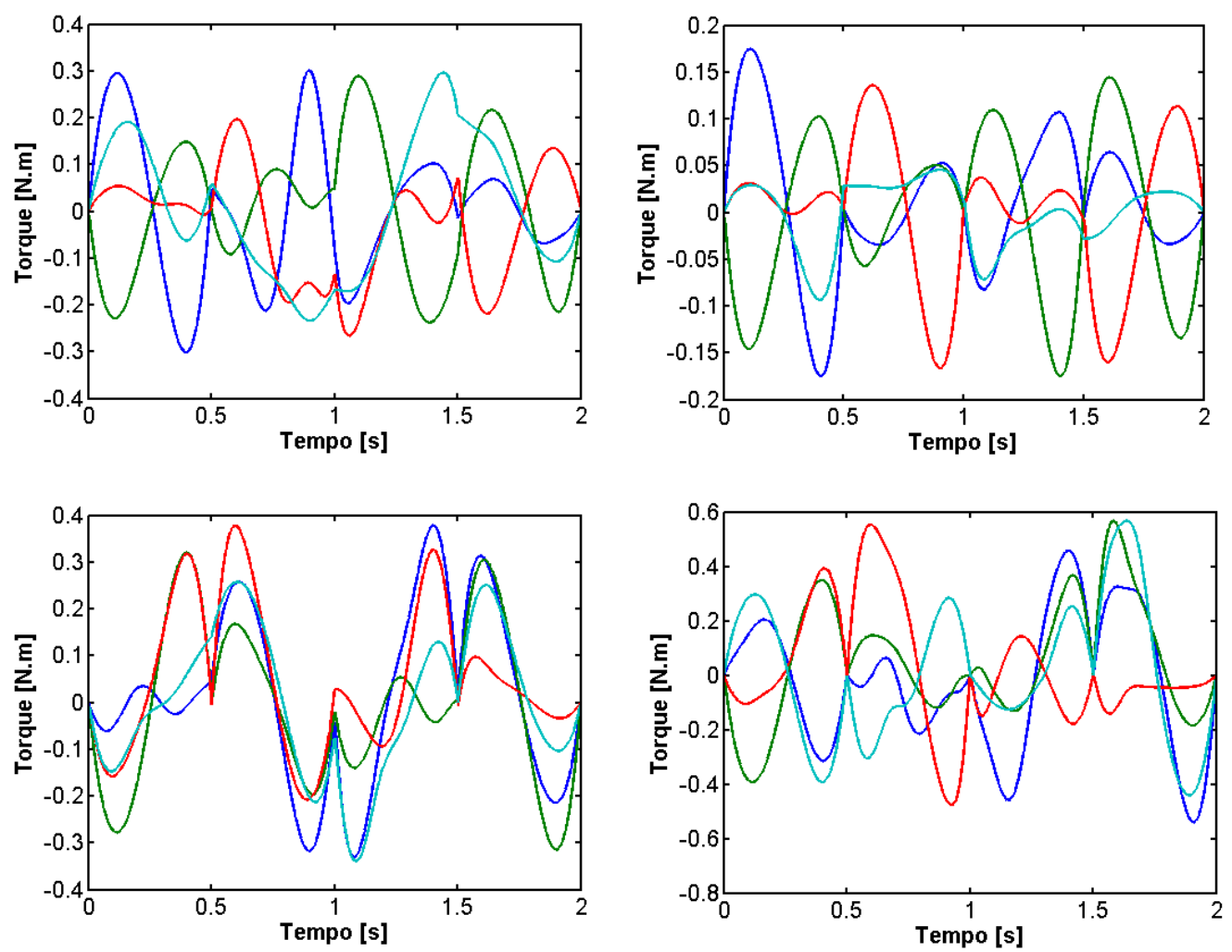

Figura 4.7: Torques executados pelo manipulador $(\underline{P}) R R R+2 \underline{R R R}$.

Os torques calculados nos melhores casos para o manipulador 3(P)RRR são apresentados na Fig. 4.9. Em todas as tarefas, o método que se sobressaiu foi o online 3. A diminuição se torna mais expressiva neste caso com mais níveis de redundância. A redução do pico de torque se mantém $18 \%$ quando é executada a trajetória I sem rotação. Diminui $31 \%$ no caso da trajetória II sem rotação, e $34 \%$ no caso da trajetória I com rotação. Na trajetória II com rotação, a diminuição do pico de torque atingida pelo manipulador $3(\underline{P})$ RRR chega próxima à diminuição provocada pelo manipulador (6)RRR, sendo de $44 \%$.

Portanto, o método online 3 é o que apresenta melhor desempenho dentro dos métodos propostos para otimizar as posições das guias lineares. O método online 2, apesar de ter apresentado bom desempenho no caso do manipulador $(\underline{P}) R R R+2 \underline{R} R R$ executando a trajetória II com rotação, ele é instável, pois o método otimiza a trajetória por partes, assim o ponto final de uma parte é o inicial do posterior, criando uma restrição que pode elevar os esforços para realizar a tarefa, ou mesmo, levar o manipulador para um ponto de singularidade, como ocorreu no caso do manipulador $3(\underline{P}) \underline{R} R R$ quando executada a trajetória II sem rotação. Os outros métodos se mostram satisfatórios, mas não tão eficientes quanto o método online 3. Essa excelência do método online 3 se deve ao fato de que este método considera a trajetória globalmente e possui mais variáveis de otimização.

Dentre os manipuladores com redundância cinemática, o manipulador com três níveis de redundância, 3()RRR, é o que tem melhor desempenho dinâmico. Entretanto, compa- 

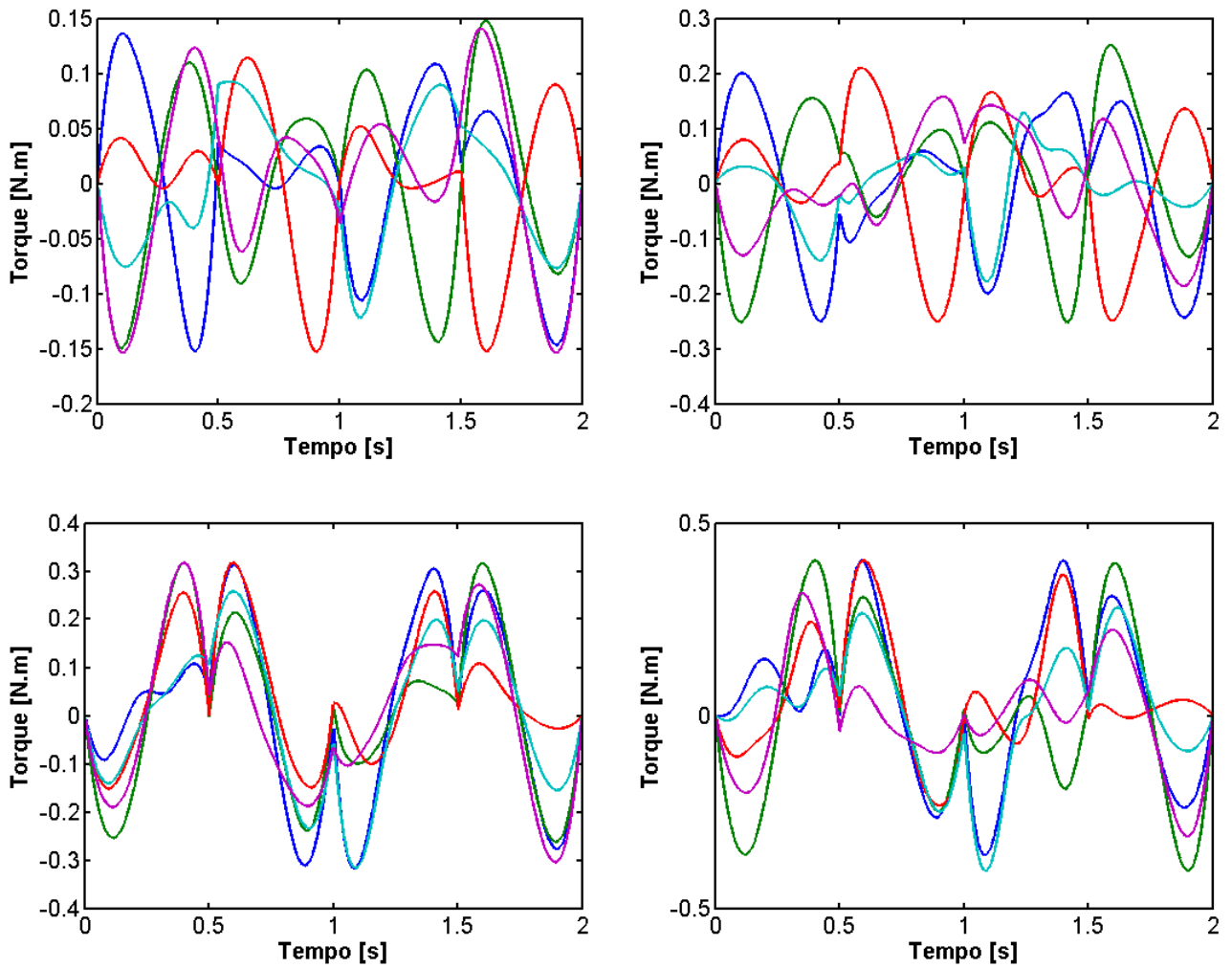

Figura 4.8: Torques executados pelo manipulador $2(\underline{P}) R R R+\underline{R} R R$.
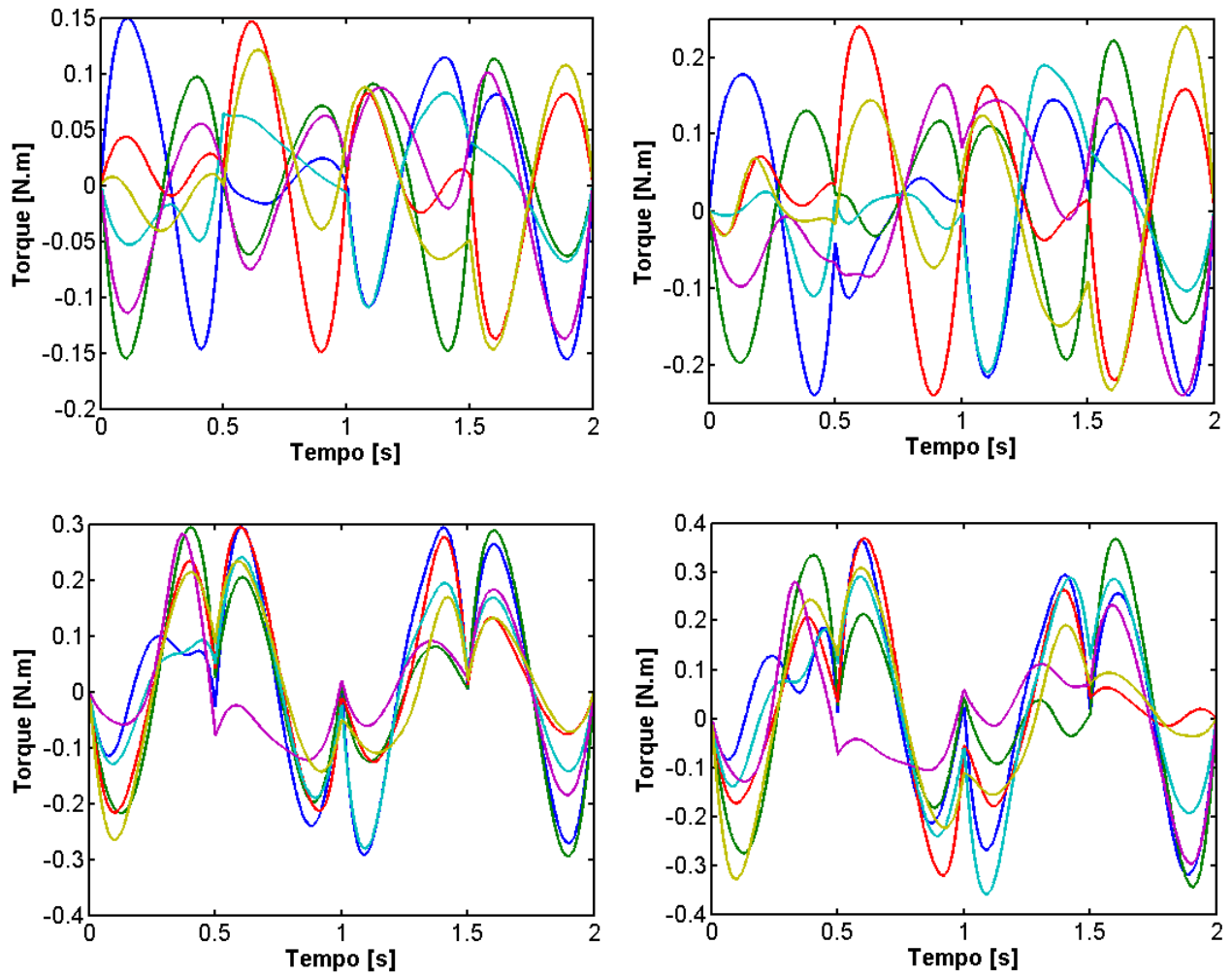

Figura 4.9: Torques executados pelo manipulador 3(P) RRR. 
rando todos os manipuladores, o manipulador com três níveis de redundância de atuação ainda possui o melhor desempenho dinâmico.

\subsection{Mapas dinâmicos calculados}

Utilizando o índice dinâmico proposto na seção 3.5 são desenhados mapas dinâmicos para todos os manipuladores. O índice é calculado ao longo da área de trabalho considerando a posição angular do end-effector igual a zero. Estes mapas trazem uma melhor compreensão do estudo dinâmico dos manipuladores. De acordo com as simulações das tarefas, foi imposto um limite de valor do índice dinâmico igual a 0.8. Portanto, se o índice passar deste valor, a respectiva área é considerada inaceitável para a execução de uma tarefa qualquer.

A Fig. 4.10 apresenta o mapa dinâmico do manipulador não redundante 3RRR. Notase uma área em vermelho que fica branca. Esta área apresenta singularidades tornando os torques muito altos nestas áreas na tentativa de realizar qualquer tarefa, logo esta área é inaceitável. As outras áreas são cobertas de cores azul claro e verde, o que pode ser considerado um índice médio.

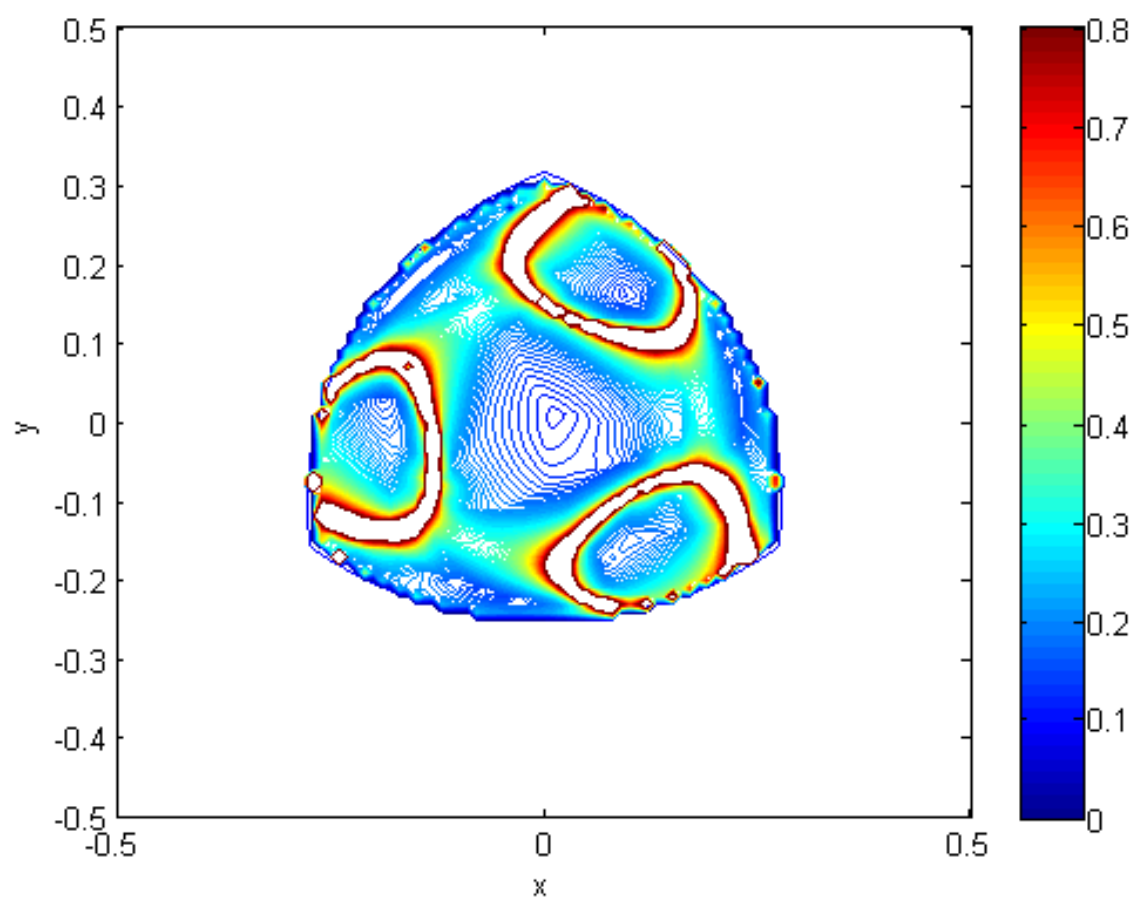

Figura 4.10: Mapa dinâmico do manipulador 3RRR.

A Fig. 4.11 ilustra o mapa dinâmico do manipulador redundante (4)RRR. Este já apresenta maiores áreas com azul escuro e azul claro, concluindo que este manipulador é 
melhor que o manipulador não redundante. Entretanto, ainda possui algumas áreas inaceitáveis. Estas áreas são singularidades do tipo 3 (seção 2.3), isto é, quando o manipulador está muito próximo dos motores pode ocorrer este tipo de singularidade elevando o esforço para realizar um tarefa.

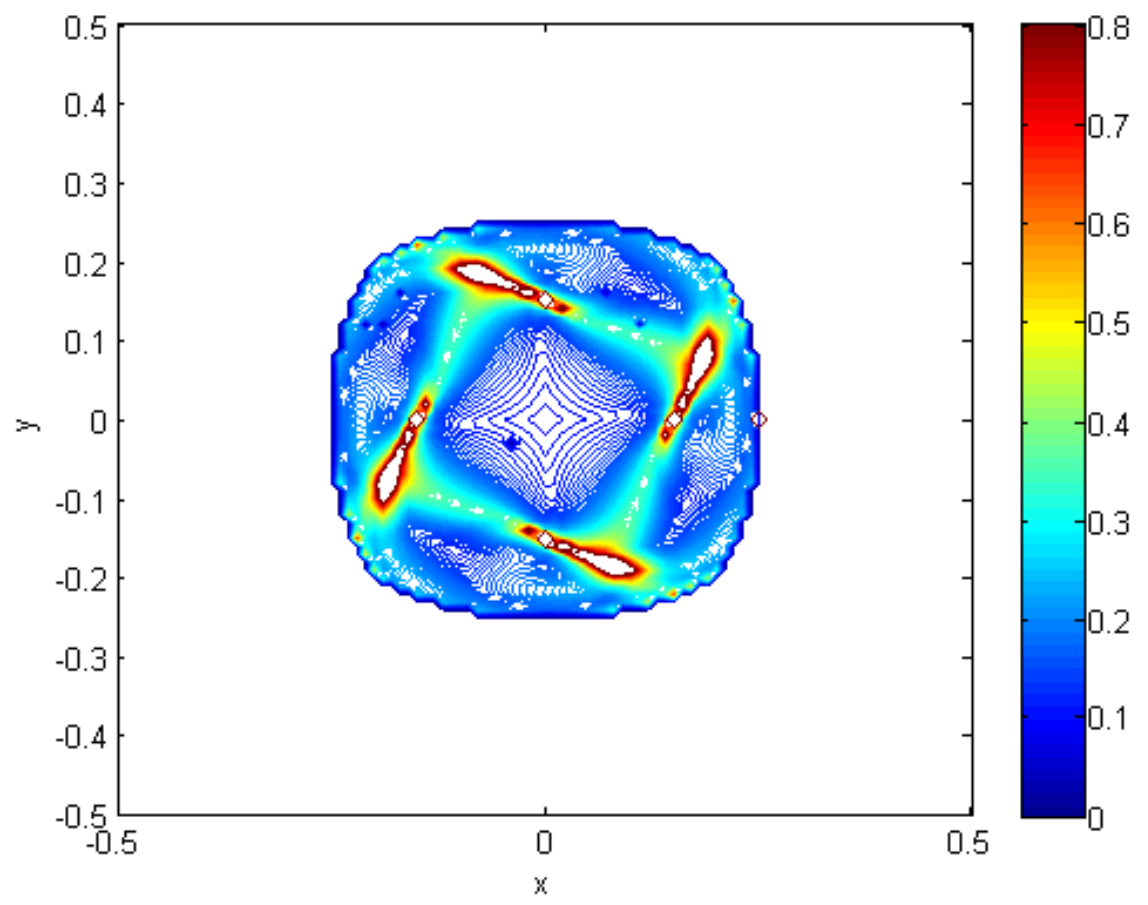

Figura 4.11: Mapa dinâmico do manipulador (4)ㄹRR.

O mapa dinâmico do manipulador redundante (6)RRR é apresentado na Fig. 4.12. Dentre os manipuladores com redundância de atuação e o não redundante, este é o que mais possui áreas em azul escuro e azul claro, apesar de ainda apresentar pontos com singularidades do tipo 3 em vermelho.

Comparando os mapas dinâmicos com os resultados das simulações das trajetórias, pode-se notar a causa do manipulador $3 \underline{R R R}$ ter picos tão elevados na trajetória II. O mapa indica que quanto mais se afasta o end-effector do centro da área de trabalho mais alto é o índice dinâmico, tornando muito altos os torques para se executar uma tarefa nesta área. Pode-se notar também que à medida com que se acrescenta a redundância de atuação, o mapa tende a ser mais homogêneo dinamicamente.

Os mapas dinâmicos dos manipuladores com redundância cinemática são apresentados juntos com a área de trabalho para demonstrar que apesar de a área de trabalho aumentar com a adição de redundância cinemática, ela não é atingível para todos os ângulos do end-effector. Como o ângulo é fixado em zero, alguns mapas não atingem os limites da área de trabalho, diferentemente como ocorre com os manipuladores com redundância de 


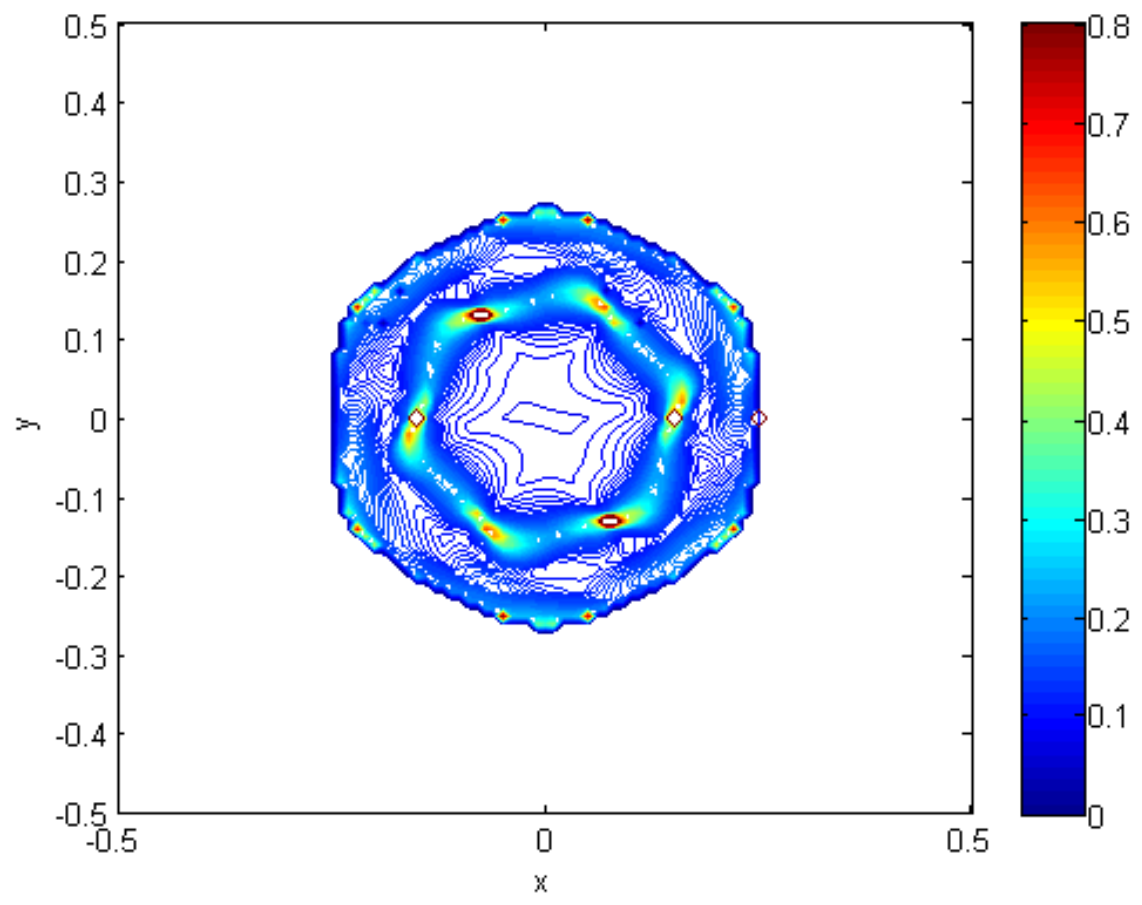

Figura 4.12: Mapa dinâmico do manipulador (6) $\underline{R R R . ~}$

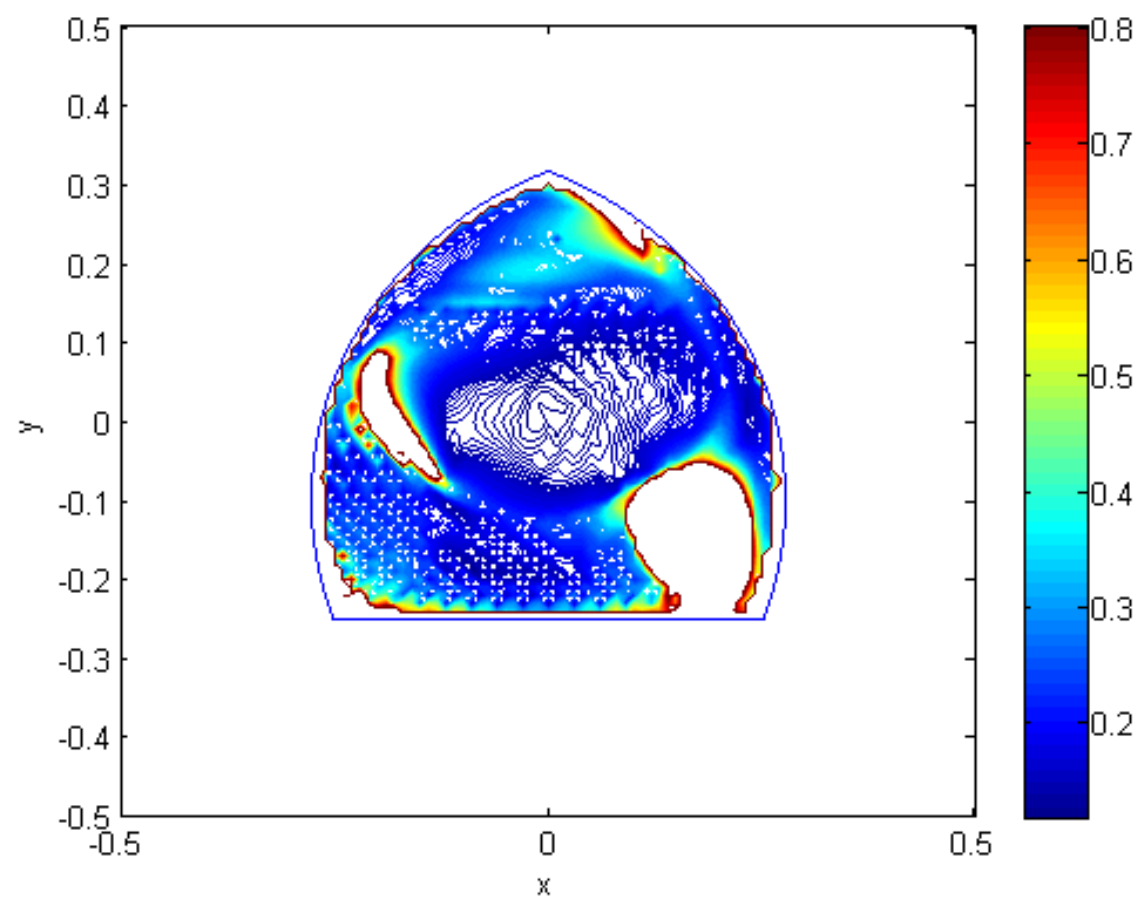

Figura 4.13: Mapa dinâmico do manipulador $(\underline{\mathrm{P}}) \mathrm{RRR}+2 \underline{R} R R$.

atuação e o não redundante que atingem o limite da área de trabalho. A área de trabalho está representada por uma linha azul que envolve os mapas dinâmicos. 
O mapa dinâmico do manipulador ( $\underline{P}) R R R+2 \underline{R} R R$ (Fig. 4.13) possui grande área azul escura o que indica um índice dinâmico baixo, logo, este manipulador possui capacidades dinâmicas elevadas. Entretanto, também possui áreas inaceitáveis pois este manipulador ainda possui singularidades do tipo 2 como pode ser visto nas áreas vermelhas que se tornam brancas.

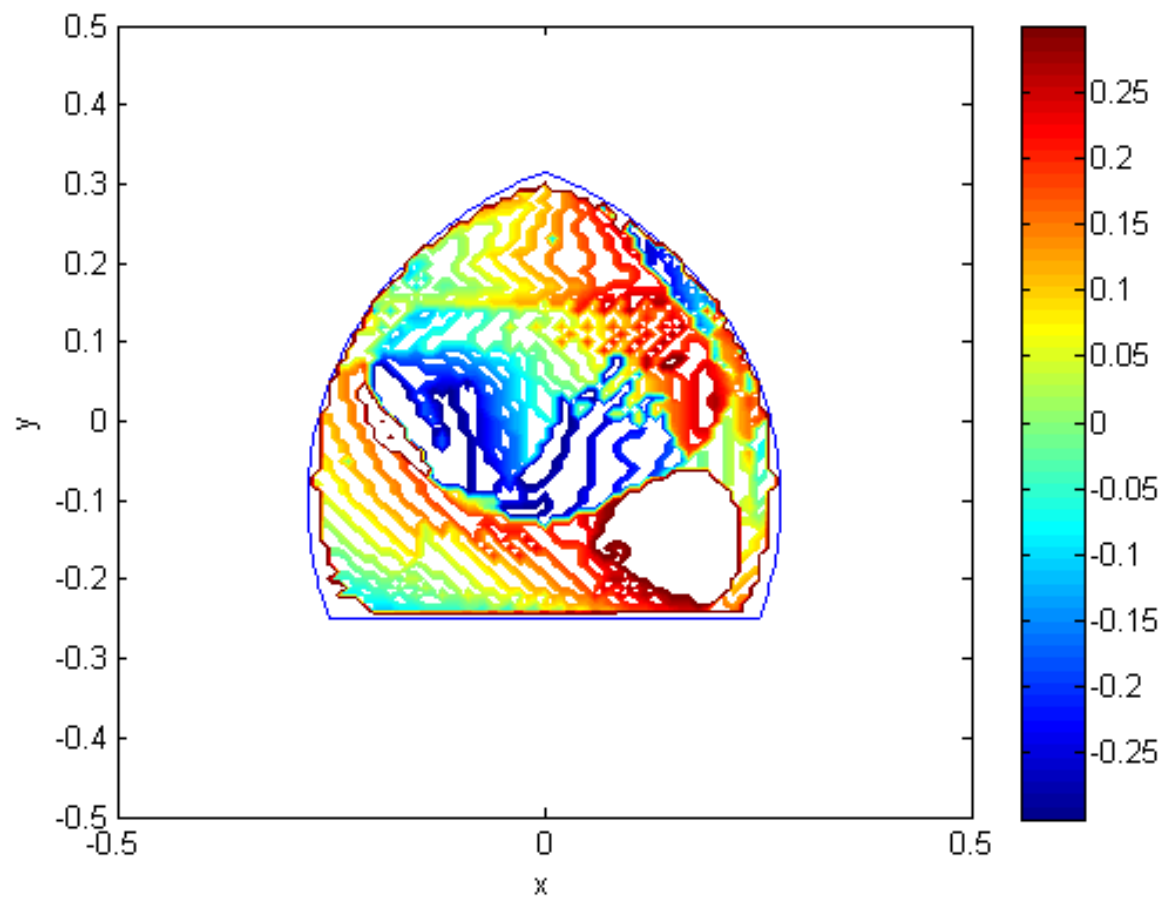

Figura 4.14: Posição ótima $\delta$ da guia linear em relação à área de trabalho do manipulador $(\underline{P}) R R R+2 \underline{R} R R$.

A Fig. 4.14 mostra a posição da guia linear necessária para calcular o respectivo mapa dinâmico. Nota-se que em algumas áreas as posições são homogêneas sendo possível realizar uma trajetória suave da guia para atingir todos os pontos ótimos ao longo da área de trabalho. Entretanto, para realizar uma trajetória extensa do end-effector já seria impossível realizar uma trajetória suave para atingir os pontos ótimos da guia linear devido à quebra da continuidade do mapa da posição da guia.

O manipulador $2(\underline{P}) R R R+\underline{R} R R$ apresenta um mapa dinâmico ainda mais azul escuro e ainda não possui singularidades, apresentando apenas algumas limitações para atingir o limite da área de trabalho devido ao ângulo fixo do end-effector.

Como o manipulador $(\underline{P}) R R R+2 \underline{R} R R$, o manipulador $2(\underline{P}) R R R+\underline{R} R R$ também não possui as posições ótimas das guias lineares uniformes. Como apresentado na Fig. 4.16 é impossível realizar trajetórias suaves para atingir os pontos ótimos das guias lineares ao longo da área de trabalho devido à não uniformidade dos mapas das posições ótimas. 


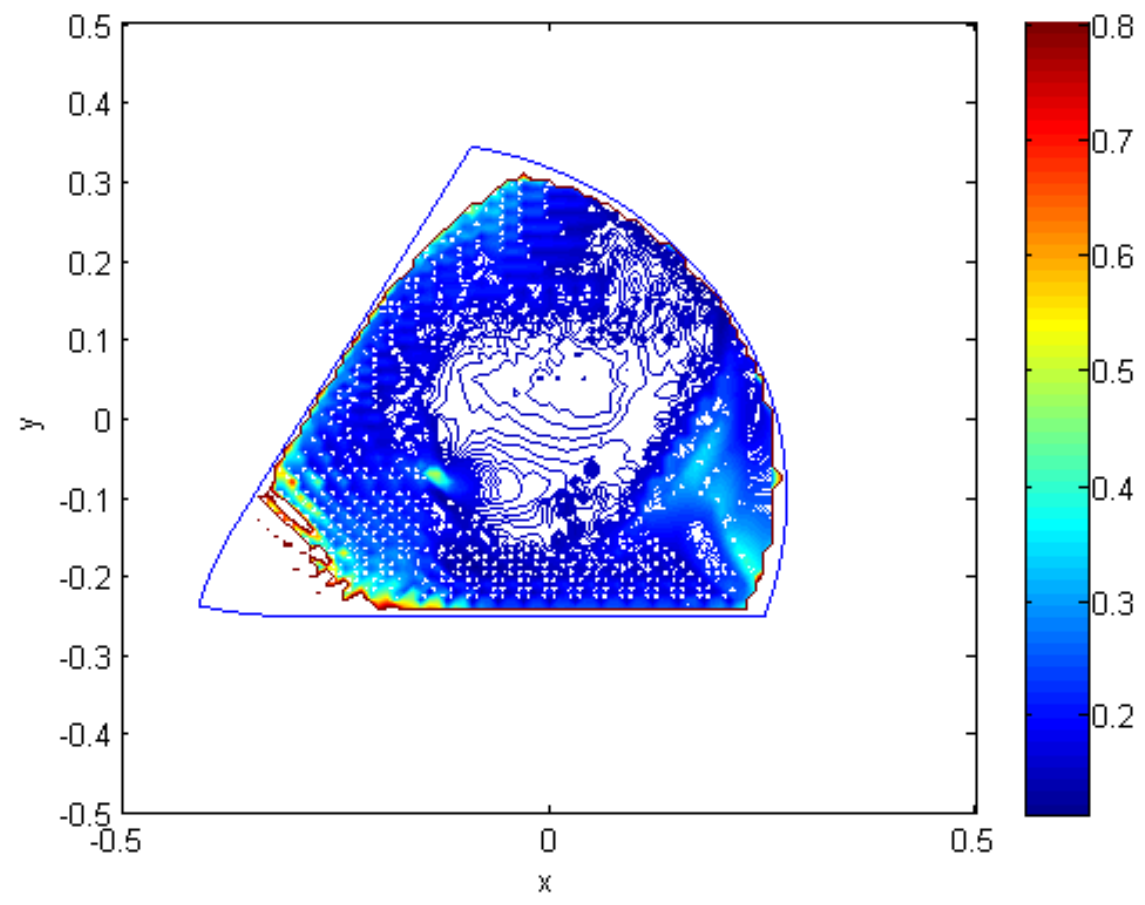

Figura 4.15: Mapa dinâmico do manipulador $2(\underline{P}) R R R+\underline{R R R}$.

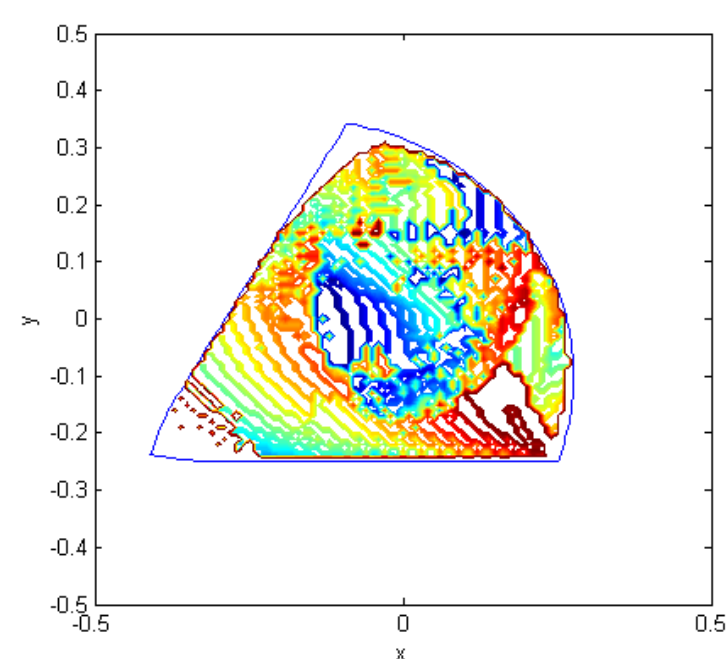

a)

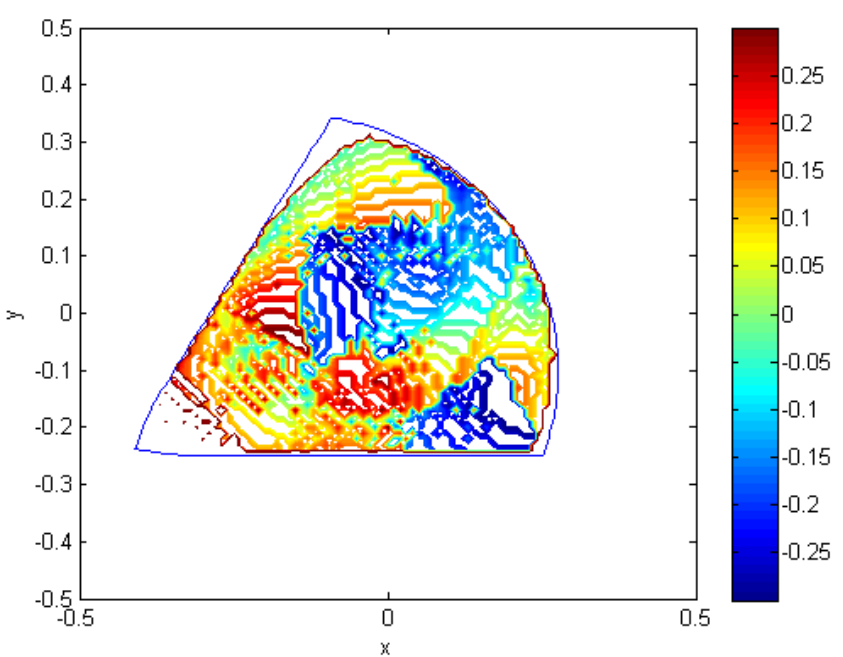

b)

Figura 4.16: Posições ótimas a) $\delta_{1}$ b) $\delta_{2}$ das guias lineares em relação à área de trabalho do manipulador $2(\underline{P}) R R R+\underline{R} R R$.

O mapa dinâmico do manipulador 3(P)RRR possui quase a mesma área em azul escuro que o mapa dinâmico do manipulador $2(\underline{P}) R R R+\underline{R} R R$, podendo representar uma limitação da introdução de mais níveis de redundância cinemática, isto é, a adição de terceiro nível de redundância cinemática não traz mais nenhum benefício dinâmico para o manipulador. 
Apesar da introdução da nova guia linear, não houve um aumento significativo da área de trabalho atingível pelo manipulador com o ângulo do end-effector fixado em zero, apesar da área de trabalho total ter aumentado.

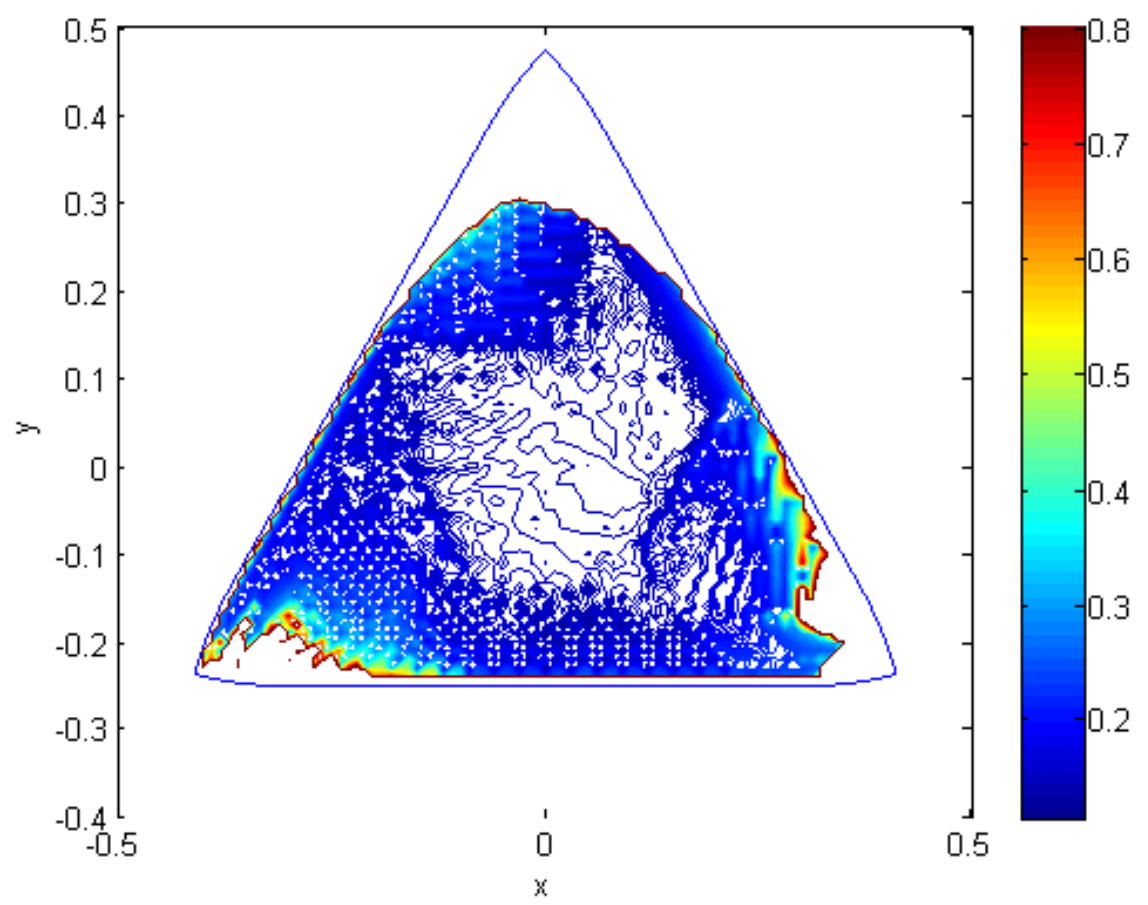

Figura 4.17: Mapa dinâmico do manipulador 3(P)RRR.

As posições ótimas estão representadas na Fig. 4.18 e, como os outros manipuladores, não são uniformes.

Comparando todos os mapas dinâmicos, é correto afirmar que o melhor é o manipulador $2(\underline{P}) R R R+\underline{R R R}$, pois esse manipulador possui grande área de trabalho com desempenho dinâmico muito bom com menos níveis de redundância. O manipulador $3(\underline{P}) R R R$ se mostrou similar ao manipulador $2(\underline{P}) R R R+\underline{R} R R$.

Porém, considerando o estudo das tarefas realizadas, considera-se que o manipulador $3(\underline{P}) R R R$ possui melhor desempenho dinâmico que o $2(\underline{P}) R R R+\underline{R R R}$ e pior que o (6) $R R R$. Isto por que os métodos de otimização utilizados não são eficazes para aproveitar todo o potencial de melhoria do desempenho dinâmico do manipulador. Métodos que envolvam feedback e controle ótimo em tempo real devem conseguir melhores resultados.

\subsection{Considerações finais}

Os resultados apresentados demonstram que tanto a redundância de atuação como a redundância cinemática promovem o desempenho dinâmico dos manipuladores. Também 


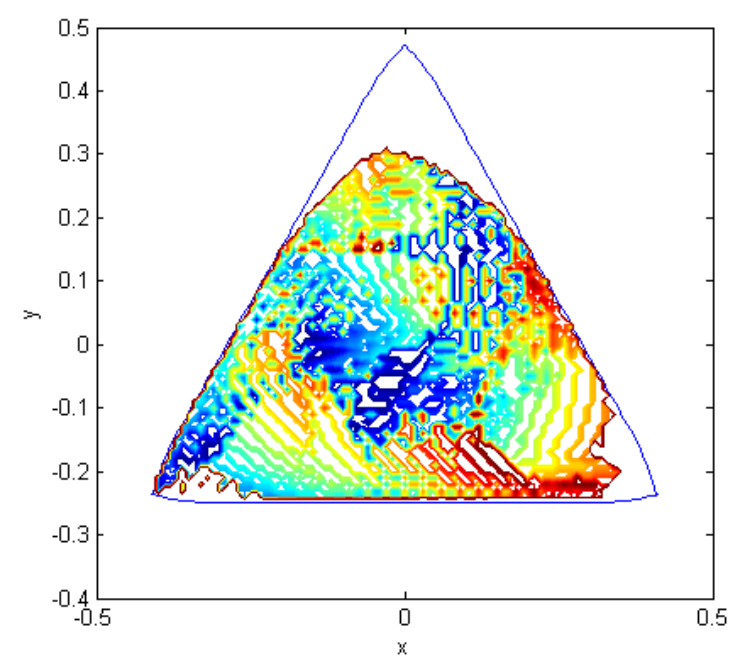

a)

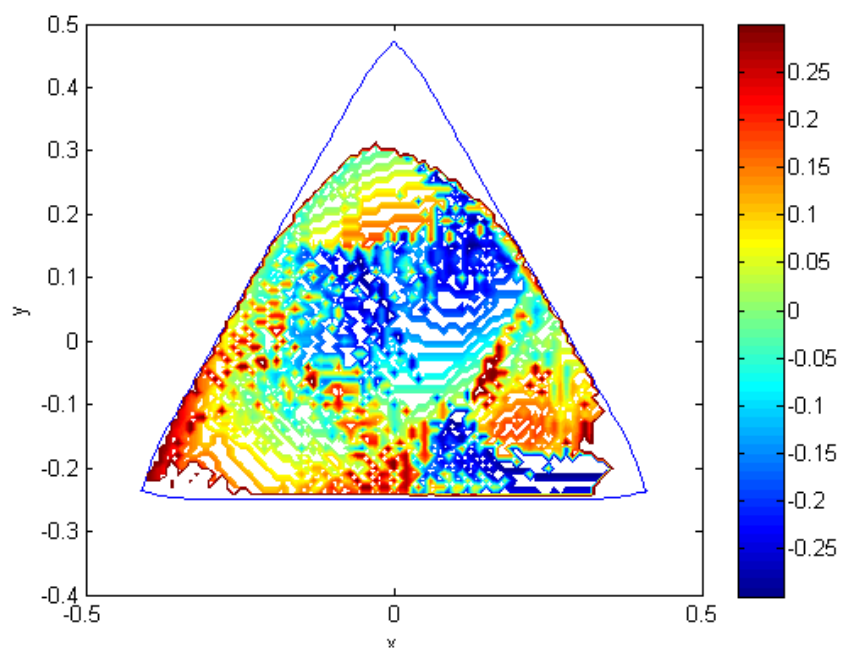

b)

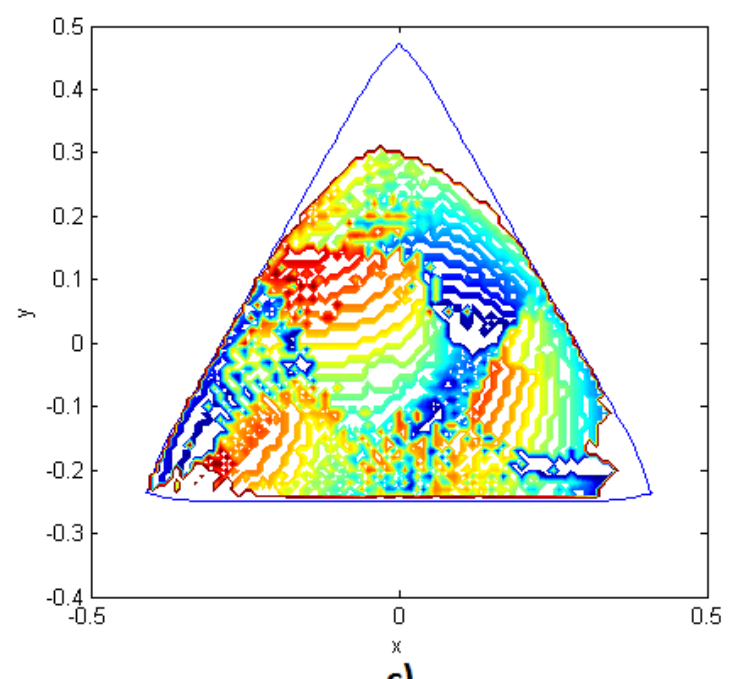

c)

Figura 4.18: Posições ótimas a) $\delta_{1}$, b) $\delta_{2}$ e c) $\delta_{3}$ das guias lineares em relação à área de trabalho do manipulador 3(P)RRR.

foi mostrado que é mais simples se determinar os torques mínimos necessários quando se utiliza redundância de atuação, pois nestes casos o modelo cinemático é único, sendo que os manipuladores com redundância cinemática necessitam de um processo de otimização para a determinação de sua cinemática. O estudo da redundância cinemática mostrou uma potencial melhora no desempenho dinâmico dos manipuladores, entretanto os métodos de otimização propostos ainda não conseguiram atingir melhores desempenhos que os manipuladores com redundância de atuação, apesar dos mapas dinâmicos indicarem que os manipuladores com redundância cinemática possuem a maior capacidade dinâmica. 



\section{5}

\section{Conclusões e considerações para trabalhos futuros}

\subsection{Conclusões}

Manipuladores com cinemática paralela possuem características que se sobressaem quando comparados aos manipuladores com cinemática em série. Uma delas é a distribuição de carga pelas cadeias cinemáticas que possibilita grandes acelerações/velocidades sendo útil para aumentar a velocidade de tarefas como, por exemplo, operações pega-epõe. Entretanto os manipuladores possuem áreas em que o controle se torna instável ou exige esforços muito grandes, chamadas singularidades. Assim, as singularidades diminuem o espaço de trabalho útil dos mecanismos.

Já foi demonstrado que a aplicação de redundância pode desviar das singularidades ou eliminá-las do manipulador, além disso, a redundância pode melhorar outras características dos manipuladores. Tendo como objetivo aumentar as acelerações/velocidades dos manipuladores paralelos, levando ao aumento de produção que possam utilizar tarefas executadas pelos manipuladores, nesta dissertação de mestrado foi investigado o desempenho dinâmico de manipuladores com redundância cinemática e manipuladores com redundância de atuação fazendo comparações com o respectivo manipulador não redundante para auxiliar na identificação de melhorias no desempenho dinâmico. Para isso foram propostas duas estratégias: executar trajetórias com a comparação do máximo 
torque atingido por cada manipulador, e propor um índice dinâmico independente da trajetória para ser calculado ao longo de toda a área de trabalho definindo mapas dinâmicos.

Para executar estas estratégias, foram elaboradas as modelagens dos manipuladores estudados de forma que estes tivessem características similares, podendo assim comparar a adição de diferentes tipos e níveis de redundância.

Trabalhos da área indicam que os manipuladores com redundância de atuação possuem um limite de ganho de desempenho dinâmico quando se adiciona níveis de redundância. Entretanto, estes trabalhos fazem análises apenas executando trajetórias o que pode levar a conclusões limitadas podendo não se afirmar com certeza se existe este limite. Com os resultados apresentados, tanto das tarefas executadas quanto dos mapas dinâmicos, os manipuladores com redundância de atuação apresentaram ganhos contínuos quando se adiciona níveis de redundância, isto é, não apresentando limite de ganho com a adição de redundância de atuação. Como também, o manipulador com três níveis de redundância, (6) RRR, mostrou ter o melhor desempenho dinâmico dentre os manipuladores com redundância de atuação, já que este possui o maior nível de redundância de atuação.

Já o estudo dinâmico dos manipuladores com redundância cinemática é mais limitado devido à necessidade de determinar um método de otimização das posições das guias lineares (juntas redundantes) dos manipuladores. Estes métodos são limitados pela quantidade de variáveis de otimização impostas, podendo não atingir resultados satisfatórios. Apesar disso, o método online 3 que utiliza 4 variáveis de otimização por guia linear obteve bons resultados, sendo que o manipulador com três níveis de redundância, 3(P)RRR, possui o melhor desempenho dinâmico entre os manipuladores com redundância cinemática.

A comparação da execução das trajetórias por todos os manipuladores demonstrou que o manipulador com três níveis de redundância de atuação é o que possui o melhor desempenho dinâmico. Entretanto, o manipulador com três níveis de redundância cinemática obteve resultados similares.

Para o estudo dos mapas dinâmicos foi proposto um índice dinâmico. O índice proposto foi idealizado a partir do trabalho de Zhao e Gao (2009) e do significado físico do índice que é o maior torque necessário para gerar uma aceleração de módulo igual 1 em todas as direções no ponto que o end-effector se encontra. Este índice se mostrou satisfatório já que ele é dependente apenas das posições do end-effector e das juntas.

Os mapas dinâmicos indicaram que a redundância cinemática tem um limite de ganho quando se adiciona níveis de redundância ao manipulador, isto porque quando comparados os manipuladores com dois e três níveis de redundância cinemática, os mapas dinâmicos não apresentam muitas diferenças. Já os manipuladores com redundância de atuação apresentam ganho crescente de acordo com a adição dos níveis de redundância. Os mapas também indicaram que a redundância cinemática apresenta melhor desempenho dinâmico em relação à redundância de atuação porém, este resultado não é refletido quando se analisa os manipuladores pela execução das trajetórias. Esta diferença pode ser explicada pelo 
resultado das trajetórias dos manipuladores com redundância cinemática ser dependente do método de otimização portanto, a redundância cinemática é uma estratégia que melhora o desempenho dinâmico, mas ainda deve ser mais estudada e trabalhada para que métodos de otimização explorem melhor o potencial dinâmico destes manipuladores.

As principais contribuições dadas por este trabalho são as modelagens que foram padronizadas de forma que tivessem características similares, podendo dizer até que a modelagem é modular, isto é, pode-se acrescentar guias lineares à cadeia cinemática, ou adicionar cadeias cinemáticas, sem realizar grandes mudanças em toda a modelagem. Além disso, foram propostos os mapas dinâmicos que oferecem uma forma visual para o melhor entendimento do estudo dinâmico, além de ser calculado em toda a área de trabalho independentemente da trajetória de uma tarefa, assim criando os mapas.

\subsection{Contribuições científicas}

- Fontes, J.V.C.; Santos, J.C.; da Silva, M.M. Torque optimization of parallel manipulators by the application of kinematic redundancy. In. Congresso Nacional de Engenharia Mecânica (CONEM), 2014, Uberlândia, Brasil. (Fontes et al., 2014b)

- Fontes, J.V.C.; Santos, J.C.; da Silva, M.M. Optimization strategies for actuators of kinematically redundant manipulators to achieve high dynamic performance. In 2014 Joint Conference on Robotics: SBR-LARS Robotics Symposium and Robocontrol, pages 31-36. IEEE. (Fontes et al., 2014a)

- Ruiz, A. G.; Fontes, J. V. C.; and da Silva, M. M. The Impact of Kinematic and Actuation Redundancy on the Energy Efficiency of Planar Parallel Kinematic Machines. In 17th International Symposium on Dynamic Problems of Mechanics Natal, Brazil Feb., 22-27, 2015. (Ruiz et al., 2015)

\subsection{Propostas para trabalhos futuros}

- Efetuar estudos de outros métodos de otimização, por exemplo, que envolvam controle ótimo em tempo real, para que haja um aproveitamento melhor do potencial de melhoria dos manipuladores com redundância cinemática;

- Adaptar os modelos para a validação experimental das modelagens e dos métodos de otimização;

- Realizar estudos dos mapas dinâmicos direcionais para avaliar se a rotação de endeffector causa grandes esforços em toda a área de trabalho; 
- Realizar estudos de manipuladores com mais níveis de redundância de atuação para verificar se ainda há ganho no desempenho dinâmico;

- Realizar estudos do impacto das incertezas dos parâmetros dos manipuladores redundante e verificar se há necessidade de controles mais robustos. 


\section{Referências}

Bonev, I. A.; Gosselin, C. M. Singularity Loci of Planar Parallel Manipulators with Revolute Joints. Robotics and Autonomous Systems, 2001.

Disponível em: http://citeseerx.ist.psu.edu/viewdoc/summary?doi=10.1.1.93. 8910

ChA, S.-H.; LASky, T. A.; Velinsky, S. A. Singularity Avoidance for the 3-RRR Mechanism Using Kinematic Redundancy. In: Proceedings 2007 IEEE International Conference on Robotics and Automation, IEEE, 2007, p. 1195-1200.

Disponível em: http://www.scopus.com/inward/record.url?eid=2-s2. 0-36349007619\&partnerID=tZ0tx3y1http://ieeexplore.ieee.org/lpdocs/epic03/ wrapper. htm? arnumber $=4209251$

Company, O.; Pierrot, F.; Krut, S.; Baradat, C.; NABAT, V. Par2: a spatial mechanism for fast planar two-degree-of-freedom pick-and-place applications. Meccanica, v. 46, n. 1, p. 239-248, 2011.

Disponível em: http://link.springer.com/10.1007/s11012-010-9413-x

Conkur, E. S.; Buckingham, R. Clarifying the definition of redundancy as used in robotics. Robotica, v. 15, n. 05, p. 583-586, 1997.

Disponível em: http://journals.cambridge.org/article_S0263574797000672

Corbel, D.; Gouttefarde, M.; Company, O.; Pierrot, F. Towards 100G with PKM. Is actuation redundancy a good solution for pick-and-place? In: 2010 IEEE International Conference on Robotics and Automation, IEEE, 2010, p. 4675-4682.

Disponível em: http://ieeexplore.ieee.org/lpdocs/epic03/wrapper.htm? arnumber $=5509921$

Donelan, P. S. Singularities of robot manipulators. Singularity Theory, p. 189-217, 2007. 
EARL, C. F.; RoOney, J. Some Kinematic Structures for Robot Manipulator Designs. Journal of Mechanisms Transmissions and Automation in Design, v. 105, n. 1, p. 15, 1983. Disponível em: http://mechanicaldesign.asmedigitalcollection.asme.org/ article. aspx?articleid $=1452105$

Fontes, J. V. C.; SAnTos, J. C.; Silva, M. M. Optimization strategies for actuators of kinematically redundant manipulators to achieve high dynamic performance. In: 2014 Joint Conference on Robotics: SBR-LARS Robotics Symposium and Robocontrol, IEEE, 2014a, p. 31-36.

Disponível em: http://ieeexplore.ieee.org/articleDetails.jsp?arnumber= 7024092

FonteS, J. V. C.; SAnTos, J. C.; Silva, M. M. Torque optimization of parallel manipulators by the application of kinematic redundancy. Conferência Nacional de Engenharia Mecânica - CONEM, 2014b.

Disponível em: http://www. conem2014.com.br/ANAIS/PDFS/CONEM2014-0505.PDF

Gosselin, C.; Angeles, J. Singularity analysis of closed-loop kinematic chains. IEEE Transactions on Robotics and Automation, v. 6, n. 3, p. 281-290, 1990.

Disponível em: http://ieeexplore . ieee.org/articleDetails . jsp?arnumber=56660

HibBeler, R. C. Engineering Mechanics: Dynamics, Volume 2. 1998.

Disponível em: http://books.google.com.br/books/about/Engineering_Mechanics. html? id=wX0eAQAAIAAJ\&pgis $=1$

Kobler, J.-P.; Kotlarski, J.; Öltjen, J.; Baron, S.; Ortmaier, T. Design and analysis of a head-mounted parallel kinematic device for skull surgery. International Journal of Computer Assisted Radiology and Surgery, v. 7, n. 1, p. 137-149, 2012.

Disponível em: http://link.springer.com/article/10.1007/ s11548-011-0619-8files/170/Kobleretal .-2012-Designandanalysisofahead-mountedparallelk pdffiles/183/s11548-011-0619-8.html

Kotlarski, J.; Abdellatif, H.; Heimann, B. Improving the pose accuracy of a planar 3(R)under-barRR parallel manipulator using kinematic redundancy and optimized switching patterns. In: 2008 Ieee International Conference on Robotics and Automation, Vols 1-9, IEEE, p. 3863-3868, 2008.

Disponível em: files/469/04543804.pdfhttp://ieeexplore.ieee.org/lpdocs/ epic03/wrapper. htm?arnumber $=4543804$

Kotlarski, J.; Abdellatif, H.; Ortmaier, T.; Heimann, B. Enlarging the useable workspace of planar parallel robots using mechanisms of variable geometry. In: Reconfigurable Mechanisms and Robots, 2009. ReMAR 2009. ASME/IFToMM International 
Conference on, IEEE, 2009, p. 63-72.

Disponível em: http://ieexplore.ieee.org/articleDetails.jsp?arnumber= 5173811

Kotlarski, J.; HeimanN, B.; OrtMAier, T. Experimental validation of the influence of kinematic redundancy on the pose accuracy of parallel kinematic machines. In: Robotics and Automation (ICRA), 2011 IEEE International Conference on, 2011, p. 1923-1929.

Kotlarski, J.; Thanh, T. D.; Heimann, B.; Ortmaier, T. Optimization strategies for additional actuators of kinematically redundant parallel kinematic machines. In: Robotics and Automation (ICRA), 2010 IEEE International Conference on, 2010, p. 656661.

KüÇÜK, S. Serial and Parallel Robot Manipulators - Kinematics, Dynamics, Control and Optimization. InTech, 2012.

Disponível em: http://www.intechopen.com/books/ serial-and-parallel-robot-manipulators-kinematics-dynamics-control-and-optimization inverse-dynamics-of-rrr-fully-planar-parallel-manipulator-using-dh-method

KUKA RoBOtER Do BRASIL LTDA. Robôs industriais, unidades de comando, sistemas de robô. 2014.

Disponível em: http://www.kuka-robotics.com/brazil/br/products/industrial_ robots/medium/kr30_3/start.htm

LIU, G. F.; WU, Y. L.; WU, X. Z.; KuEN, Y. Y.; LI, Z. X. Analysis and control of redundant parallel manipulators. In: Robotics and Automation, 2001. Proceedings 2001 ICRA. IEEE International Conference on, 2001, p. 3748-3754 vol.4.

Marquet, F.; Company, O.; Krut, S.; Pierrot, F. Enhancing parallel robots accuracy with redundant sensors. In: Proceedings 2002 IEEE International Conference on Robotics and Automation (Cat. No.02CH37292), IEEE, 2002, p. 4114-4119.

Disponível em: http://ieexplore.ieee.org/articleDetails.jsp?arnumber= 1014390

MehtA, V. K.; DAsGuptA, B. A general approach for optimal kinematic design of 6-DOF parallel manipulators. Sadhana, v. 36, n. 6, p. 977-994, 2011.

Disponível em: http://link.springer.com/article/10.1007/ s12046-011-0057-xfiles/99/MehtaeDasgupta-2011-Ageneralapproachforoptimalkinematicde pdffiles/131/s12046-011-0057-x.html

MERLET, J.-P. Redundant parallel manipulators. Laboratory Robotics and Automation, v. 8, n. 1, p. 17-24, 1996. 
Disponível em: http://doi.wiley.com/10.1002/(SICI) 1098-2728(1996)8:1<17: : AID-LRA3>3.0.CO;2-\#

Merlet, J.-P. Parallel Robots. Springer, 2006.

Disponível em: http://www.springer.com/engineering/mechanical+engineering/ book/978-1-4020-4132-7

Mohamed, M. G.; Gosselin, C. M. Design and analysis of kinematically redundant parallel manipulators with configurable platforms. Robotics, IEEE Transactions on, v. 21, n. 3, p. 277-287, 2005.

Muller, A. Consequences of Geometric Imperfections for the Control of Redundantly Actuated Parallel Manipulators. IEEE Transactions on Robotics, v. 26, n. 1, p. 21-31, 2010.

Disponível em: http://ieeexplore.ieee.org/lpdocs/epic03/wrapper.htm? arnumber $=5345788$

NAhon, M. A.; Angeles, J. Force optimization in redundantly-actuated closed kinematic chains. In: Robotics and Automation, 1989. Proceedings., 1989 IEEE International Conference on, 1989, p. 951-956 vol.2.

Niemann, S.; Kotlarski, J.; Ortmaier, T.; Muller-Schloer, C. Reducing the optimization problem for the efficient motion planning of kinematically redundant parallel robots. In: 2013 IEEE/ASME International Conference on Advanced Intelligent Mechatronics, IEEE, 2013, p. 618-624.

Disponível em: http://ieeexplore.ieee.org/lpdocs/epic03/wrapper.htm? arnumber $=6584161$

RaO, S. S. Engineering Optimization: Theory and Practice. 813 p., 2009. Disponível em: http://books .google.com/books?id=YNt34dvnQLEC\&pgis=1

RochA, D. M.; Silva, M. M. Workspace and singularity analysis of redundantly actuated planar parallel kinematic machines. In: XV International Symposium on Dynamic Problems of Mechanics, Búzios, RJ, Brazil, 2013, p. 1-10.

Ruiz, A. G.; Fontes, J. V. D. C.; Silva, M. M. The Impact of Kinematic and Actuation Redundancy on the Energy Efficiency of Planar Parallel Kinematic Machines. 2015.

Thanh, T. D.; Kotlarski, J.; Heimann, B.; Ortmaier, T.; Do Thanh, T.; Kotlarski, J.; Heimann, B.; Ortmaier, T. Dynamics identification of kinematically redundant parallel robots using the direct search method. Mechanism and Machine Theory, v. 52, n. 0, p. 277-295, 2012.

Disponível em: http://www. scopus.com/inward/record.url?eid=2-s2. 
0-84862577230\&partnerID=tZOtx3y1http: //www. sciencedirect. com/science/ article/pii/S0094114X1200033Xhttp://www.scopus.com/inward/record.url?eid= 2-s2.0-84859571974\&partnerID=tZOtx3y1

WANG, L.; WU, J.; WANG, J.; You, Z. An Experimental Study of a Redundantly Actuated Parallel Manipulator for a 5-DOF Hybrid Machine Tool. Mechatronics, IEEE/ASME Transactions on, v. 14, n. 1, p. 72-81, 2009.

Wu, J.; LI, T.; WANG, J.; WANG, L. Performance Analysis and Comparison of Planar 3DOF Parallel Manipulators with One and Two Additional Branches. Journal of Intelligent \& Robotic Systems, v. 72, n. 1, p. 73-82, 2013.

Disponível em: http://dx.doi .org/10.1007/s10846-013-9824-8

WU, J.; WANG, J.; WANG, L.; LI, T. Dynamics and control of a planar 3-DOF parallel manipulator with actuation redundancy. Mechanism and Machine Theory, v. 44, n. 4, p. 835-849, 2009.

Disponível em: http://www.sciencedirect.com/science/article/pii/ S0094114X08000839

WU, J.; WANG, J.; YOU, Z. A comparison study on the dynamics of planar 3-DOF 4-RRR, 3-RRR and 2-RRR parallel manipulators. Robotics and Computer-Integrated Manufacturing, v. 27, n. 1, p. 150-156, 2011.

Disponível em: http://www.sciencedirect.com/science/article/pii/ S0736584510000797

ZHAO, Y.; GAO, F. Dynamic formulation and performance evaluation of the redundant parallel manipulator. Robotics and Computer-Integrated Manufacturing, v. 25, n. 4-5, p. 770-781, 2009.

Disponível em: http://www.sciencedirect.com/science/article/pii/ S0736584508000926 